ONTOGENCY OF NESTING HABITAT RECOGNITION ANO PREFERENCE IN NEONATAL HERRING GULL CHICKS, LARUS AROENTATUS PONTOPPIOAN

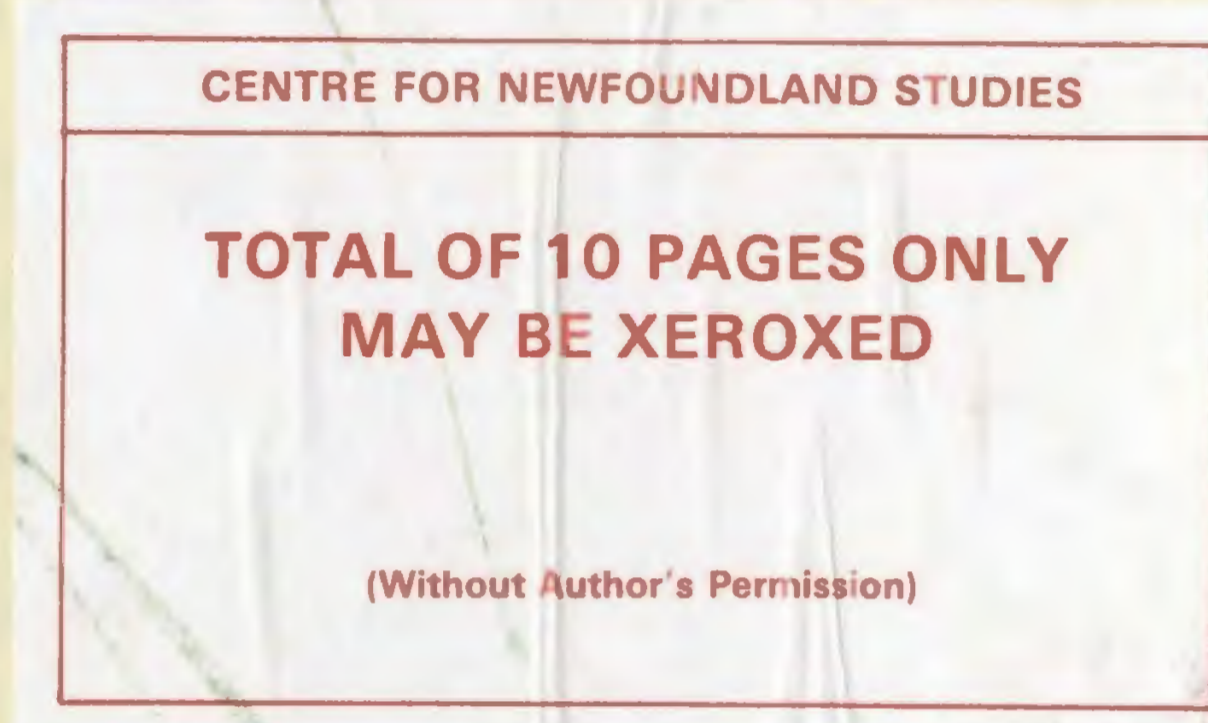

CATHRYN M NOSEMORTHY 


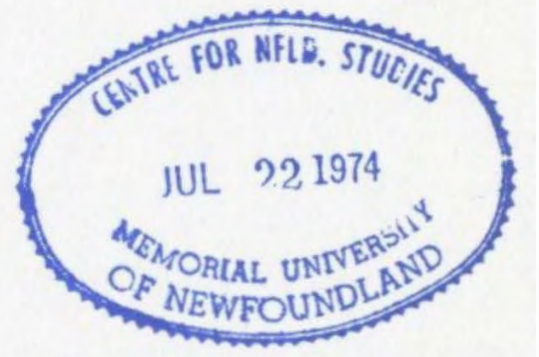



ONTOGENY OF NESTING HÁBITAT RECCOGNITION AND PREFER̈ENCE IN NEONATAL HERRING GULI CHICKS, LARUS ARGENTATUS PONंTOPPIDAN -

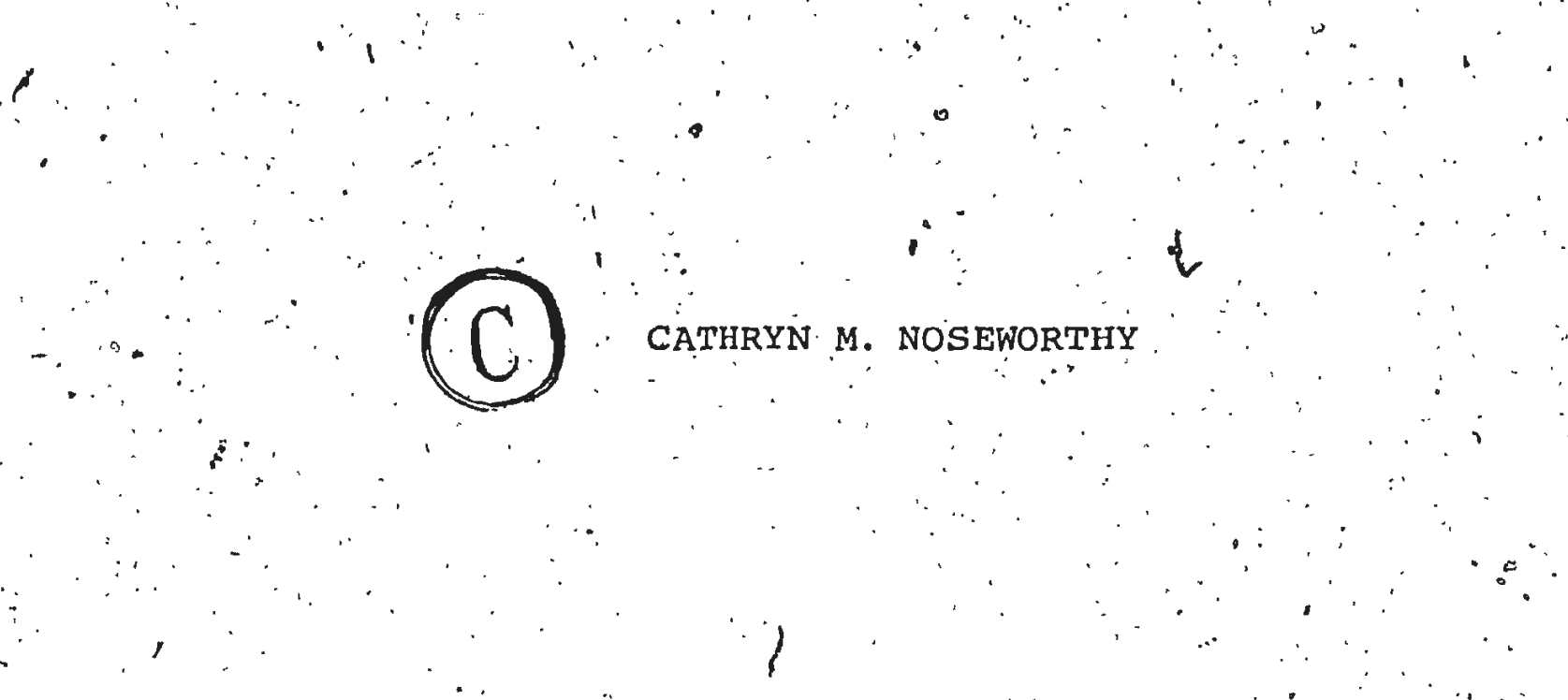

A Thesis submitted in partzal fulfillment of the -requirements - for the degree of Master of Science

Memorial University, of Newfoundland Department of Psychiology

- $1973^{\circ}$ 
Abstract

This investigation was designed to examine the development of nesting habitat recognition and preferences as a function of habitat and social stimuli.in neonatal Herring Gull chicks. The initial experiment studied the daily development of nest site preference during the first. week post-hatch' and thereafter weekly development until fledging. The test procedure, which was essentially the same for all experiments, consisted of relocating chicks $20 \mathrm{~m}$. Ifrom the nest and observing their movements, Dhing these observations, latency, time moving, initial orientation, final distance from the nest, and initial and final vegetation characteristics were recorded. "Results indicate" that Herring Gull chicks exhibit a preference, for the nest site area during the first week post-hatch and this pre-' ference wanes, after the first. week until fledging. Chicks. of all ages showed a prefergnce for vegetation similar to that of the nest site area. Nest site preferences, are ecotypically controlled since foster-reared chicks exhibited the same preference for thpir foster nests as did normalreared chicks for their natural'nests. :

Several experiments examined the effect of vegetation characteristics and social stimuli provided by other chioks on nest site attachment and recognition. Vegetation. type and the presence of siblings were found to be important stimulus properties of the nest situation in nest area 
attachment. Chicks exhibited a preference for vegetation similar to that at the nest site and for siblings over noñ-" siblings: Nest site recognition appeared to predominantly a visual response; at least. in visually experienced animais. Vegetation characteristics, landmarks and the presence of other chicks were found to be dimong the cues used to recognize the nest site. The results of these experiments were interpreted as supporting. the hypiptheses that nesting habitat preferences are evident in Herring Gulls during the prefledging period and that habitat and social stimuli are important in the development of nest site preferences and Jecognition. These neonatal habitat preferençes may be influential in determining later preferences for nesting sites. and may be responsible for the observed stereotypy in adult habitat preferences." 
The author is especially grate

"serving as her thesis, supervisor, research associate, boat captaint, mentor and friend. Acknowledgement is given to. an Opportunities for Youth Grant to the Avian Study Group of the Animal Behaviour Laboratary and National Research Council Grant \# A8344 to Jon Lien for financial support. Thânks are also expressed to: John Evains and Leslie M. $\therefore$ Tuck, for valuable advice as committee members; Lois Hayweiser, for serving as a.committee member, assisting in the field work, and particularly for demonstrating that. field research can be a civilized endeavour; Jack Strawbridge and Steve Andrews, for sharing their expertise in statistics and computer science; Joe Brown, for being. such à competent field assistant; Linda Gaborko, Laura Finlayson, Gary Hopkins; Sue Noseworthy; Jim Hancock and Pat Redmond for. assisting. in various stages of the field work; and clar Button, Deane Merdsoy, Barb Wakeham and sue Stoker for innumerable hours of discussion and listening. 
Abstract. . . . . . . . . . . . . . . . . . . . . . . .

Acknowledgements

ii i

List of Tables.

$v i$

Iist of figures........................ ix

Introduction to the Problem...................... 1

The study site...........................

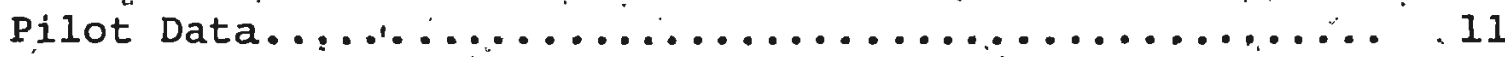

Experiment 1: Development of ${ }^{\circ}$ Nest Site Attachment

$\because$. Introduction $\ldots \ldots . . \ldots \ldots \ldots \ldots \ldots \ldots \ldots \ldots \ldots \ldots \ldots \ldots \ldots$

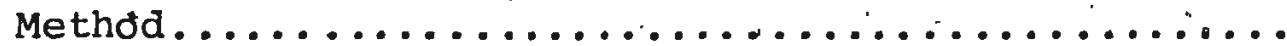

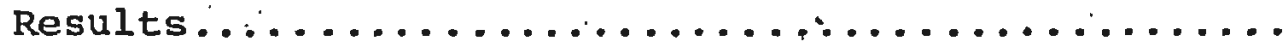

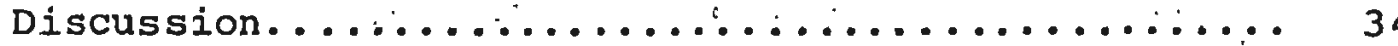

Experiment 2: Role of Vision in Nest Site Attachment and Recognition

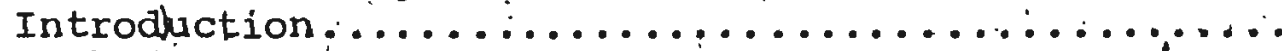

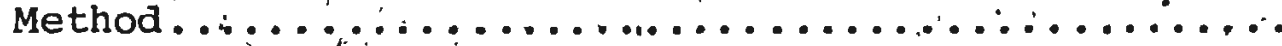

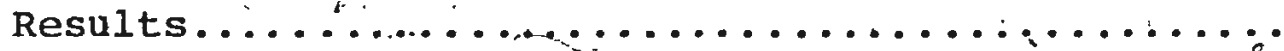
Discussion.

Experiment 3: Rolie of Stimulus 'Conspicuousness'. and 'Landmarks' in Nest Site Recognition

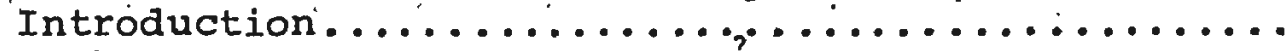

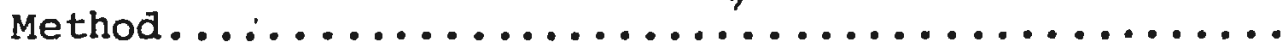

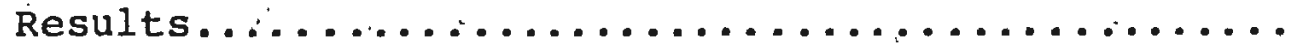

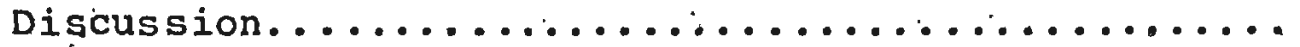

Experiment 4: Development of Individual Recognition

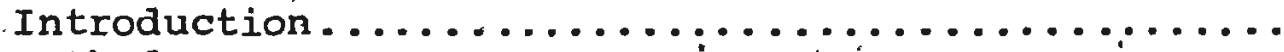

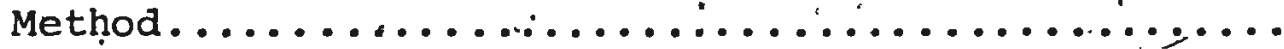

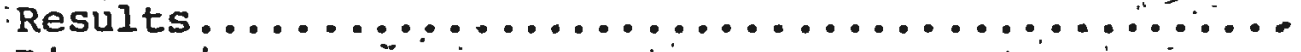

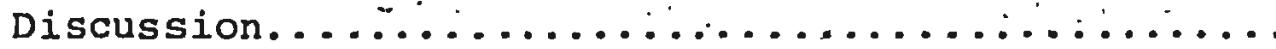

Experiment 5: Role of Social stimulation in Nest

Site Attachment and Recognition

Introduction. 
Experiment 6: Effect of Rearing and Testing

Conditions on Nest Site Attachment and Recognition

Introduction. .......................... 77

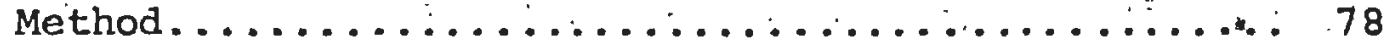

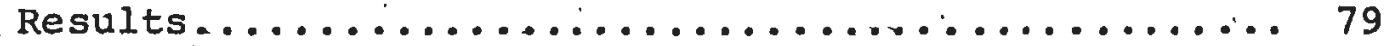

Discussion.......................... 82

General Discussión.......................... 84

Appendix. . . .......................... 91

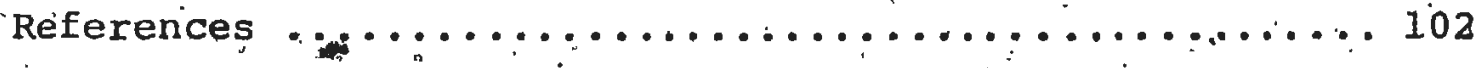

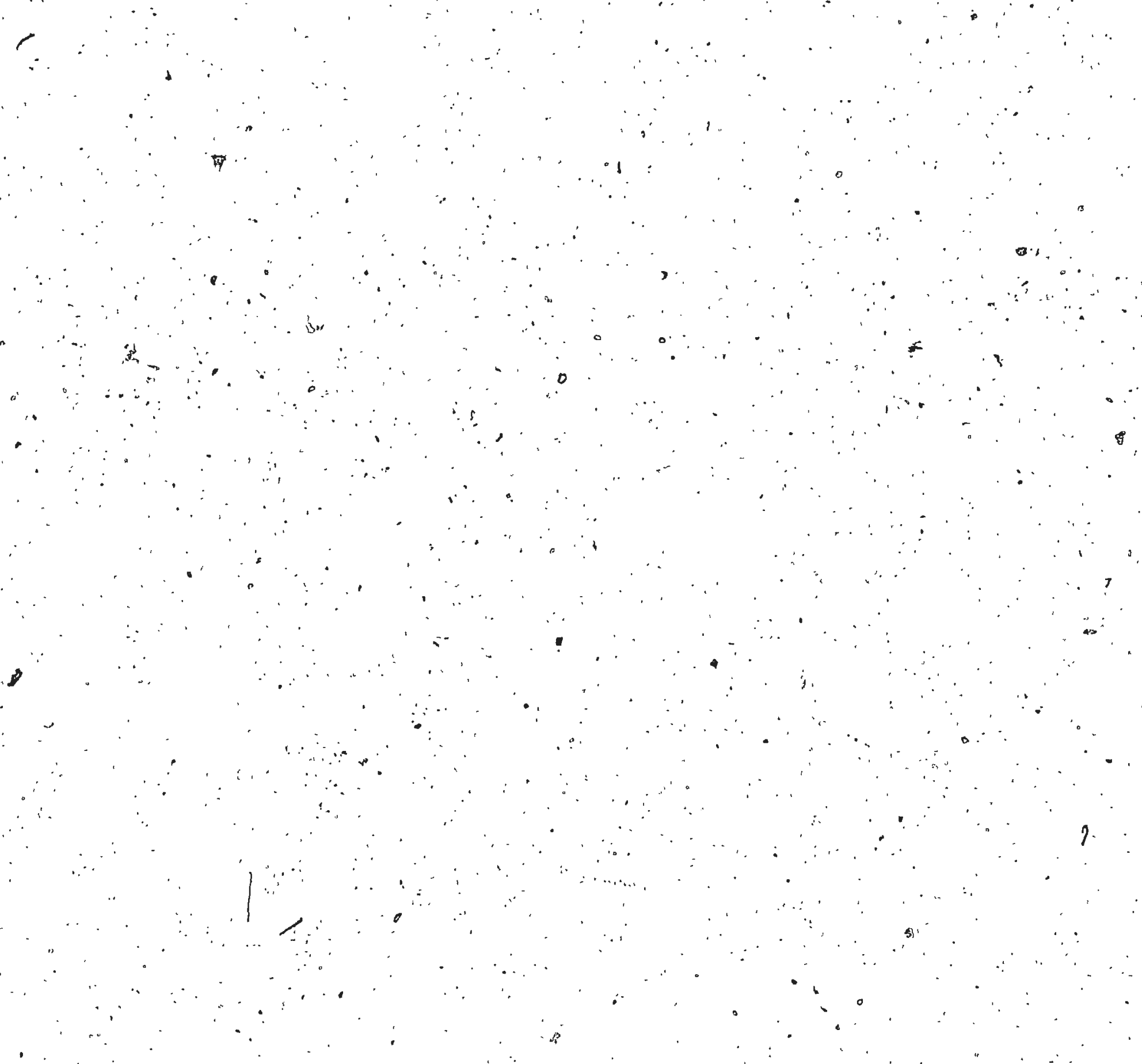


$1:$ Percentage of Chicks,by Age Returning to the Capture Territory, Same Vegetation or Different Vegetation.

2 Means and,Standard Deviations of Response speed, : Time Moving, Initial orientation, and Final Distance from the Nest of Chicks during) the First Week Post-hatch.................... 21.

3 ' Summary of Analysis of Variance of Transformed Latency (Response Speed) of Chicks Tested during the First Week Post-hátch.............22

4. Summary of Analysis of Variance of Time Moving during the First Week Post-hatch..............23

5 Number of Chicks Reaching Nest Return Criterion during the First Week Post-hatch.

6 Means and Standard Deviations 6 tatency, Time Moving, Initial Orientation, and Final Distance from the Nest of Foster-reared and. Normal-

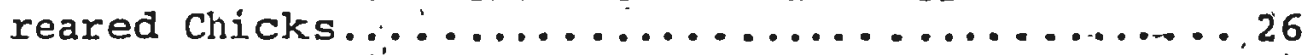

7. Means and Standard Defíations of Response speed (Transformed Laténcy) Initial orientation, Time Moving, Final Distance and Initial

7 Distiance from the Nest for Chicks Relocated during Weeks 1-5.

8. Summary of Analysis of Variance of Initial Orientation. for Relocated Chicks during

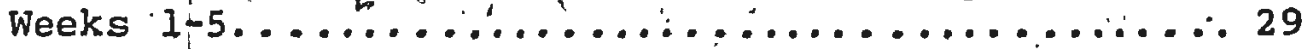

9 Summary of Analysis of Variance of Final Distance from the Nest for Relocated Chicks during Weeks $1-5 \ldots \ldots \ldots \ldots \ldots \ldots \ldots \ldots \ldots \ldots \ldots \ldots \ldots \ldots \ldots \ldots . \ldots \ldots$

10 Number of Chicks Reaching Nest Return Criterion on Relocations during weeks $1-5 \ldots \ldots \ldots . . . . . .30$

11 Significant Correlations and Probability Levels.for Chicks Tested during the First Week Post-hatch:

i2 Significant Correlations and Probability Levels for Chicks Relocated during Weeks I-5..... 34 
,

13 Means and Standard Deviations of Time.

Moving, Initial orientation, Latency, and

Final. Distance from the Nest of Hooded and

Normal Chicks, Experiment $2 \ldots \ldots \ldots \ldots \ldots \ldots \ldots . . .$.

14 Means and Standard Deviations of Transformed Latency (Response Speed); Time Moving,

Initial Orientation and Findil Distance from

the Nest for Chicks in Experingent $3 \ldots \ldots \ldots . . . .52$

15 Summary of Anälysis "of Variance of Initiál

Orientation, Experiment $3 \ldots \ldots \ldots \ldots \ldots \ldots \ldots \ldots$

16. - Summary of Analysis of finariance of Final

Bistance from the Nest, Experiment $3 . \ldots \ldots \ldots \ldots . . .56$

17 Latency and Time Mơving on Vocálization and Non-vocalization Trials in Experiment 4.......

18 Experimental Design of Experiment $59 . \ldots \ldots \ldots \ldots 66$

19 . Means and Standard Deviations of Transformed Latency. (Response speed), Initial orientation, Time Moving ard Finaj Distance from the Nest,

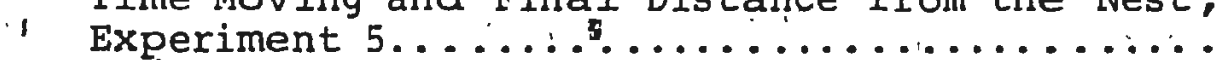

20 . Summary of Analysis of Variance of Rèsponse Speed (Tränsformed Latency), Experiment 5..... 72

21 Summary of Analysis of Variance of Final

Distance from the Nest, Experiment $5 . . . . . . .$.

22. Time Moving, Initial Orientation, Latency and

Finnal Distance from the Nest of Chicks Released with Siblings and Non-siblings, Experiment $5 \ldots . .7$

23 Experimentai Design ef Experiment $6 \ldots \ldots \ldots \ldots . \ldots 78$

24 Means and Standard Deviations of Transformed Latency (Response speed), Initial orientation, Time Moving and Final Distance from the Nest, Experiment $6 \ldots \ldots \ldots \ldots \ldots \ldots \ldots \ldots \ldots \ldots$

25 . Summary of Analysis of Variance of Response Speed (Transformed Latency), Experimot 6......

Appendix

26 List of Plant Genera Found on Little Bell Is land 
Table

viii

27 Means and Standard Deviations of Latency and Transformed Time Moving for Chicks Tested during the First Week Post-hatch,

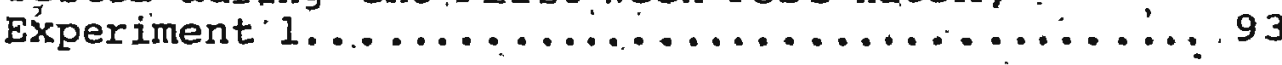

28 ' Summary of Analysis of Variance of Latency for Chicks Tested during the Firgt week Post-hatch, Experiment to

7.29 ' Summary of Analysis of Variance of Time Moving (Transformed) for Chicks Tesfed during the First Week Post-hatch, Experiment 1.......994

30. Number of Chicks Relocated during Weeks' 1-5, Experiment $1 . \ldots \ldots \ldots \ldots \ldots \ldots \ldots \ldots \ldots \ldots \ldots$

31. List of Variables in the Correlation Matrix for Daily-tested, Chicks.

32 Significant Correlation coefficients and Probability Levels for Chicks Tested during the First Week Pöst-hatch. ............... 98

33. Means and Standard Deviations of Latency, Time Moving (Transformed) and Final Distance from "the' Nest (Transformed), Experiment 5......99

34. Summary of Analysis of Variance of Latency,

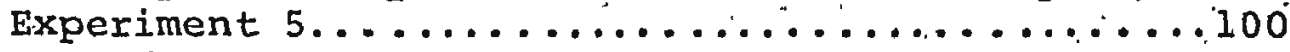
35 Summary of Analysis of Variance of Final Distance (Trurstermed), Experiment 5..........100

36 Means and Stahdard Deviations of Latency,

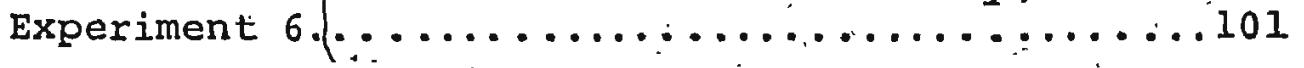

37. Summary of Analysis of Variance of Latency; Experiment 6.........................101 
Figure

1 The study Site, Littile Bell Island, Conception Bay; Newfoundland.

2. The Study site, Iittle Bell Island,

Conception Bay, Newfoundland............... 10

3. 'Wooden Carrying Bóx' Used in All- Experiments

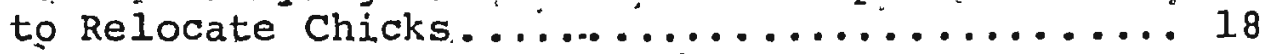

4: Herring Gul1 Chickw Wearing Experimental. Hood Used to Occlude Vision............... 41

5 : Fir Thtee Used as a Highly Conspicuous

Landmark in Experiment $3 \ldots \ldots \ldots . \ldots . \ldots 48$

6 I Fir Tree Used as a Moderately Conspicuous

Landmark in Experiment $3 \ldots \ldots \ldots . \ldots . \ldots 49$

7 Fir Tree Used as a Low Conspicuoús

Landmark in Experiment $3 \ldots \ldots \ldots \ldots \ldots . \ldots . \ldots 50$

Apparatus Used to Test Individual Recognintion Among 'siblings' in' Experiment 4............61

Interaction of Nest and Test Conditions on Response Speed (Transformed Latency), Experiment 


\section{Introduction to the Problem}

Species preferences for particulark neșting habitat's are well documented (Elton, 1930;,Lack, 1933; 1937; 1954; Moreau, 1935; Lack \& Venables, 1939; Miller, 1942; Kendeigh, 1945; Thorpe, 1945; Snyder, 1948; Collias, 1951; Tinbergen, 19.53; Hinde, 1959; Emlen, 1963; Hilden, 1965; Klopfex \& Haiman,1965; Beer, 1966; and Klopfer, 1969), as is the tendency of individuals of many. avian species to return to similar habitats and frequently to the same necsting area or terrttory for breeding in successive years 'Stoddard, 1.931 ; Boyd \& Landsbóróưgh, 1937; Emlen, 1938; 1940; 1963; Gross, 1940;" Kendeigh, 1941; Ruiter, 1941;, Stoner ștoner, 1941; Lack," " 1943; Nice., 1943; Farner, 1945; Miller, 1947; Austin, 1949; Vọn Haartman; 1949; Richidale, $1951 ;$ Klujver; 1951; 'Tinbergën; 1953; Beęr, 1966; LeResche \& Sladen, 1970; anda Bongiogrio, 1970): .Similar pheromena have also beeri reported in salmon (Hasler, 1956; 1960) and insects (Rau, 1934; Thorpe, 1944).' - Some evidence indicates that such marked habetat preferences are firmIy estabilished in young animals. klopfer (1963; 1965) 'tested folitiage" préferences in young Chipping Sparrows, Spizella passerina passerina Bédhstein, and found that the typical species-preferred fol tage was chosen" by young. - Wecker (1963) reported" that laboratory-reared Prairie Deer Mice, Peromyscus maniculatus bairdi Hoỳ " \&ennicott, derived from wild field stock chose the typical speciespreferred habitat of the field, over a woods habitat. It 
has also been demonstrated that laboratory-reared prairie and Woodland Deer Mice, Peromyscus maniculatus gracilis Le Conte, in a choice test in the laboratory, prefer artificial habitats most closely resembling the natural habitat of their species (Harris, 1952), even though, they could fully tolerate other habitats (Dice, 1922). Fabricius (1951) tested, several species of hand-raišed dúcklings in an open field te'st and found that young preferred the typical adult habitat.

Goethe "(19.37) demonstrated an attachment to the nest site in Herring "Gull chicks. " Chicks were" found to return to their own nest site after being transported 18-63 meters 'from the nest: Noseworthy, Lien \& Stoker' (1973) found that Herring,Gull chicks, under three weeks of age returned to the; nest site, while older chicks did, not return to the nest territory but relocated in vegetation similar to their collection point. Ring-billed Gull chicks, Larus deląwarensis. . ord, "also, have been found to prefer a familiar to a novel rearing area in the laboratory, although this preference was. 'not, significant at 4-5 days post-hatch (Evans; 1970a) : Hess $\therefore(1.959)$ exposed domestic chicks to a patterned environment at. different "times during, the first several days after hatching and found $\ddot{a}$ preference only on Day 2 , post-hatch. It also appear's that chicks know the nest territory in détail. "Tinbergen, Brockhuysen?' Feekes, Houghton, Kruik \& Szule', 1962) since chicks of. several species have been observed, during alarm.or disturbance, to repeatedly seek out familiar 
shelters in neighboring vegetation to the nest site (Jtrong, 1914; Goethe, 1937; Kirkman, 1937; Tinbergen, 1953; Moynihan, .1959; Beer, 1966; Evans, 1970a). Furthermore, Evans (1970a): experimentally demonstrated.that this repeated selection of the same hiding place depends on a learned preference. 1. Young Ring-billed Gull chicks learned the discriminations. and motor patterns necessary to-move repeatedly to a specific location in a test pen (Evans, 1970a). Attachment to the rearing habreat; then, is apparent during the first few weeks of life, although the precisse chronological development has not been established for' any, of the above specié. How such rearing area preferences are established during ontogeny is also speculative. Several authors (Thorpe, 1944; 1945; Miller, 1942; Collias, 1951; and Hilden, 1965) have suggested that habitat preferences are established through environmental imprinting, a rapid, stereotyped exposure learning similar to social imprinting. Date reported by Drost' (1958) provides support for this hypothesis. He transferred 1000 young. Herring Gulls from a sea coast to inland zoological gardens for rearing. It was found that many of these gulls, when adults, returned, to the rearing place, or to similar areas in different localities, for nesting. Indirect evidence coimes from Hess' (1959) data on preferences for a patterned environment and the demonstration of imprinting to stationary objects (Hess, 1959; Gray, 1960; and Bateson, 1966). Additionally, there is evidence that domestic chicks prefer familiar over unfamiliar 
" conspicuous static objects (Bateson, 1964a) and that conspicuous visual stimuli can act as reinforcers (Bateson \& -Reese, 1969; Evans", 1'972). Evans (1970a) has, also shown that the visual characteristics of rearing pens are learned by Ring-billed Gull chicks.

Other authors have attributed habitat preferences to an innate mechanism of the species (Lack, 1933; 1954; Svardson, 1949). Studies in which reciprocal transfer of gull eggs have been made, however, indicate ecotypic control of such behaviours. Emlen (1963) found that Herring Gull chicks raised on cliff ledges or vegetated platieaus 'responded differentially, in escape behaviour. Cliff-reared chicks remained motionless on an elevated test platform while plateau-reared chicks exhibited, escape locomotion.

1 fostering of eggs from'these two groups showed that chicks responded appropriately in escape tests according to the rearing habitat. 'Smith (1966), studying esçape behaviour of three gull species differentially adapted to cliff nesting, also found that chicks' escape responses varied according to the rearjing habitat. Although foster chicks' were not tested for preferences for the foster rearing areas, the fact that they remained at the foster nests indicates that such preferences were developed. Finally, Schuzi (1938; 1940) transferred Short-billed Gull, Larus canus Linnaeus, eggs to Black-headed Gull, Larus ridibundus Linnaeus, nests for incubation and found that, when adult, some of these birds returned to their foster rearing place for nešting. 
social stimulation has "t"been suggested to." be an' important factor in establishing habitat preferences (Klopfer \& Hailman, 1965). Individuals may be attracted to a particular area because of an attraction to familiar animals rather than an intrinsic preference for the ärea, 'so that each generation adopts the preferences of the parent generation: Preferences for conspecifics, have been demonstrat"ed in several avian species (Howells \& Vine, 1940;: Kilham, Klopfer \& Oelke, 1968; Gottlieb, 1965), even in the absence of prior food reinforcement during social feeding (Eyans, 1970a). As well, social stimulation has been reported to enhance the formation of éarly spring 'club' , aggregations (Tịbergen, 1953) and the selection of fieeding areas in adjlt gulls (Frings; Frings, Cox \& Peissner, 1955).. Food and social preferences passed from one generation to another have also beén documented in mammals, such.as the Black-tailed Prairie Dogs, Cnyomys Iudovicianus ludovicianus Ord, (King, 1955), Japanese Mac̈aques; Macaca fuscata Lacepede, (Miyadi, 1959) and in some birds. (Fisher \& Hinde, 1950). Moreover, evidence indicates that attractiveness of the. colony is an important factor in habitat selection by Herring Gulls nesting for the first time (Drost, 1958). It is likely; therefore, that social stimulation is an important factor in establishing habitat preferences, particularly in Herring Gulls, whose colonial nësting habits and average clutch size of three resúlt in'continuous social stimulation. 
one dificulty with any hypothesis of the development of habitat preferences is the lack of information on the factors involved in habitat recognition. It is possible, for instance, that habitats that appear very different to. -the observer may in fact contain the cues relevant to the organism, so that it is necessary to consider the organism's 'umvelt' (Von Uxuel1, 1921) or perceived environmient in studying habitat preferences. Klopfer (1963; 1965; 1967)", in a series of experiments to determine the foliage perct site preferences in sparrows, found that for the whitethroated Sparrow, Zonotrichia albicollis Gmelin, the light intensity and distribution of shadow patches were the relevant cues for distinguishing perch sites, while for

- the Chipping Sparrow the relevant cues appeared to be foliage size, shape and density. "The fact that different vegetation stimuli were important to these two species make it apparent. that generalizations across species, even closely related ones, cannot validly be thade. The heavy reliance of birds on the visual modality would indicate' that, although other sensory capacities may be used, vision would be of primary importance in nest site attachment and recognition. Evidence supports' this supposition. Lack (1933; 1954), $\therefore$ Lack \& Venables (1939) and Wasilewski (1961) have suggested that the relevant features by whigh avians distinguish habitats are of a 'gestalt' nature and involve the visually prominent, conspicuous ffeatures of.the habitat, such as the vegetation: 
Vogetation characteristics, such as the height; spacing and species, have also been correlated with habitat preferences (Pitelka, 1941; Kendeigh, 1945;'Guillon, 1960). Moreover, Bongiorno (1970), in an experimental study of nest site selectipn by adủlt Laughing Gulls, Larus atricilla Linnaeus, demonstrated that chánging the vegetation topography of the habitat by mowing resulted in decreased probability of nesting. He concluded that vegetation characteristics were importantohabitat features used by these gulls in nest site selection. Adult gulls also appear to have a detailed knowledge of the nest area using visually prominent habjitat featurés. Baerends, Drent, Glas \& Groenewold (1970) found that adult Herring Gulls return to the nest site, even when eggs and young are displaced." some distance away, and that they prefer an empty, strange nest on the nest site to their own' nest and eggs displaced $75 \mathrm{~cm}$.

Landmarks have been shown to be among the cêues used:to locate the nest site. Tinbergen (1953) demonstráted that displacement of a visually prominent landmark correspondingly disoriented the Herring Guli from its nest; although only temporarily: Fúrthermore, Baerends et al (1970). reported that acceptance of a displaced nest was facilitated by a corresponding displacement of a conspicuous landmark. 'Other nest site stimuli to which birds respond are not known. 
However, vẹry littele is known concerning recognition cues in young and how they develop. There is observational evidence that neonatal Herring Gull chicks discriminate. between vegetation types and use vegetation characteristics as cues in nest site recognition (Noseworthy et al, 1973). It would appear then that cues which should be of primary. importance in the development, of nest site/ attachment. and recognition in guils are those, related to the habitat, such as vegetation, landmarks, etc. and social stimulation. The present series of experiments were designed to assess the role of selected aspects of habitat and social factors in the development of nesting habitat recognition and preference in neonatal Herring Guil chicks.

\section{$\therefore$ - Thie study site}

Little Bell Islard, measuring 1500 meters by 400 meters, located in Conception Bay, Newfoundland, was choseh as the study site (see Figs. 1 and 2). In the springsummer of 1972 , Little Bell Island had an observed breeding population of 876 pairs of Herring Guils, Larus argentatus pontoppidan. Other avian species breeding on the island. in smali numbersincluded common starlings, sturnis vulgaris Linnaeus, Savannah Sparrows, Passerculus sandwichensis Gmelin, Great Black-backed Gulls, Larus marinus Linnaeus, Ring-billed Gulls, Larus delawarensis ord, and Black Guillemots, Cepphus grylle Linnaeus.: The latter two were not present in 1971. No mammals were observed on the island. 


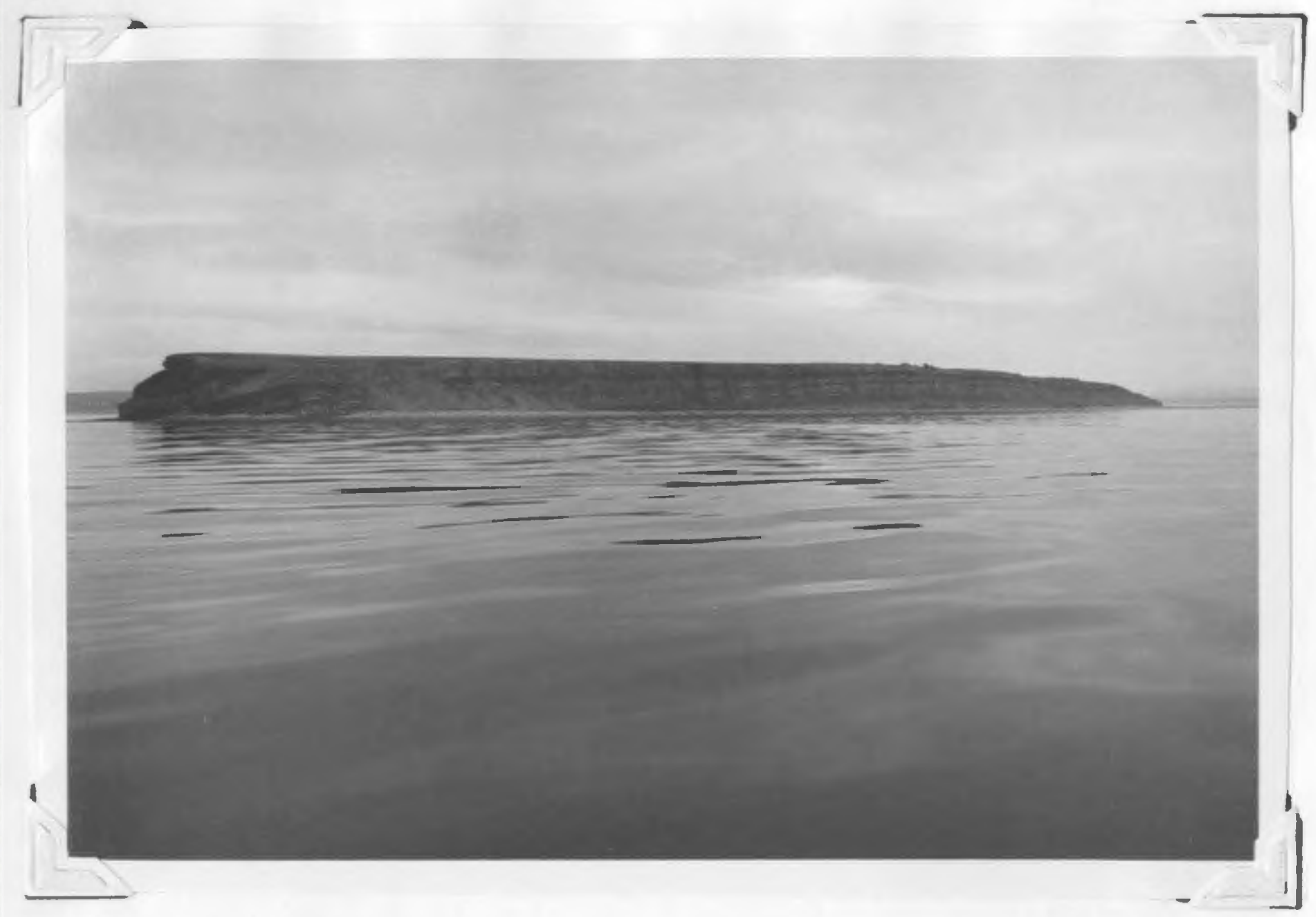

FIG. 1. The Study Site, Little Bell Island, Conception Bay, Newfoundland 


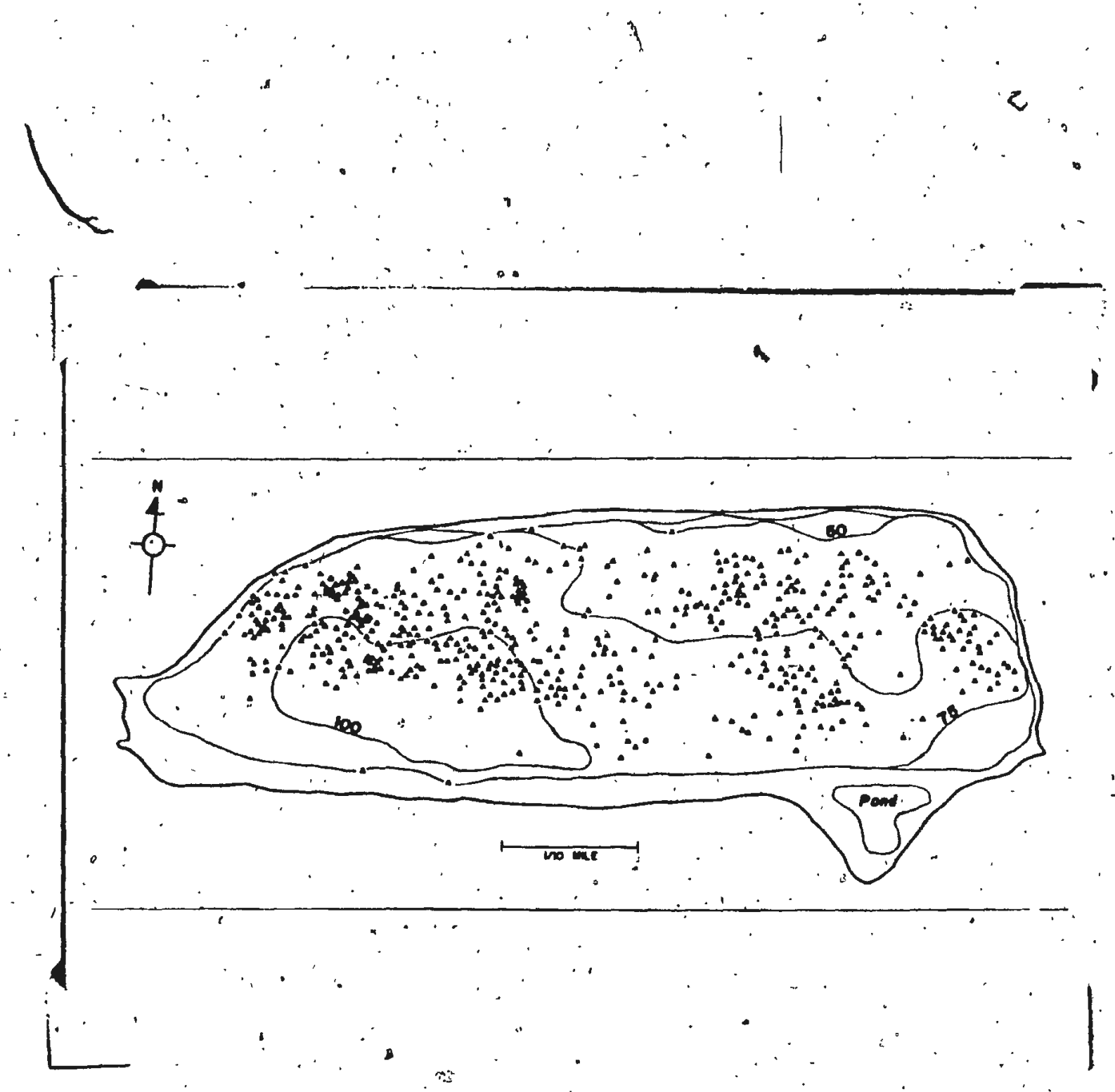

$\triangle$ - HERRIÑG GULL NEST.

$$
\text { (and }
$$

FIG. 2. The Study site, Little Bell island, Conception Bay, Newfoundland. 
The vegetation of the island may be divided into distinct areas of grassland, marshland, shrub and herb areas, as well as areas of mixed vegetation. The predominant vegetation types in which Herring Gull nests odcurired were: 39.08 "in grassland," 30.08 in shrubs, 30.38 in herb areas and . 7\% in moss areas (see Table 26, Appendix).

\section{$-3$ \\ Pilat Data}

Preliminary investigations were carried out to: 1) obtain a detailed description of the nesting microhabitat of the Herring Gull population under study:"2) determine whether young Herring Gull chickș of this population exhibited a preference for the nest site area; and 3 ) determine whether this behaviour varied with age.

In the spring of 1971 -and 1972, Little Bell" Isiland was surveyed into 50 meter quadrats and the rumber and the location of each nest in each quadrat recorded. Seven variables were recorded for each nest including: clutch size, nest exposure, nest level, predominant vegetation of

$\rightarrow$ the nest site, predominant vegetation of the surroundirig area, basic nest material and distance. from the nearest nest. Nẹst exposure was judged by the experimenter on a three point scale of exposed, moderately hidden and well hidden (see Noseworthy et al, 1973 for pictures defining this scalef. - Data were analysed using.means, frequency distributions: and a correlation matrix of all variables. Only the 1972 data" will be discussed here, since the 1971 data have 
been presented elsewhere (Noseworthy et al, 1973). The total number of Herring Gull nests recorded on the island was 876 , an increase of 314 over the 1971 total." The majority (44.28) of nests contained 3-egg clutches, 26.98 contained 2-egg clutches, 28.88 contained l-egg clutches, while only one. $(.1 \%)$ nest contained 4 eggs. The majority of nests (56:88) were in the open, 35:78 were partly hidden, while only $f .58$ were well hidden. Almost precisely., the same percentages were recorded in $1971(578,368$, and 78 , respectively).'Tinbergeh (1953) noted that Herring Gulls prefer open areas except for nesting, when sites near plants or bushes are selected. The low proportion of nests in. cover in this study, however, indicates that Herring Gulls of the Little Bell Island population prefer open areas for nesting, especially since approximately one-third of the : island would provide amṕle cover.

Nests at ground level accounted for $76.9 \%$ of the total while 23.18 were on hummocks. Most nests (69.38) were built in low-lying vegetátion (grass, 39.08; herbs, $30.38), 30.08$ were in shrubs, while only .78 were found in. moss. Vegetation surrounding the nest site was agar predominantly grass and herbs (39.08, 30.58, respectively), 27.38 was shrubs and . 18 was möss.

| The majority of nests, $(64.3 \%$ ) had grass as the basic nest material, $34.6 \%$ had moss, while herbs were found in only 1.18 of the nests. It appears, therefore," that Herring Gulls do not necessarily utilize the most available materials. 
for nest construction. Moreover, no relationship was found between nest site vegetation and the basic nest. material $($ rho $=.02$, p.<.42):. Similar observations have been made by Beer: (1966) who reported that Black-headed Gulls may. colvect nest material from $.15 \mathrm{~m}$. to $450 \mathrm{~m}$. from the nest، The average distance between nests was $7.3 \mathrm{~m}$. : Some 408 were $5 \mathrm{~m}$. from the nearest nest, 15.38 were only $3 \mathrm{~m}$. away, while $2.8 \%$ were more than $20 \mathrm{~m}$. from the nearest.nest. Nests tended to be farther apart in covered areas and closer

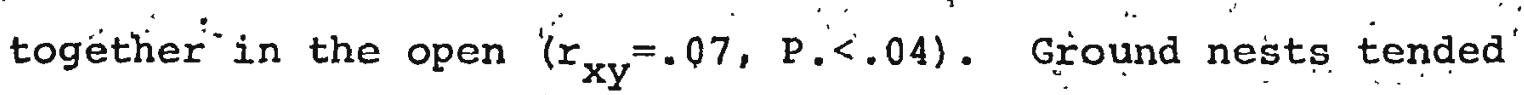
to be closer together than hummock nests $\left(\mathrm{r}_{\mathrm{xy}}=.07, \mathrm{P}:<.05\right)$. These relations may reflect the preference for low-lying vegetation areas for nesting, or may be a response to aerial predation since Iittle Bell Isländ has no ground predators. (To examine whether Herring Gull chicks of the Little Bell Island population exhibited a preference for the nest site area; a total of 31 chicks, l-5 weeks old, were captured from grass, herb and shrub sites in the nest colony in the summer of 1971.: Once a chick "was captured, it was placed in a cardboard box. with no cover and transported $30-50 \mathrm{~m}$. to. a different vegetation type and released. The experimenter witharew approximate $1 y 50 \mathrm{~m}$. and observed the chick through binoculars. The following measures were recorded: final location of chick, vegetation type at the collection point and at the final resting location, and vegetation density. Density was judged by the experimenter on a three point scale, sparce, moderately. dense, and dense. Locomotion was observed 


\section{$\therefore \quad \cdot \quad \cdot 14$}

until the chick 'remained in one location for 10 minutes. Results indicated that a significant number of chicks returned to the same territory (within $1 \mathrm{~m}$. of the nest) or to a vegetation area similar to the ohe in which they had been captured (chi=8.53,'P.<.02, see Table 1). This relocation in the original vegetation was significant for ali vegetation types and did not vary with the type of vegetation in the capture or release area. Additionally, the choice of relocation vegetation seemed relatively unrelated to the amount of cover afforded by the vegetation, since chicks were observed to relocato in less dense vegetation of the original capture site type in preference. to denser, different vegetation nearby:

$\rightarrow$

\section{Table 1}

Percentage of Chicks by Age Returning to Capture Territory; Same Vegetation, or Different vegetatión

\begin{tabular}{|c|c|c|c|c|c|c|}
\hline . & Age & $\because \mathbf{N}$ & $\begin{array}{l}\text { Capture } \\
\text { Territtory } \\
\text { : }\end{array}$ & Same & $\begin{array}{l}\text { Total } \\
\text { Returning } \\
\text { to Same } \\
\text { Vegetatio }\end{array}$ & $\begin{array}{c}\text { Differient } \\
\text { Vegetation }\end{array}$ \\
\hline 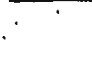 & & $n>1$ & & & . & \\
\hline $1-3$ & Weeks. & 17 & 39.9 & 49.0 & $\begin{array}{r}88.9 \\
\quad .9\end{array}$ & - 11.1 \\
\hline $3-5$ & Weeks & 14 & $\therefore \quad 0.0$ & 84.7 & 84.7 & 15.3. \\
\hline & $\because$ & , & , & $!$ &. & $-\cdot$ \\
\hline
\end{tabular}

Comparisons between young chicks 1-3 weeks' of age with older chicks, 3-5 weeks of age, showed no significant 
difference between the two groups, as most birds in all ages-returned to the original vegetation type. . Họwever, a "significant'difference between yoüger and"older chicks was found in the tendency to return to the capture territory (chi=7:00, P.<. 0 ) $:$ ' The younger chicks most frequently. returned to the original capture territory, usually the nest, while older birds returned to simizar vivegetation but did -. not relocate in the capture area (Table '1).

$\because$ It.appears, therefore, that some Herring Gùlê chicks. do exhibit an attachment to the nest territory and that this behavioùr wanes with age:. How and when the atfachment to the nest site' area develops and how the nest site is reIocated requires, investigation. Moreover, how the apparent vegetation "preferences of oldèr "chicks' are established is speculative. These problems were examined in six experiments'. The first experiment studied the development of neṣt site. attachment per se from hatching to fliedging. The second experiment assessed the effects of visual deprivation on nest site atuchment and recognition. The thiral experiment examined thérole of stimulus "conspicúousness" and landmàrks. In nest site recognition. Experiment $A$ attempted to demonstrate individual recognition among chicks. Experiment 5 studied the use of social stimuli in nest site attachment and recognition. Finally . Experiment 6 examined the éfects $c$ Sy social rearing and testingon nest site attachiment and recognition. 
Experiment. 1. The' Development of Nest Site Attachment The pilpt data collected indicated that Herring Gull chicks under three weeks of age exhibit an attachment to the nest territory. However, the post-natal development, of this attachment is not known. It has been observed that during ¿ the first week post-hatch gull chicks have a well developed locomotor ability but are nearly totàlly dependent on parental

- care for survival (Evanș, 1970a). During this period parents do not recognize, individual chicks but rather find their' own young by location; 'with feeding and prooding, etc., restricted to a. specific nest.site territory. It is adaptive, therefore, that "chicks have an attachment to the nest site and that excursions from this area be held to a minimum during the first week of life. Attachment to the neṣt territory was, therefore, hypothesized to be an important mechanism controlling locomotion and ensuring, adéquate parental, care during the first week After this time, the onset of individual recognition by parents and young aids maintenance of family unity. It was expected that an attachment to the' nest"site area would be found in daily tests during the first week post-hatch and that a decreasing preference would be evident in weekly, tests after this time until fledging.

\section{"Method}

Subjects

A sampile of $84 \cdot$ Herring Gưll chicks' was randomly. selected from the nests located on the west half. of Little 
Bell Island. One-half of the island was selected for feasibility. purposes, since the study sițe had to be traversed. 'and nests checked several times daily. Chicks were chosen from three-egg clutches and were individually marked after hatching so that age could be accurately determined when chicks were recaptured. The location of the nest site, as well as the type, height and density of the surrounding." vegetation, was recorded on a grid map of the island. Density of vegetation was rated by the experimenter on a three point scale, 1-sparce, 2-moderately dense, and 3-dense. Chicks were then assigned randomly to one of seven groups for testing on days 1-7 post-katch.

\section{- Procedure}

\section{When chick achieved testing age, its nest was.} iocated, the chick found and removed from the nest site. It was then placed in a wooden carrying box. with a transparent cover $(30 \mathrm{~cm}$. "x $30 \mathrm{~cm}$ " x $30 \mathrm{~cm}$., see Fig. 3). The chick was then transported $20 \mathrm{~m}$. in a random direction (previously determined by a random series' of North, South, East and West) and released. Clutch siblings were left in the nest or nest area undisturbed.' The following measures were recorded: latency (in seconds), time moving (in seconds), initial orientation (in 'degrees.'deviance from ra straight line of the chick to the nest as judged by the experiment(k), final'. distance from the nest (in meters), number, of returns (less than $10 \cdot \mathrm{m}$. from the nest), and the type, height and density. 


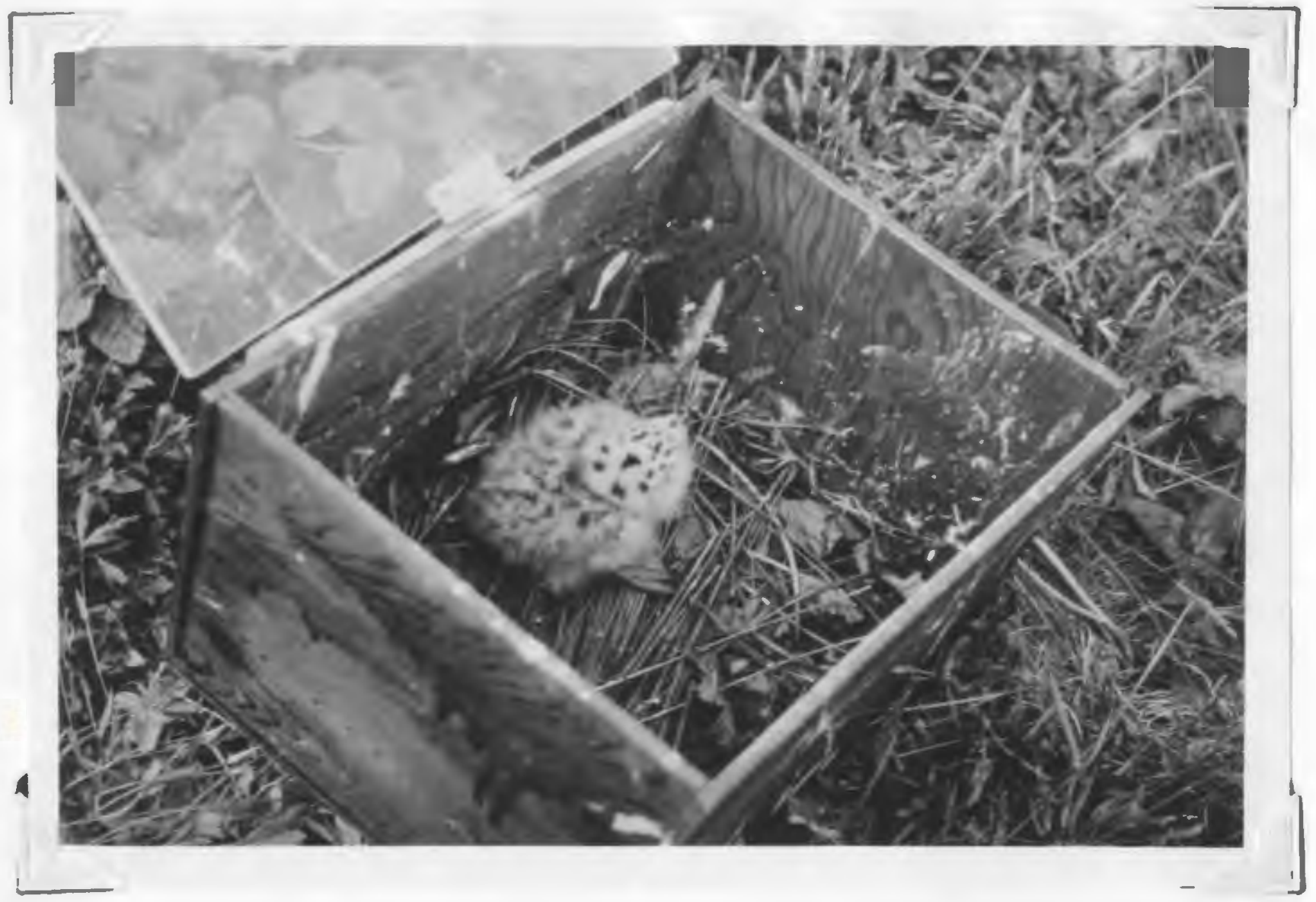

FIG. 3. Wooden Carrying Box Used in All Experiments to Relocate Chicks 
of the vegetation at the final resting location. Testing wàs terminated when the chick was within one meter of the nest site or had been immobile for 10 minutes. All chicks were returned to the collection point after testing. To determine whether atthchment to the nest site was ecotypically controlled, 12 additional eggs were selected using the same selection and recording procedures described previously. These eggs were then, reciprocally transferred to foster nests so that the vegetation type at the foster nest was different from that of the natural nest? Hatching occurred between 5-10 days after transfer. Chicks were reared in the foster nests until testing on Day 6 post-hatch, using identical test procedures as were previously described. Day 6 post-hatch was 'chosen as the testing age since initial。 testing indicated it was the first day on which a preference was exhibited.

\section{\&}

Temperature, wind speed and precipitation were recorded to. provide a check on the similarity of test conditións between groups. These measures were also intercorrelated with the previously described dependent measures to determine if there was any relationship between chick behaviour and these environmental conditions.

Relocation of all test chicks (both first week and foster-reared chick's)' at weekly intervals until' 5 weeks of age was attempted to determine whether excursions from the nest site area were restricted to areas similar to the nest" site and whether any age "changes in area preferences were 
evident. Test chickș wëre located by experimenter and assistant thoroughly searching" the nest territories, and. if they were not found, a surrourding $50 \mathrm{~m}^{2}$ area was searched. The first chick tested weekly was randomly chosen to ensure that chicks were not being tested at the same times in each testing session. Once a chick was found, it was placed in the wooden carrying box and transported $20 \mathrm{~m}$. from its collection poinţ. It was then released in a vegetation typer that was different from that of the collection point. The same measures were recorded as for daily-tested chicks as' well as initial distance from the nest (in meters) and the type, height and density of the vegetation at the collection point. The testing procedure was then identical to that described for daily-tested chicks.

\section{ᄉ} Results

Data are reportec in the following order: first, data for daily-tested chicks' will be given, then the results for. - foster-reared chicks, weekly-tested chicks, and finally'the correlational data on environmental conditions and the dependent measures. Daily-tested chicks

The means and standard deviations of all dependent measures for daily-tested chicks are presented in Table 2. Iatency. The variance of latefricy within subjects ${ }^{-}$. was high for all experiments and the variance was not homo- . geneous. The $F \max$ test for homogeneity of variance of

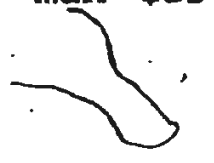


Table 2 .

":- Means and Standard Deviations of Response Speed, Time Moving, Initial Orientation, and Final Distance from Nest of Chicks During the First week Post-hatch

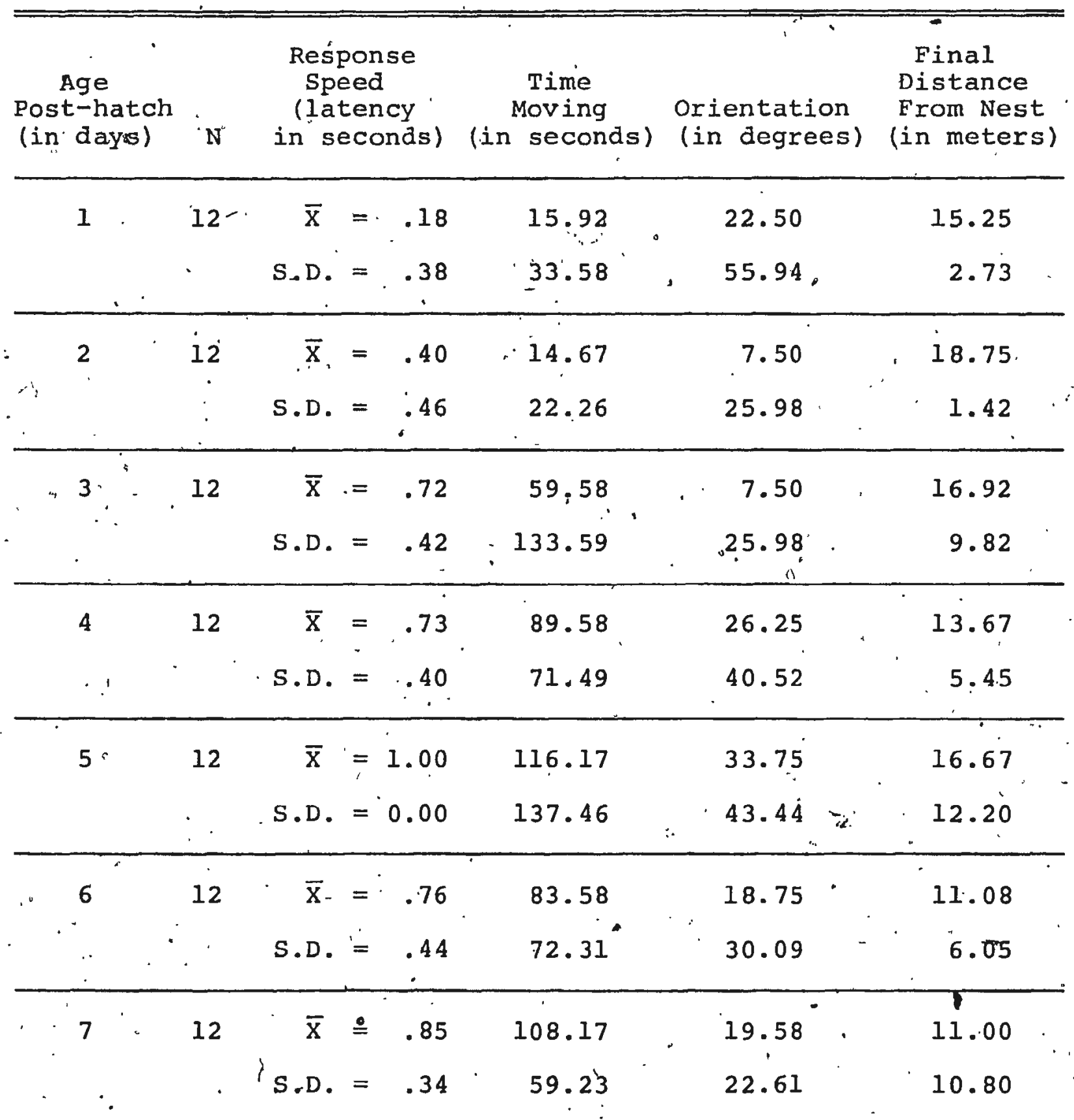


latency for daily-tested chicks yielded an $F \max =30.01$ $(P .<.01)$. In order to reduce the variability, response speed, the reciprocal of latency was calculated and is discussed throughout the text (see Tables 27 and 28, Appendix, for raw data summaries). A significant difference in response speed between chicks of different ages was found ( $F=6.51$, P.<.001). A summary of this analysis is presented in Table 3. Individual comparisons (t tests, winer, 1971) indicated that Day 1 and 2 chicks had significantly lower response speeds than all other age 6 roups $(\overline{\mathrm{X}}=.18, .40$, dompared.to $.72, .73,1.0, .76$, and .85 , respectiviely; $t=4.39,0 .<.03$ ). No other age groups differed from each other, although a trend of increasingly higher response speeds with increasing age was evident.

Table 3

Sumary of Analysis of Variance of Transformed Latency (Response Speed) of Chicks Tested during the First Week Post-hatch

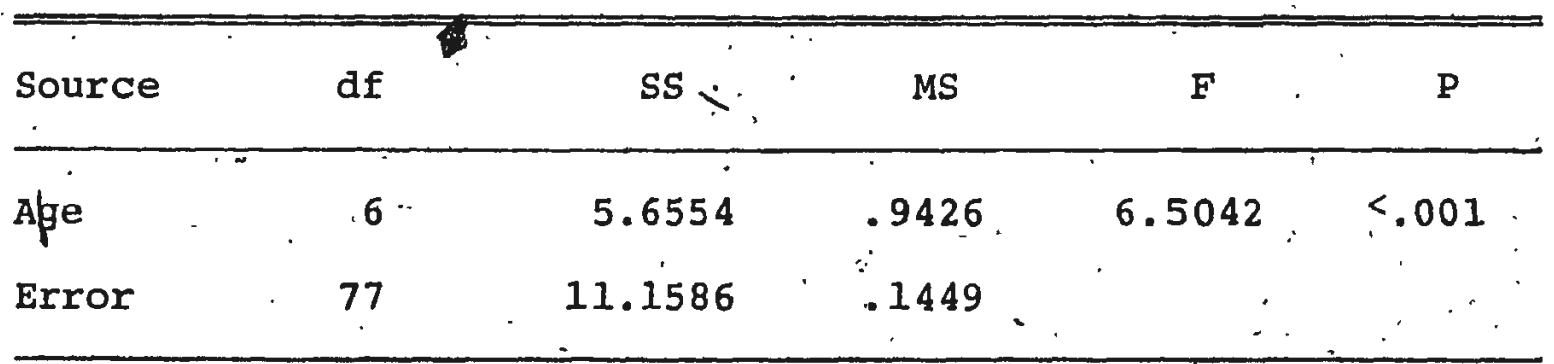

Time Moving:- An $E$ max test for homogeneity of variance of time moving was significant (F $\max =32.62, \mathrm{P} .<.01$ ). A $\log$ transformation of "time moving was done and both raw and transformed data analysed.' Since analysis of variance 
produced the same significant differences on raw and transformed data 'see Tables 27 and 29 for transformed data summaries), the raw data will be discussed here. A significant difference among groups was found on time moving $(F=2.90$, P.<.01). A summary of this analysis is presented in Table 4. Individual comparisons (studentized Range Statistic) showed that Day 1 and 2 chicks spent significantiy less time moving than all other age groups $(\bar{X}=15.92 n 14.67$ sec. as compared to $\bar{x}=59.58,89.58,116.17$; 83.58 and 108.17 sec. respectively; F=4.03, P.<.04). No other age groups differed significantly from each other although as with response speed, a trend of increased time moving with greater age was evident.

\section{Table 4}

Summary of Analysis of Variance of Time Moving during the First Week Post-hatch

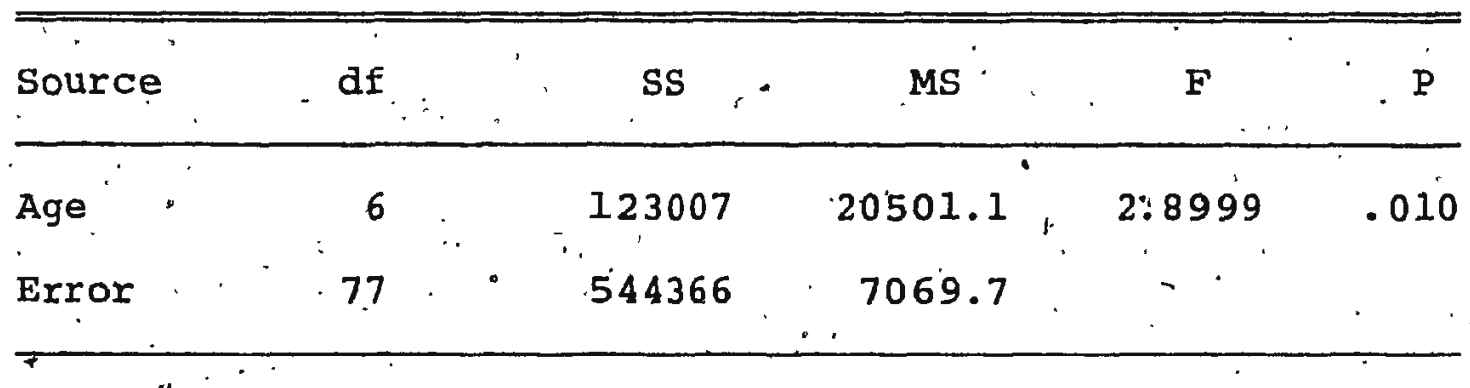

orientation. An $F \max$ test for homogeneity of variance of orientation was not significant ( $F \max =7.47$, P.?.05). Analysis of variance of orientation was not significant $(F=.81, . P .>.05)$. The mean degrees deviance of orientation to the nest was 19.4 . 
Distance. An F max teșt, of homogeneity of variance of distance from the nest was significant ( $F \max =13.96$, P. $(.05)$. A $\log$ transformation was performed on distánce. No sighificant differences were found in analy'sis of variance of, either raw or transformed data (F=1:59, P.).05; F=1.46, P.>.05; respectively's':. The mean distance from the nest was $14.8 \mathrm{~m}$.

Number returns. Subjects were difided into those returning within at least $10 \mathrm{~m}$. of the nest and the number not reaching this criterion (see Table 5). It was evident. from this division that the number of chicks reaching the criterion increased with greater age. A çhi.square'test. showed that the number of chicks reaching criterion was significantly greater than expected by chance on Day 6 : and 7. (chi=6.36, P.<.03; chi=15.12, P.<.001; respectively) and significantly less than expected on Day 1 and 2 (chi= $5.06, \dot{\mathrm{P}} .<.03 ; \operatorname{ch} i=8.60, \mathrm{P} .<.001)$.

Table 5

Number of Chicks Achieving Nest Return Criterion during the First Week Post-hatch

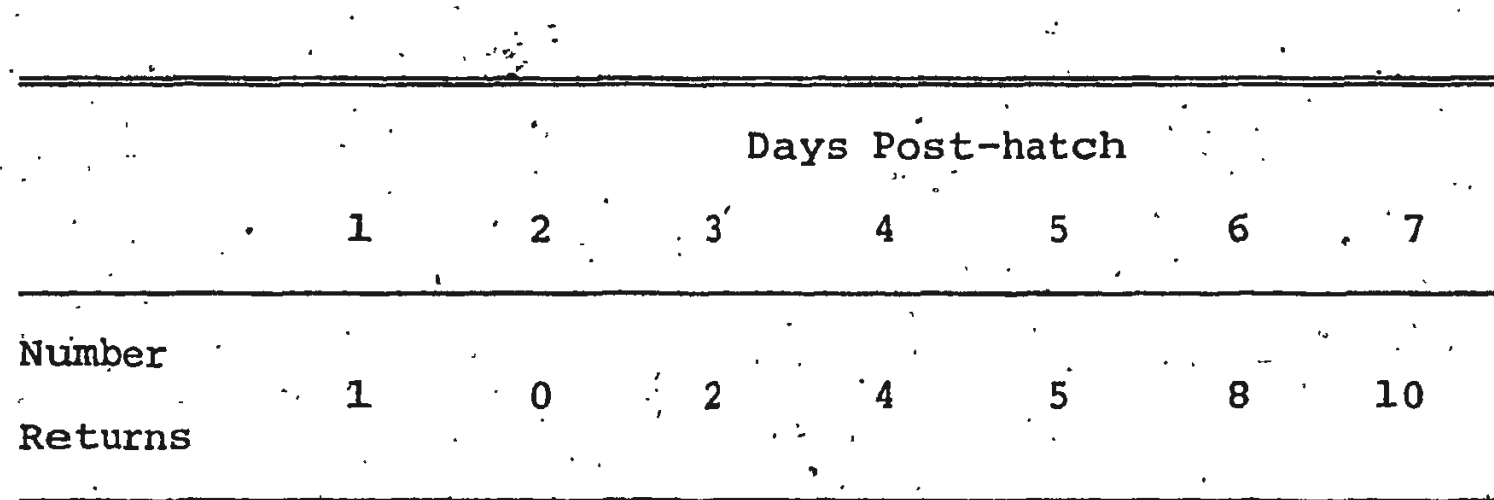




\section{Foster-reared Chicks}

The means and standard deviations of all dependent measures on foster-reared chicks are shown in Table 6. Foster-reared chicks were compared to normal-reared chicks (Group 6 from Daily-tested subjects). An F max test of the differences between variances' of the two groups was not siğnificant on any dependent measure (latency, $F<1$, P.>.05; time moving, F=1.67, P.>.05; orientation, F=1.15, P.>.05; distance, $F=1.78, P .>.05$ ) so a t-test was used to compare the two groups. No significant differences were found between the two groups on latency $\left(t<1, p_{0}>05\right)$, time moving . $\left(t<i, P_{0}>05\right)$, drientation $\left(t<1, P^{\prime}>05\right)$ or $\dot{d i s t a n c e}(\ddot{t}<1$, P.>.05).

\section{Relocations}

All subjects were not found for each weekly test. session (see Table. 30, Appendix), which may have led to a systematic bias in the data since chicks recaptured may be those with strong preferences while those not found may have weak or no area preferences. If this were the case, only chicks with.strong area preferences would be included in the sample. The data were inspected, therefore, to determine if the same chicks were being found weekly. As shown by Table 30, this was not the case.' Only 9 chicks had complete Ifrecords for the 5 weeks. Omissions were generally due to : a chick not being located for one or two of the 5 weeks. since this was the casd, subject means were substituted for missing cells for analysis. The means and standard, 
Table 6

Means and Standard Deviations of Latency, Time Moving, Initial Orientation, and Final Distande-from the Nest of Foster-reared and Normal-reared Chicks tested on Day 6 Post-hatch

$+$

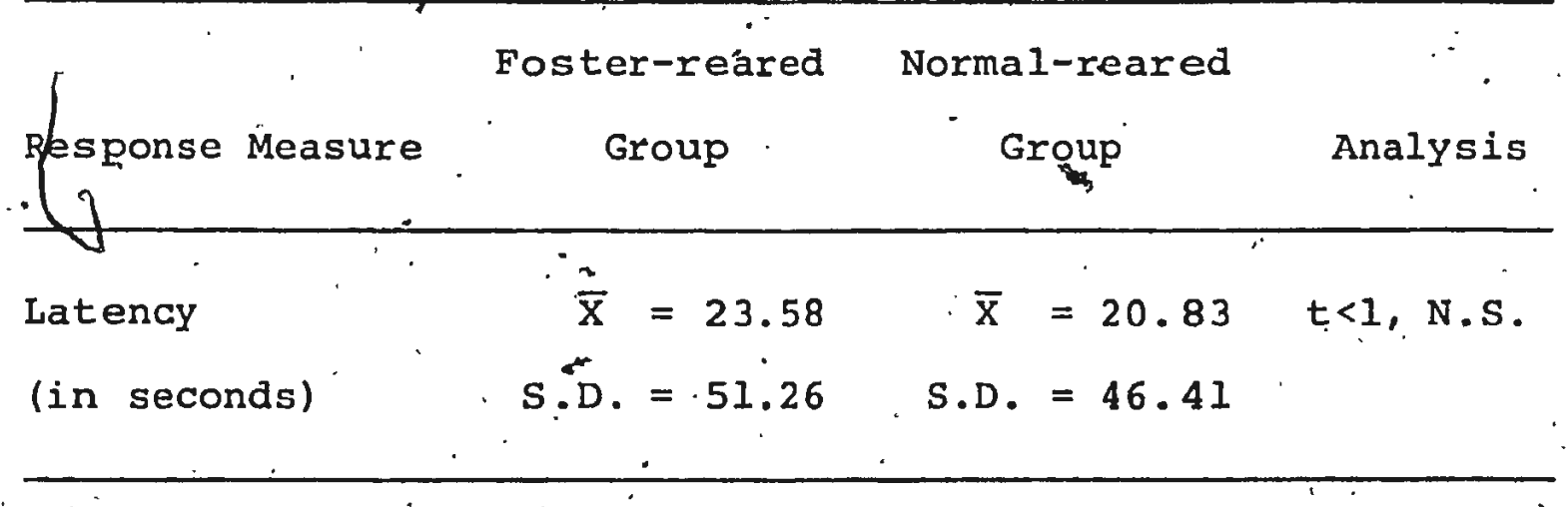

Time Moving $, \quad, \quad \frac{\prime}{\bar{x}}=69.58 \quad \bar{x}=78.33 \cdot t<1 ; N . S$.

$(\text { in seconds })^{*} \cdot \mathrm{S} . \mathrm{D}:=78.33$ S.D. $=72.74$

Initial orientation $\bar{x}=11.25 \quad \bar{x}=18.75 \quad t<1, N . S$. (in degrees). S.D. $=26.78$ S.D. $=28.80$,

Final Distance $\bar{x}=14.17 \quad \therefore \bar{x}=11.08 \quad t=1.42, N_{n} \mathrm{~s}$.

(in meters) $\cdot$ S.D. $=4.34$ S.D. $=5.79$ 
deviations fol all dependent mpasures in the weekly tests are presented in Table 7. Orientation data was incomplete for Week 5 and time moving for weeks 4 and 5 due to weather and equipment failure, so these. were not used in the. analysis.

- Latency. An F max test for homogeneity, of variance was significant for latency (F $\max =4.02$, P.<.01). A reciprocal transformation was done" and both raw and transformed data analysed. No'significant differences were found on eithet raw or transformed data $\langle F=<1, P\rangle$..05 ;. $F=1.58$, P.>.05, respectively).

Time Moving. Time moving was not analysed because of the missing data for Weeks 4 and 5 . It is evident from the data for Weeks $1-3$ and from experimenter observation. that time moving increased with age (see Table 7).

Orientation: An $F \max$ test for the homogeneity of variance was not significant for initial orientation (F thax= 1.81, P.>.05). Analysis of variance indicated a significant difference among groups on orientation. $(F=13.45, \mathrm{P} .<.001)$. A summary of this analysis is presented in Table 8. "Individual comparisons (Studentized Range Statistic) revealed that the means of week 1 and 2 (19.13, 24.64, respectively) were not different from each.8ther but were significantly lower than the mans of week 3 and $4(39.50,58.22$; respectively; $F=24: 77,(\hat{P}<.007)$ : The mean of week 3 was also siǵnificantly lower than that of Week $4(F=7,69$, P.<:01). 


\section{- Táble 7}

Means and Standard' Deviations of Transformed Latency (Response Spefa), Initial Orientation, Time Moving, Final Distance and Initial Distande from the Nest for Relocated Chicks during Weeks 1-5.

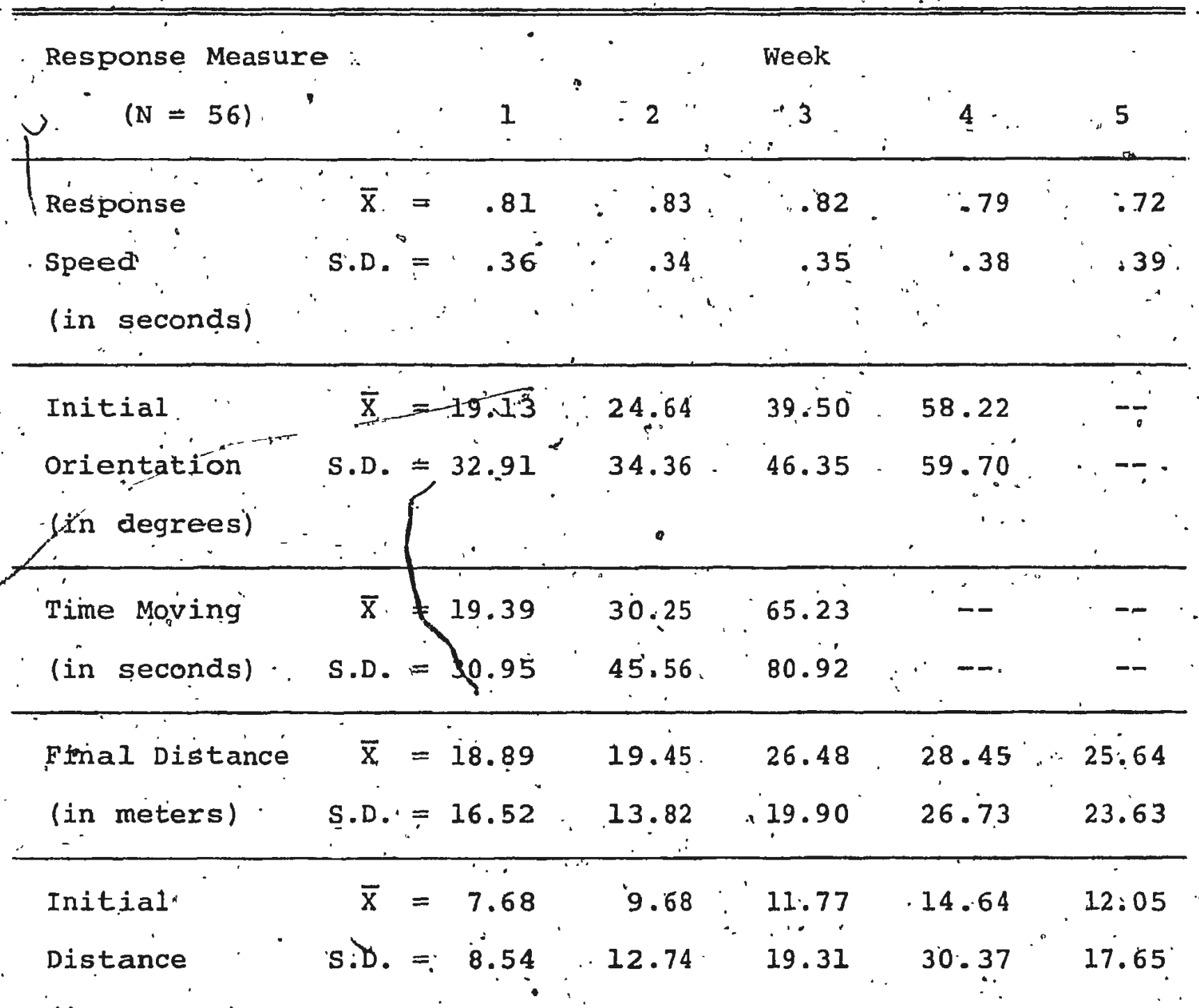

(in meters) 


\section{9 \\ Table" 8}

Summary of Analysis of Variance of Initial orientation for Relocated.Chicks during Weeks I-5

\begin{tabular}{l} 
Source \\
\hline Age
\end{tabular}

variance was not significant (F max=1.01, P.>.05). Analysis:

of variance revealed a significant difference among groups. on final distance $(F=2.93$, , P.K.02). Al summary of this analysis is presented in Table 9. Individual comparisons (t-tests) showed that the mean distance was significantly lower for Weeks 1 and $2(\bar{x}=18.89, i 9.45$, respectively) than for wejs $3-5, \bar{x}=26.48,28.45,25.64$, respectively; $E=6.31$, .p.<.01).

Initial Distance. An F max, test for homogeneity of variance was hot significant (F. $\max =1,98$, . . > 05). No

- differençs among groups were found in analysis of variance $\left(F=1^{-} 5.6 ;-05 \%\right.$

Number Returns: A division was made of those chicks returnipg within $10 \mathrm{~m}$ of the nest and those not reaching 
Table 9

Sưmary of Analysis of Variance of Final Distance from the Nest for Relocated Chicks during Weeks i-5

\begin{tabular}{|c|c|c|c|c|c|c|}
\hline Source ? & $d f^{\prime}$ & $\ldots \mathrm{ss}$ & 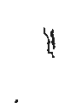 & MS & $F$ & $\dot{\mathrm{P}}=$ \\
\hline Age : & 4 & 4211.82 & . & 1052.96 & 2.9280 & .02 \\
\hline $\begin{array}{l}\text { Age } x .=- \\
\text { Subjects }\end{array}$ & 220 & 79116.90 & & 359.62 & & \\
\hline Erròr" & 55 & 38174.30 & & 694.08 & & \\
\hline
\end{tabular}

this criterion (see Table io) a A chi square test showed that the number. of returris was significantly greater than expected by . chance for Week 1 and 2 chicks (chi=33.48, P.<.001; chi= $12.26, \mathrm{P} .<.001$, respectively) and significantly less than expected for week 4 and 5 , chicks (chi=16.90, P.<.001; chi= $1 i .22, \mathrm{P} .<.001$, respectively).

Table 10

Number of Chicks Reaching Nest Return Criterion on Relocations during Weeks 1-5

Week

$1 \quad 2 \cdot 3 \cdot 4 \cdot 5$

Number Returns

29

$2 \cdot 3$

$9, \quad 3$

5 


\section{Correlations}

Daily-tested Chicks. Table 11 presents the significant correlations with their associated probabilities obtained. from the correlation matrix. The list of variables used in the correlation matrix is presented in Table 31, Appendix. A Pearson product-moment coefficient was used for interval and ratio data.While a Spearman!s rank coefficient wasiused for the ordinal, data. Significant correlations that were 'not meaningful in terms of the present experiment are presented, in Table 32, Appendix.

The chick's initial distance from the nest was negatively related to final distance. from the nest. $\left(r_{x y}=-.34\right.$, P.<.001) and positively related to wind speed ( $\mathrm{x}_{\mathrm{XY}}=.24$, P.<.03). There was a positive relationship between location vegetation type and time moving (rho=.27, P.<.01). The - height of the lociation vegetation was also"positively related to time moving $\left(r_{x y}=.73,{ }^{\circ} \mathrm{P} .<.001\right)$ and negátively related to wind speed $\left(r_{x y}=-.22, P_{;}<.05\right)$. The density of the location vegetation was positively related to time moving ( $(r h o=.31, \mathrm{P} .<.010)$ and negatively related to wind , speed (rho=-.27; P.<.02). The denser the vegetation in which the, chick was found, then, the higher the wind speed, and the longer the time the chick spent moving.

There was a positive relationship between vegetation. height at the release point and time moving $\left(r_{x y}=: 46, P .<.001\right)$. Vegetation height at the final resting location was negatively related to final distance $\left(r_{\mathrm{xy}}=-.22, \mathrm{P} .<.04\right)$. There was a 


\section{-Table 11}

Significant Correlation Coefficients and Probability Levels for Chicks Tested during the First Week Post-hatch

.

Variable

Correlation

coefficient $\quad \mathbf{P}$

1. Initial and final distance from the nest

$r_{x y}=-.34 \quad .001$ 2. Initial distance from the nest and wind

$r_{x y}=.24^{\circ} .030^{\circ}$

3. Location vegetation and time moving

$. r h o=.27 \quad .010$

4. Location vegetation height and time moving

$r_{x y}=.73 \quad .001$

5. Location vegetation height and wind speed

6. Location vegetation density and time moving

7. Location vegetation density and wind. speed
$r_{x y}=-.22 \quad .050$
rho $=.31 \div .010$
rho $=-.27 \quad .020$

8. Release vegetation height and time moving

9. Final vegețation héight and final distance

10. Final distance and wind speéd

11. Nest site and location vegetation type

12. Location vegetation and final vegetation type

$$
r_{\mathrm{xy}}=.46^{\cdot} \cdot .001
$$

$\mathrm{r}_{\mathrm{xy}} \doteq-.22 \quad .040^{\prime}$

$r_{\mathrm{xy}}=.27 .010$

rho $=.51 \quad .001$

rho $=.36 . .010$

13. Release vegetation and final vegetation type

rho $=.37^{\circ} .010$

14. Initial orientation and final distance from the nest

15. Inițial orientation and latency

$r_{x y}^{0}=.26 \quad .020$ $\therefore r_{\mathrm{xy}}=.24 .040$ 
positive relationship between final distance from the nest and wind speed $\left(r_{x y}=.27, p_{0}<.01\right)$ and between the vegetation type at the nest and at the collection point (rho=.51,. P.<.001). Final vegetation "type was also positively reláted to location vegetation type (rho $=.36$, P.<.01) and release vegetation type (rho=.37, $\mathrm{P} .<.01)$. Finaily, there was a positive relation between initial orientation and final distance from the nest $\left(r_{x y}=.26, P .<.02\right)$ and initral orientattion and latency $\left(r_{\mathrm{xy}}^{\prime}=.24, \mathrm{P} .<.04\right)$.

Relocations: The significant correlations and their associated probabilities are shown in Table" 12 . Correlation - matrices were also calculated for each weekly relocation. since the same significant relations were found for each week; only the pooled data is presented.

A positive relationship was found between initial and final distance from the nest $\left(r_{x y}=.64, P .<.0001\right)$. Vegetation type at the collection point was positively related to both the nest site vegetation type (rho $\left.=.49, \mathrm{P}_{3}<.0001\right)$ and the vegetation type at the final resting, location ( $r h o=.49$, P.<.0001). Moreover, the vegetation type at the nest site and the vegetation type at the final resting location were also positively related (rho $=.62 ; \mathrm{P} .<.0001)$. Initial orientation was positively related to final distance from the nest $\left(r_{x y}=.43, y_{0} .0001\right)$. Finally, time moving wa's positively related to both location vegetation type (rho=.33, P.<.001) and final vegetation type (rho=.51, P.<.0001) ؛ 


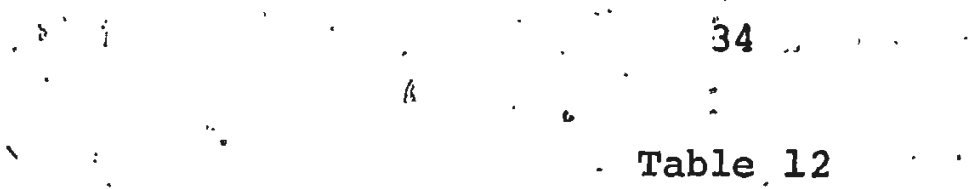

Significant Correlation Coefficients and Probability Levels for Relocated Chicks during Weeks $1-5$

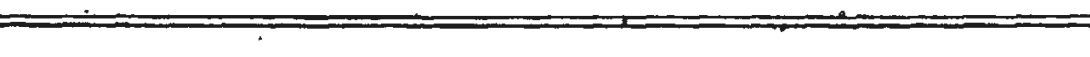

Variable

Correlation

Coefficient P

1. Initial and final 'distançe from the nest

2. Location and final vegetation type

(o)

3.- Location and nest site vegetation, type

rho $=.49 \quad .0001$

4. Nest site and final vegetation type

rho $=.62 \quad .0001$

5. Final distance and initial orientation

$r_{\mathrm{xy}}=.43 \quad: 0001$

6. Time moving and location vegetation typ

rho $=.33: 0010$

7. Time moving and final vegetation type,

rho $=.51 \quad .0001$

\section{Diṣcussion}

The data support the hypothesis that during the first week post-hatch Herring Gull chicks exhibit an attachment to the nest site area. The increasing number of returns to the nest and the decrease in the distance from the nest with increasing age indicate that attachment is optimal on Day 6-7 post-hatch. The failure to demonstrate a preference earlier than this is probably due to a performance 'difficulty in very. young chicks, rather than a lack of attachment to the nest area.. During the first three days of testing, a majority. of test chicks remained quite near the release point while many 
did not move at all. "This lack of mobility in very young chicks has also been reported for Laughing Gull chicks (Beer, "1969). However, the degrees deviance of orientation to the nest of $1-3$ day old chicks was less than ralf that of older chicks $(\overline{\mathrm{X}}=12.529 .1$, respectively $)$. This, indicates that chicks "could find the nest 'site but were unable to locomote the distance. Under undisțurbed conditions, for example, test chicks (1'-3 days old) rarely were observed.

1. $20 \mathrm{~m}$. from the nest by the experimenters. such excursions are usually limited by agonistic behaviour of birds from other nest territories.

Weekly relocation data revealed a decreasing nest site attachment with increasing age on all dependent measures which supports the prediction made. It is also evident that chick excursion areas enlarged with increasing age as shown - by the increasing distance from the nest in which chicks were found and in which they relocated on testing over weeks.

Nest site attachment appears to be ecotypically controlled, as evidenced by the failure to find differences between foster and normall-reared chicks. It should be noted that foster chicks spent at least half of the incubation period in their natural: nests, which had no apparent effect on their post-hatch behaviour. The period spent in foster nests was the latter half of incubation, which may be the more crucial period since embryos are more fully developed. It seems probable that a preference for the nest site area is conditipned as a result of the reinforcing events at the 5 
nest area, for example, feeding, shelter, protection from Rredators, social stimulation, etc. At the same time, excursions outside this area are discouraged by the presence of other territories which are actively defended against intruders. The experimenters often observed a young chick of the study age passing through a foreign'territory and being attacked by adults from the air and chicks on the ground. This mechanism of attachment could easily be tested in the laboratory by systematically introducing feeding, shelter, social stimulation, etc., into a rearing area and testing for a rearing area preference after each presentation. These stimuli could then be systematically removed to determine if and when the preference breaks down: In this way an indication of what stimuli are necessary to establish and maintain rearing area preferences could be obtained. ". Correlational data indicated that vegetation characteristics were among the cues used in relocating the nest site. The vegetation type in why chicks were found, both before and after testing, was usually the same as the nest site vegetation type. It appears, therefore, that chicks come to prefer the vegetation surrounding the nest, and when extended excursions occur restrict their activities to areas of the same or similar vegetation. The importance of vegetation characteristics in nest site selection has been zeported by Bongiorno (1970) for adult lyaughing Gulls and by Anderson (1971) for Prairie Chickens. It may be then, that both young and adults use vegetation cues and that vegetation 
preferences developed early in life are continued into adulthood. Therefore, a long term study should be done of the behaviour of chicks from hatching to the first nesting season to determine if in fact young and adults use the. same nest site cues and whether early nest site preferences influence later nest site selection. LeResche \&.Sladen (1970) have done a comparable study. although they did not investigate cues in nest' site selection 'but rather the incidence of adults nesting in their natal sites. . They found that 40.8 of first'year breeders in an Adelie Penguin colony selected nest sites within 200 meters of their natal sites.

The possibility that chicks were using sky cues to relocate the nest was examined by comparing testing with the wooden carrying box. using an opague and a transparent cover." Tweive chicks were tested under each condition using identical procedures to those previously described. No differences were found between the two groups on any dependent measure. The present study indicates a heavy reliance on visưal stimuli as cues in nest site relocation. Whether in fact. vision is necessary in nest site recognition is examined in Experiment 2. Auditory stimuli may also be used as cues to relocate the nest site. During testing, adults were observed constantly vocalizing from the air. Although it was not possible to identify which birds were the parents of the test chicks, it was possible that parent vocalization could aid chicks. in relocating the nest area. Observations 
38

of marked adults during testing or testing deafened chicks could be done to examine this possibility. In addition, the 'presence of chicks at the nest may be used as cues' in nest. ... relocation. Later experiments evaluate the role of other chicks in attachment to and recognition of the nest site. 
Experiment 2. The Role of Vision in Nest site Attachment

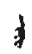
and Recognition

Although the importance of vision in initiating approaich responses to moving objects and conspecifics has been demonstrated (Bateson, 1966; Evans, -1972), little datá has been reported on the role of vision in the development of preferences for and recognition of rearing areas. Anderson (197i) reported that Prairie. Chickens use visual clues, such as vegetation height and composition, to establish territorial boundaries and are itromgly attached to these. The preferences for vegetation exhibited by young Herring Gull chicks (Experiment. 1) indicate also that visual stimuli are important in nest site recognition. Evans' (1970a) study of preferences for a rearing chamber in young Ring-bilied Gull chicks àlso supports this hypothesis. In these expëriments, howevèr, other sensory modalities, which were operative, could also affect recognition and attachment. The present study was designed, therefore, to assess the necessity of vision in nést. site attachment and recognition.

Method

Subjects

Twenty-four Herring Gull chicks were randomly selected from Little Bell Island. Chicks were chosen from three-egg of Plutches, and were individually marked after hatching. The location of the nest was recorded, as well as the type, height and density of vegetation surrounding the nest. : 
Chicks were divided equally into two groups. Group I were to be fitted with hoods, made of white nylon baby socks, to occlude vision (see Fig. 4). The hood area directly over the eyes consisted of raised hemispheres, stiffened with white ril polish to provide translucent surfaces and prevent direct contact with the eye. Group 2 were" to be fitted with the same kind of hoods with, no eye occluders. "Normal chicks were Day 7 chick's from Experiment 1. Daily health checks' were made on all chicks.

Procedure

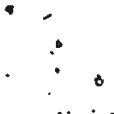

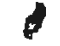

The testing procedure was to be the same as that described for daily-tested chicks ain Éxperiment 1. Initially the test hoods were placed or 6 subjects which włre checked two hours later. - Two of these subjects were observed via a telescope for one hour after hood fitting.: The chicks generally remained quiescent at the nest. The parent gulls, however, on aerial inspection of their nest, appeared very disturbed. Both parents were observed to frequently emit distress calls during the observation period!: swoop close to the nest, but not alight. Since other parents in the area were alighted at their nests, this behaviour was interpreted to be a reaction to the visual appearance of the hooded. . chicks in the nest. Consequently; a. period of three and one hạlf hours was spent observing two additional chicks. Records of parent and chick behaviour were taken at 5 min. intervals. It was found that during the entire period neither parent approached the nest, even düring distress 


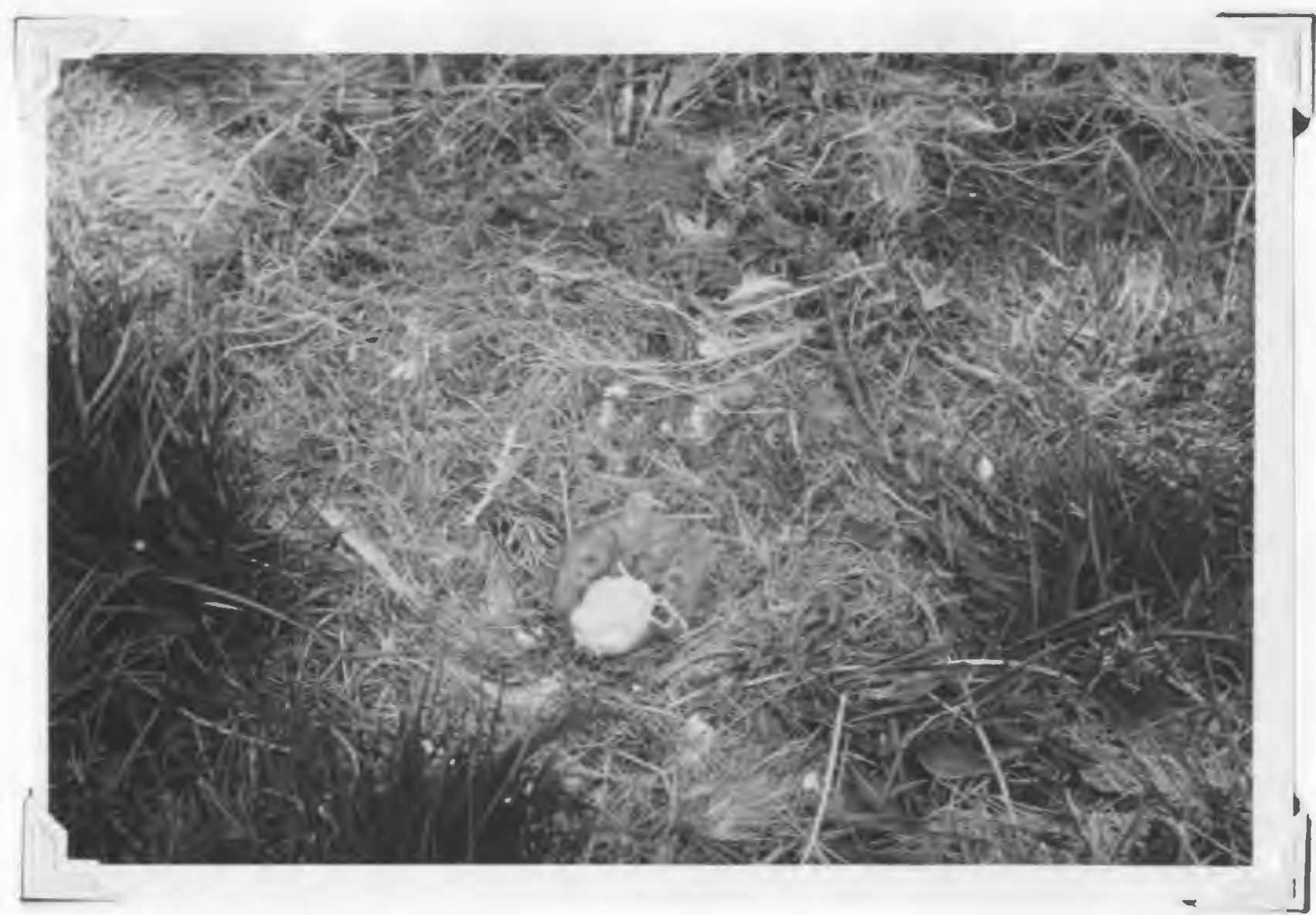

FIG. 4. Herring Gull Chick Wearing Experimental Hood Used to Occlude Vision 
vocalization by chicks. The same disturbed behaviour present in the firsthour of observation was also evident.

Since parents would not approach the nest during a $3 \frac{1}{2}$ hour period it was concluded that hooded 'chicks would not survive since this amount of time woüld exceed the necessary brooding and feeding interval, at least for the". first few days-post-hatch (Baerends et al, 19.70). The experiment as proposed was therefore not feasible. It " appeared that the visual appearance of hooded chicks was. not acceptable to parent gulls. To complete this experiment successfully, then, it woth be necessary to use occluders that did not drastically change the yisual appearance of chicks. Contact lenses would fulfil thi's requirement. .Howeveri difficulties of using these in the field, of allaying infection,-and of developing maintenance techniques could not be overcomein the short period of time left in the nesting season.

Although the necessity pof vision for nest site attachment could not be evaludied, it was still possible to obtain some indication of the necesisity of vision to nest site' recognition.. Six chicks, 7 days post-hatch, were fitted with occluder hood', given a 10 min. period to adapt to the hood, and were then tested for nest site relocation using the same procedures as described in Experiment 1. However, the test period was extended to $30 \mathrm{~min}$. 


\section{Results}

Hooded chicks were compared to Day 7 chicks from Experiment 1. The means and standard deviations of ail - dependent measures are presented in Table 13. Án F test for the differences between-variances was significant on time moving $(F=7.05$, P.<.0.02) and latency $(F=8.10$, P.<.001), so a Welch 't prime approximation (Ferguson, 1966) was used' to compare groups on these measures. A t-test was used for distance and-initial orientation. Results showed a significant difference between groups on initial orjentation $t \mathrm{t}=4.65$, P.<.003); final distance $(t=2.66, P .<.02)$ and latency $\left(t^{\prime}=4.07 ; P^{\prime}<.01\right)$. The hooded group exhibited.longer

- latencies, whe further from the nest and exhibited" a: greater deviance in initial orientation than did the normal group. The data was also inspected to determine if hooded chicks" relocated in similar vegetation to that at the collection point. ${ }^{2}$ No significant trends were detected, $3 / 6$ chicks settled in the same vegetation the as surrounded the nest,.. $3 / 6$ did not. However, $5 / 6$ chicks relocated in vegetation of similar height and density to that of the collection point.

\section{Discussion}

Loss of vision significantly affects nest site recognition at least in visually experienced animals. To evaluate the eftef visual deprivation on naive chicks it would be necessary to occlude vistion from hatching as 
Table 13

Means and Standard Deviations of Time Moving, Initial Orientation, Latency, and Final Distance from the Nest for Hooded and Normal. Chicks, Experiment. 2

\begin{tabular}{|c|c|c|c|c|}
\hline $\begin{array}{ll}\because \\
\text { Résponse Measure }\end{array}$ & & $\begin{array}{l}\text { Hooded } \\
\text { Group }\end{array}$ & $\begin{array}{l}\text { Normäl } \\
\text { Group }\end{array}$ & Analysis \\
\hline $\begin{array}{l}\text { Time Moving } \\
\text { (ịn seconds) }\end{array}$ & $\begin{array}{r}\bar{X}= \\
S . D .=\end{array}$ & $\begin{array}{c}83.67 \\
75.06 \\
-\end{array}$ & $\begin{array}{r}108.17 \\
59.23\end{array}$ & $\begin{array}{c}t^{\prime}=1.34, N, \mathrm{~S} \\
\vdots \vdots\end{array}$ \\
\hline
\end{tabular}

Initial orientation $\bar{x}=112.50^{\circ} \quad 19.58 \quad t=4.65,8^{\circ},<.003$

(in degrees) $\quad$ S.D. $=.5,0.31 \cdot 22.61$

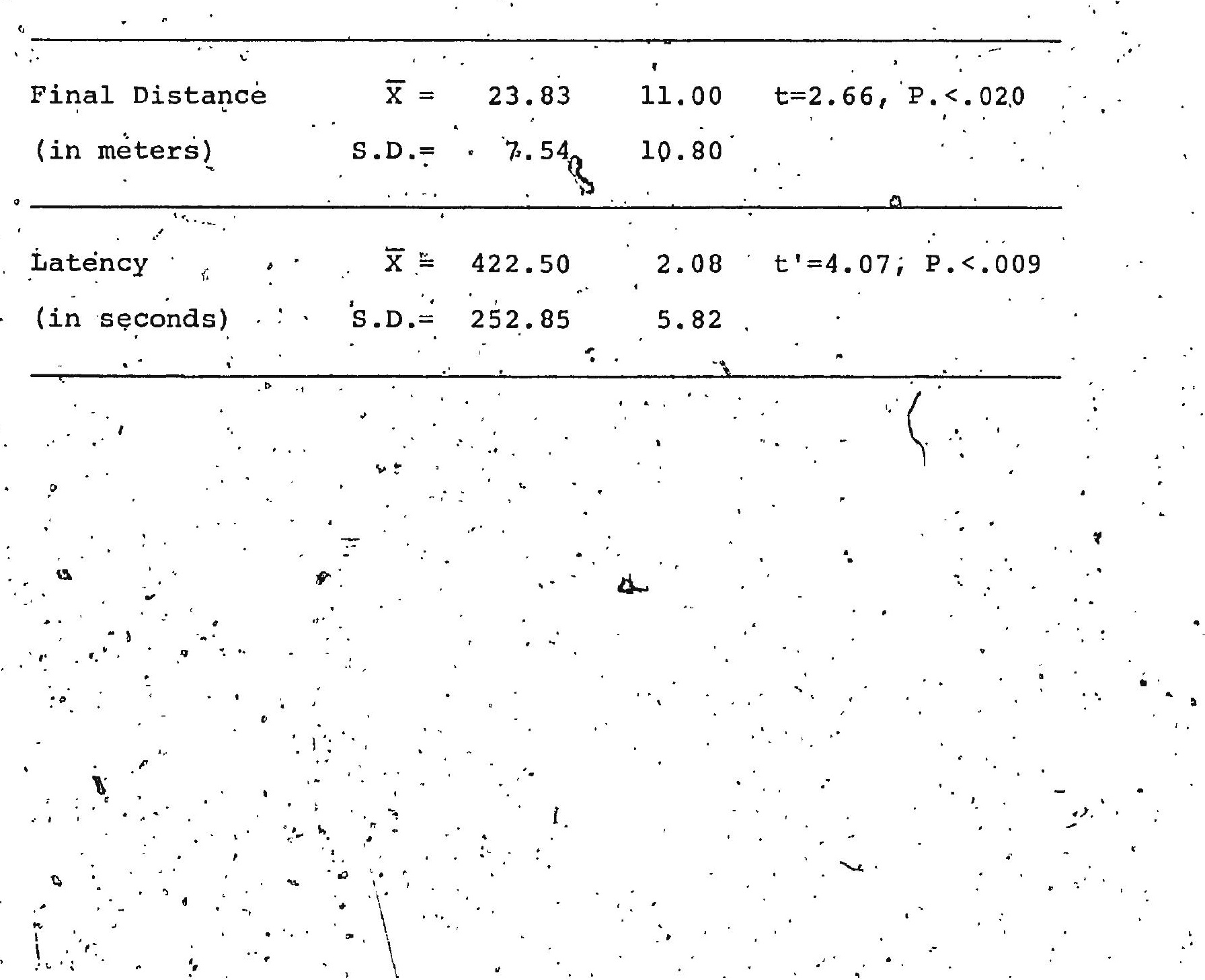


previously described. It is quite possible that the lack of any visual experience in naive chicks may be compensated for by using other sensory modalities to orient to the nest area. Such chicks may in fact be able to locate their nests using auditory or tactile stimuli. The fact that in this experiment visually experienced animals responded to such cues as height and density of vegetation supports this speculation." The experiment as originally planned would have to be done to investigate this possibility" The present data' indicate that under normal conditions, vision is heavily relied upon in nest site recognition:

The reaction of parents to hooded chicks poses an interesting problem: "Data on individual recognition of chicks by parents (Smith, 1966; Tinbergen, 1953; Cullen, 1957) make it seem unlikely that parents were reacting to their own chicks since this reaction was present on Day 1 postt-hatch. It is more probable that.parents were exhibiting species recognition of chicks and that deviation from this norm was not acceptabie. This could be tested by using first year breeders that do not have experience with previous broods,' or by using occluders that do not change the visual appearance of chicks, i.e. contact lenses. It is also possible that parents were reacting to a change in the nest site stimuli since chicks are normaliy a part of the'stimulus configuration of the frest. Data obtained in later work do in fact indicate. $\because \because$ that changes in the nest site stimuli, i.e: placing strange chicks at the nest, will disrupt behaviour of adults. 
Experiment 3. The Role of Stimulus "Conspicuousness". and "Landmarks" in Nest Site Récognition

4

It has been suggested that birds recognize their nest areas by the "conspicuousness" of the visualiy prominent features of the habitat, such as landmarks and vegetation (Ifack, 1933; 1954). Experimental evidence supports this suggestion for adults. Tinbergen (1953) demonstrated that : relocation of a visually prominent landmark correspondingly disorie'nted adult Herring 'Gulls from the nest. Baerends et al (1970) reported that relocation of a landmark facilitated acceptance of a displaced nest by Herring Gullis. Anderson (1971) has shown that Prairie Chickens, Tympanuchus cupido Linnaeus, use major differences. in the height and composition of vegetation to establish territoriạl boundaries and are strongly attached to these stimuli. Although "conspicuousneșs" has been advanced as a major stimulus characteristic controlling early stimulus preferẹces in young biras (Batesón, 1966), no data have been reported on the cues used by chicks in recognition of rearing or nest areas. Stationary imprinting studies (Bateson, 1964b; 1966) indicate that conspicuous '. stimuli are effective in establishing preferences for static objects. Correlational data from Experiment 1 also indicate that vegetation characteristics, important in adult recognition, are also among the cues used by neonatal Herring. Gull chicks in relocating the nest area. The present experiment was designed to determine whether conspicuousness 
of stimuli serves as a cuf in nest site recognition by chicks and whether relocation of a conspicuous landmark would cause a cọrresponding disorientation from the nest.

Method

Subjects

4. A sample of 18 Herring Gull chicks was randomly. selected from grass vegetation on Little Bell Island. Chicks were chosen from three-egg clutches and were individually. marked after hatching so that age could be accurately " determined from the date of hatching. The location of each" nest site was recorded on a grid map of the island, and the height; type and density of the surrounding vegetation: reçorded as described previoúsly (Experiment 1). Chicks were.tested on Day 6 post-hatch.

Procedure

- Prior to chick hatching, artificial landmarks consisting of fir trees, were placed vertically $1 \mathrm{~m}$. NE of the tesk nests. Conspicuousness was assumed to vary with the height of these trees. Three heights were used: (I) $1.5 \mathrm{~m}$. conspicuous, (2) $1 \mathrm{~m}$. moderately conspicuous, and (3) $.5 \mathrm{~m}$. low conspicuous (seé Figs. 5, 6, and 7, respectively),

All. chicks were tested under two conditions. In one condition the landmark was moved $5 \mathrm{~m}$. NE of the nest and in the second condition the landmark remained in its original position: To control for possible order effects, half. of the chicks were.tested under the above schedule whirle the 


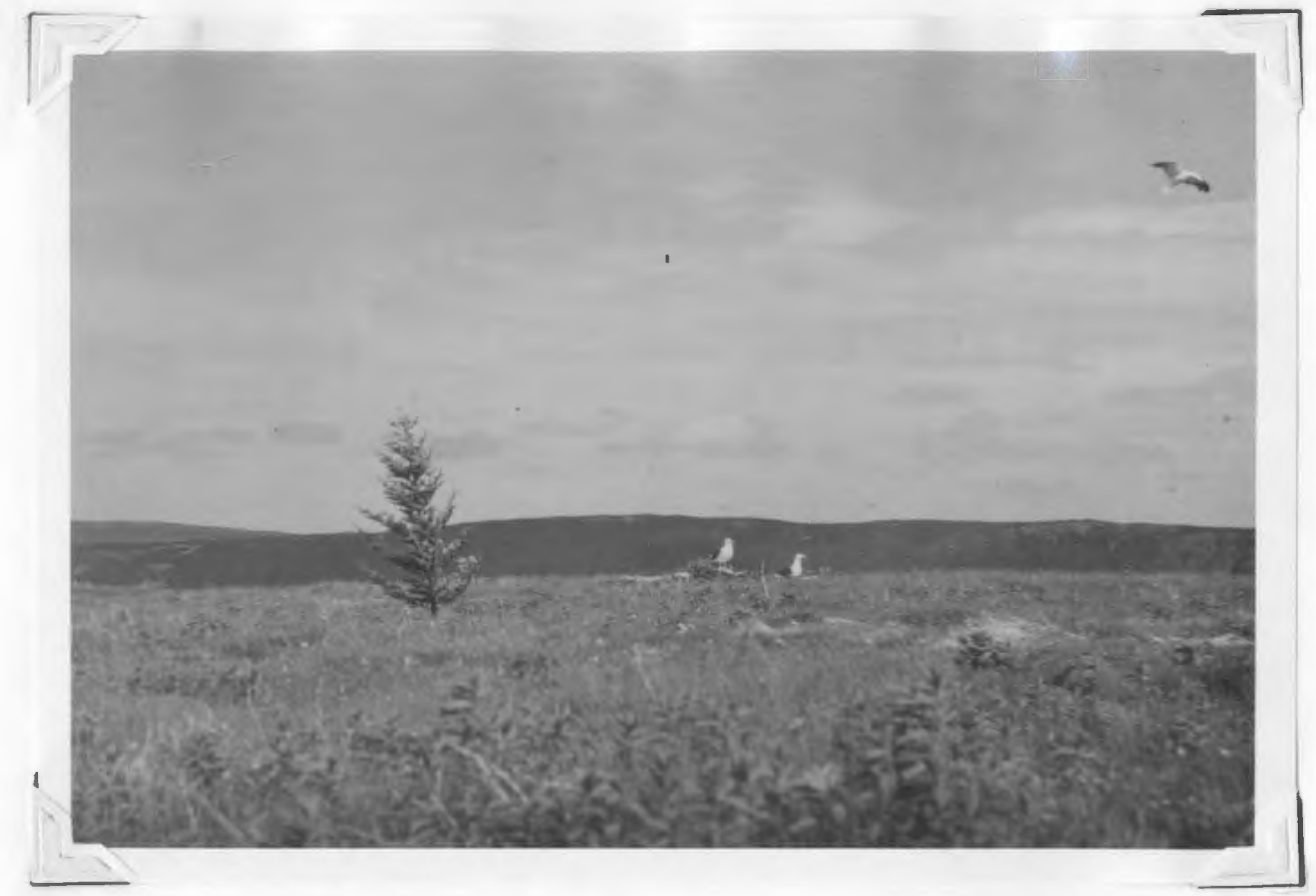

FIG. 5. Fir Tree Used as a Highly Conspicuous Landmark in Experiment 3 


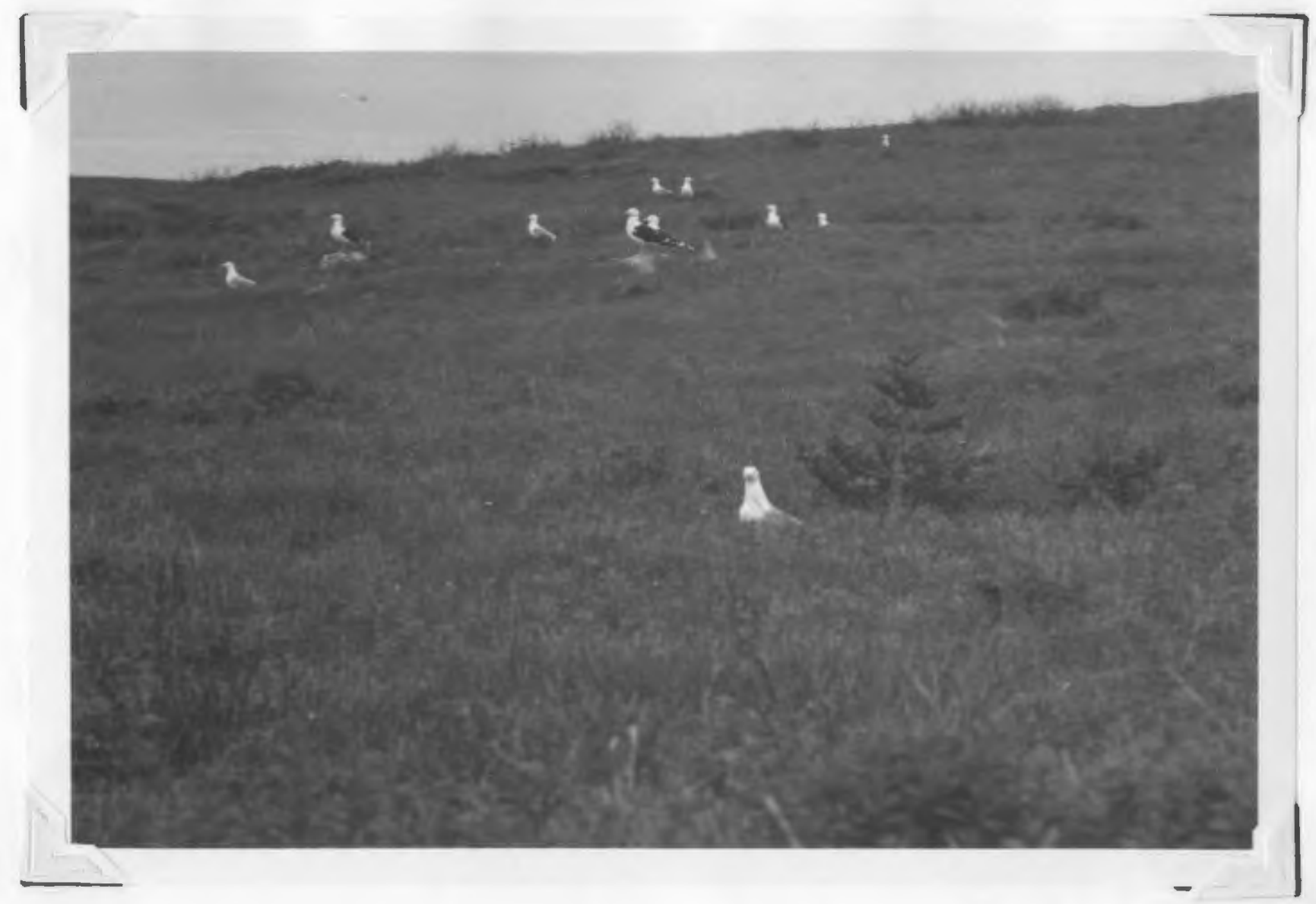

FIG. 6. Fir Tree Used as a Moderately Conspicuous Landmark in Experiment 3 


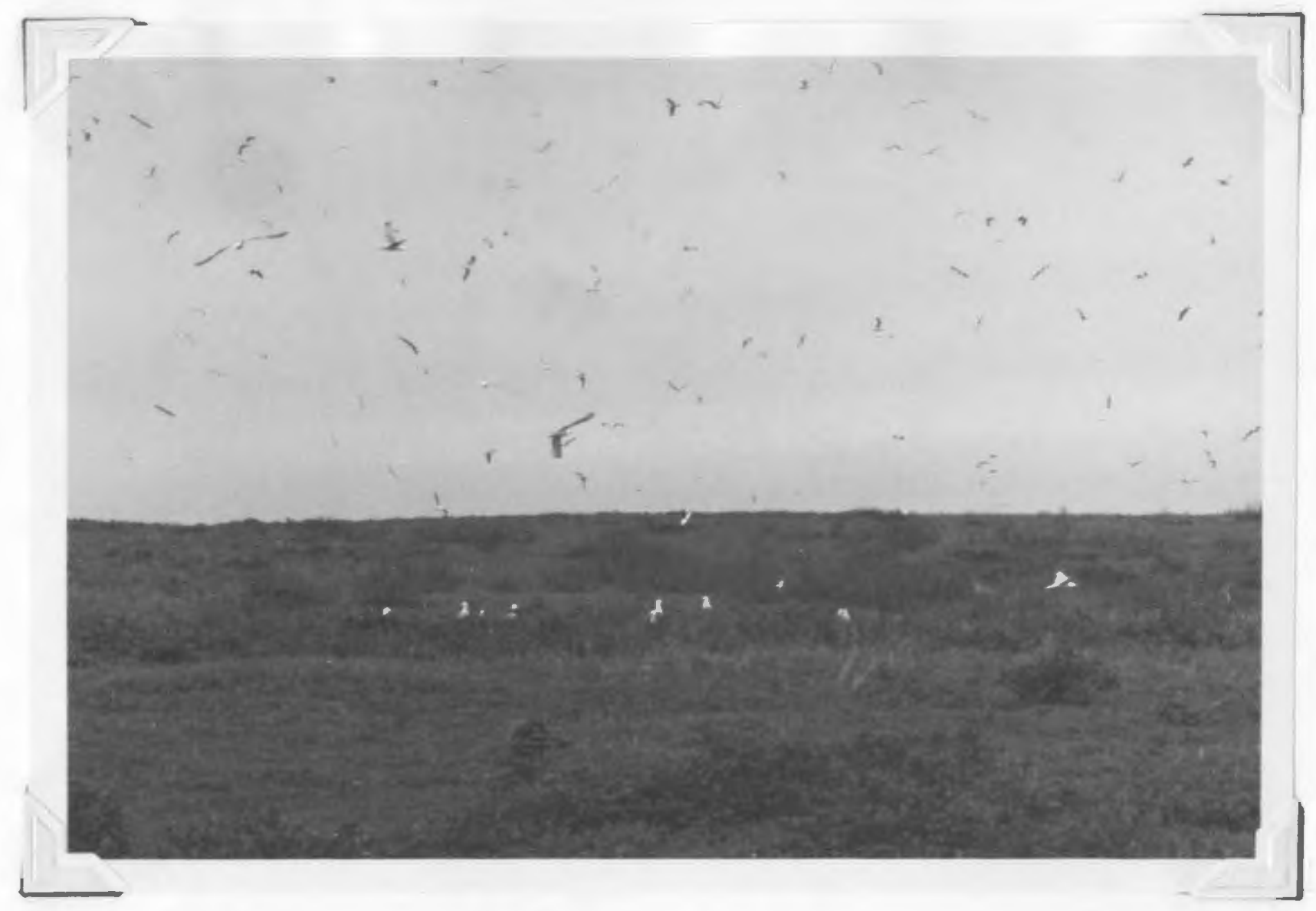

FIG. 7. Fir Tree Used as a Low Conspicuous Landmark in Experiment 3 
half were tested with the order reversed, i.e. landmark in its original position followed by the landmark moved.

For testing the chick was removed.from the nest area, 'placed in the wooden carrying box, and removed $5 \mathrm{~m}$. from the nest for a period of three minutes. During this time the landmark was moved for half of the chicks, and left unaltered for the other half. The chick was then transported $20 \mathrm{~m}$. from the nest in a random direction and released.".

Following completion of the first trial, the chick was retested in the same way, except that the position of the landmark was reversed. That is, if on the first trial the chick was, tested with the landmark moved, then on the second trial, the landmark was unaltered for testing, and vice versa. Movement latency (in seconds), time moving (in. seconds), initial orientation (in degrees deviance from a straight line to the nest), and final distance from the nest (in meters) were recorded. Testing was terminated when the chick was within one meter of the nest site or was immobile for $10 \mathrm{~min}$. All chicks were returned to the collection point after testing.

\section{Results}

- The means and standard deviation's for all dependent measures are presented in Table 14.

Latency. An F max test for homogeneity of variance was significant for latency (F $\max =30.00$, P.<.01). A . reciprocal trainsformation was performed on latency and both 


\section{Table 14}

Means and Standard Deviations of Transformed Latency (Response Speed), Time Moving, Initial -

Orientation and Final Distance from the Nest for Chicks in Experiment 3

\begin{tabular}{|c|c|c|c|c|c|c|c|c|c|c|c|c|}
\hline 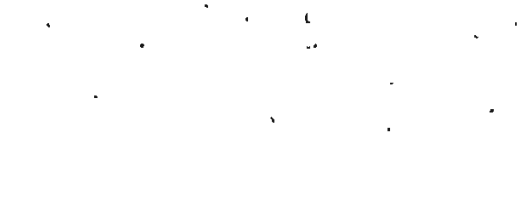 & $\cdot$ & His & & $\cdot$ & $\cdot$ & $\begin{array}{l}\text { orispicu } \\
\text { Mod }\end{array}$ & $\begin{array}{l}\text { ous Leve } \\
\text { erate }\end{array}$ & & . & & ow & $\begin{array}{l}\ddots \\
\cdot\end{array}$ \\
\hline $\begin{array}{l}\text { Order of Landmark } \\
\text { Position }\end{array}$ & $M I$ * * & $\therefore \quad$ M2 & M2 & MI & MI & M2 & M2 & MI : & $\cdots M I$ & M2 & $\mathrm{M} 2$ & MI \\
\hline $\begin{array}{l}\text { Response speed } \quad \bar{x}= \\
\text { (in seconds) S.D. }\end{array}$ & $\begin{array}{c}.38 \\
.53\end{array}$ & $\begin{array}{l}1.00 \\
0.00\end{array}$ & $\begin{array}{l}.39 \\
.52\end{array}$ & $\begin{array}{r}.75 \\
.43\end{array}$ & $\begin{array}{r}-.68 \\
. .55\end{array}$ & $\begin{array}{l}\because 70 \\
.52\end{array}$ & $\begin{array}{l}1.00 \\
0.00\end{array}$ & $\begin{array}{l}.70 \\
.52\end{array}$ & $\begin{array}{l}.1 .00 \\
0.00\end{array}$ & $\begin{array}{l}1.00^{\circ} \\
0.00\end{array}$ & $\begin{array}{l}.70 \\
.52\end{array}$ & $\begin{array}{l}1.00 \\
0.00\end{array}$ \\
\hline $\begin{array}{lr}\text { Time Moving } & \overline{\mathrm{X}}= \\
\text { (in secords) } & \text { s. D.. }= \\
& \end{array}$ & $\begin{array}{l}83.67 \\
95.08\end{array}$ & $\begin{array}{l}59.00 \\
10.81\end{array}$ & $\begin{array}{l}60.00 \\
10.00\end{array}$ & $\begin{array}{l}38.33 \\
33.59\end{array}$ & $\begin{array}{l}45.00^{\circ} \\
21.79\end{array}$ & $\begin{array}{l}59.33 \\
46.75\end{array}$ & $\begin{array}{r}107.00 \\
59.09\end{array}$ & $\begin{array}{l}64.67 \\
1.4 .50\end{array}$ & $\begin{array}{l}72.00 \\
57.24\end{array}$ & $\begin{array}{l}52 \cdot 00 \\
20.30\end{array}$ & $\begin{array}{l}118.67 \\
101.44\end{array}$ & $\begin{array}{r}\quad 49.00 \\
19.47\end{array}$ \\
\hline $\begin{array}{l}\text { Initial } \\
\text { Orientation } \\
\text { (in degrees) }\end{array}$ & $\begin{array}{r}45.00 \\
0.00\end{array}$ & $\begin{array}{l}0.00 \\
0.00\end{array}$ & $\begin{array}{l}33.33 \\
20.21\end{array}$ & $\begin{array}{l}60.00 \\
51.96\end{array}$ & $\begin{array}{l}60.00 \\
25.98\end{array}$ & $\begin{array}{l}0.00 \\
0.00\end{array}$ & $\begin{array}{l}75.00 \\
25.98\end{array}$ & $\begin{array}{l}16.67 \\
28.87\end{array}$ & $\begin{array}{l}30.00 \\
25.98\end{array}$ & $\begin{array}{l}0.00 \\
0.00\end{array}$ & $\begin{array}{l}30.00 \\
51.96\end{array}$ & $\begin{array}{l}30.00 \\
25.98\end{array}$ \\
\hline $\begin{array}{l}\text { Final Distance } \overline{\mathrm{X}}= \\
\text { (in meters) }\end{array}$ & $\begin{array}{r}13.67 \\
7.50\end{array}$ & $\begin{array}{l}8.67 \\
3.51\end{array}$ & $\begin{array}{l}11: 00 \\
.7 .50\end{array}$ & $\begin{array}{l}2=2.67 \\
10.12\end{array}$ & $\begin{array}{r}17.33 \\
1.21\end{array}$ & $\begin{array}{r}7.00 \\
9.50\end{array}$ & $\begin{array}{l}22.00 \\
11.36\end{array}$ & $\begin{array}{r}18.33 \\
.63\end{array}$ & $\begin{array}{r}14.33 \\
7.33\end{array}$ & $\begin{array}{r}12.33 \\
.4 .16\end{array}$ & $\begin{array}{r}20.33 \\
8.74\end{array}$ & $\begin{array}{r}14.67 \\
4.11\end{array}$ \\
\hline
\end{tabular}

**M1=Landmark Moved; $\cdot M 2=$ Landmark Unaltered 
raw and transformed data añlysed. Analysis of variance revealed no significant differences on either raw or transfórmed datá.

Time Moving. An F. max. test of homogeneity of yariance of time moving was significant ( $\mathrm{F} \max =8.64, \mathrm{P} .<.05)$. A $10 \mathrm{~g}$ transformation of time moving was performed and both'raw and transformed data analysed. Analysis of variance showed. no significant differences on either raw or transformed data.

orientation. An F max test for homogeneity of variance was not significant ( $F \max =4.01, P .>.05)$. Analysis of variance indicated a.significant main effect of landmark position on nest site orientation $(\mathrm{F}=10.05, \mathrm{P} .<.008)$. A summary of this analysis is presented in Table 15. The mean degrees deviance from the rest for the "landmark moved condition was 45.56 while the mean degrees deviance for the landmark unaltered was 17.78 . Testing with the landmark then led to significantly greater deviance from the straight line to the nest than did testing with the landmark unaltered. Orientation to the landmark itself was significantly more deviant in the moved condition $(\bar{x}=21,1)$ than in the unaltered condition of the landmark $(\bar{x}=16.1 ; t=4.6, \mathbb{P} .<.01)$. However, orientation. on the landmark itself was significantly less deviant than orientation to the nest $(\bar{X}=21.1 ; 45.56$, respectively, $t=8.21 \%$ P.<.01) in the movied condition whịle no difference occurred in the unaitered condition $(\bar{x}=16.1,17.78$, orientation to the landmark and the nest respectively, t<i, P.>.05). 


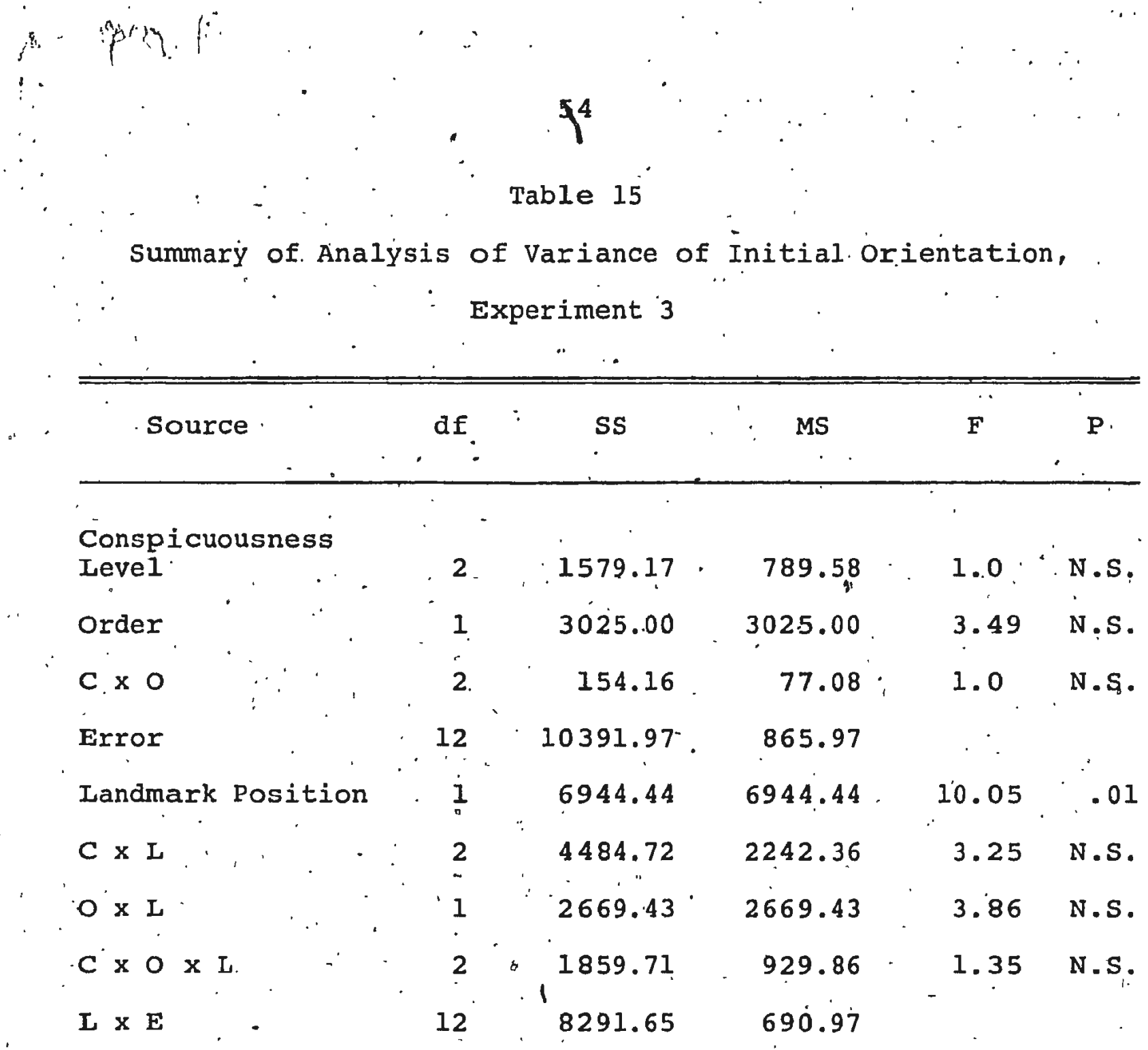


Final Distance. An $F$ max test for homogeneity of variance was not significant $\left(F \max =3.60,0_{0},>05\right)$. A significant main effect of landmark position on final distance was found in analysis of variance ( $F=5.53 ; \dot{P} .<.03)$. A summary of this analysis is presented in Table 16. The mean distance from the nest for the landmark moved condition was 16.44 while the mean distance for the landmark unaltered condition was 12:27. Final distance from the nest was lower when the landmark was in its original position during testing than when it was moved.

\section{Discussion}

The results support the hypothesis 'that. landmarks are among the cues used in nest site récognition and that changing the stimulus configuration of the nest causes disorientation. Testing, with the landmark moved resulted in greater deviance. in initial orientation to the nest and greater distance from the nest than did testing with the landmark in its original position. This data agrees with that of Tinbergen (1953) which demonstrated that adult Herring Gulls are also disoriented by movement of a prominent landmark. Young and adults then may use similar cues in nest site recognition. The possibility exists that the movement main effect was in part due to experimental manipulation, that is the act of moving the landmark disrupted behaviour. However, care was taken to treat subjects under moved and unaltered conditions in the same way. The time periods in the carrying 
Table 16

Summary of Analysis of Variance of Final Distañce from the Nest, Experiment $3 \$$

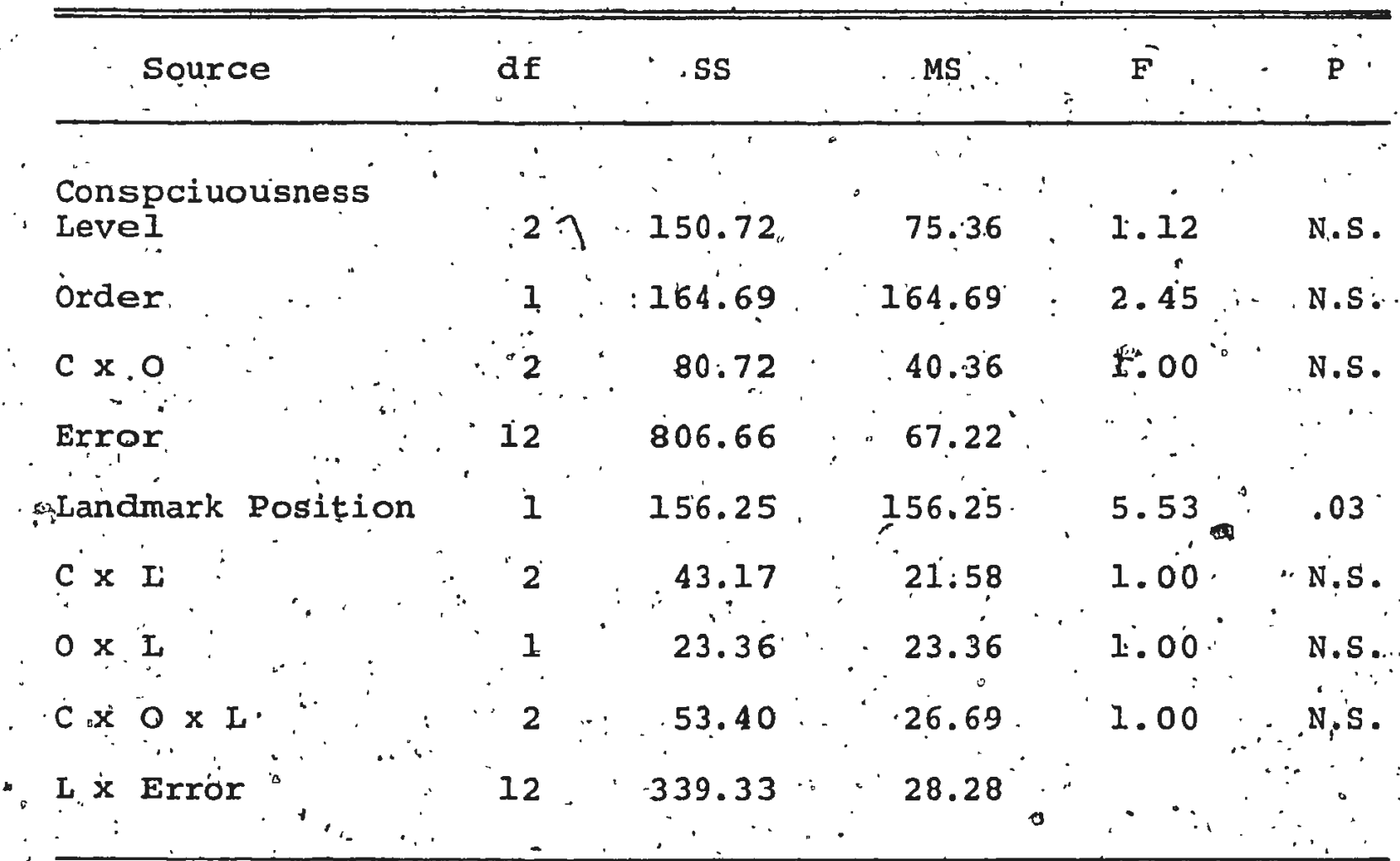


box were identical, the chicks were placed in the carrying bóx before any manipulations took place, and the experimenters attempted to behave in the same manner during the three minute interval whether or not the landmark was being moved. It appears, therefore, unlikely that an "éxperimenter effect is present: Moreover, the fact that orientation to the landmark was superior to orientation to the nest in both moved and unaltered conditions oindicates that chicks were responding to the landmark and not to movement per sep. The failure to find differencès across ląndmark height' level's may be related to the scalle of "conspicuousness" chosen. "It is evident from Figs. 5, 6", dnd 7. that although " the three height levels are distinguishable to the human eye, $\therefore$ each may serve as a conspicuou's object within the surrounding vegetation to a Herring Gull chick. For this reason; low $\rightarrow$ conspicuous trees may be just as effective a stimulus as "highly conspicuous trees when both are against a low grass background. To test this, landmarks which are at the same levei as the surrounding vegetation could be included in the scale. Alternatively, to evaluate the rolejof conspicuous stimuli a large area surrounding the nest could be levelied. so that no 'conspicuous landmarks were available.

A futhex reason for the failure to find conspicuousness differences may be that a combination of cues is used. in nest relocation and that conspicuous stịmuli exist in other "sensory modalities. It is possible, for example, "that horizontal cues could be used on Little Bell. Island in 


\section{$58^{8}$}

relocating nests. This may be evaluated by testing chicks in fog versus no fog or with a line of sight to the nest. versus no line of sight to the nest. Visual and auditory. stimuli provided by șiblings and parents may also be important in nest relocation. The latter suggestion is assessed in later lexperiments.

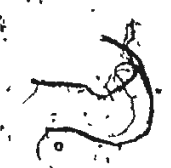

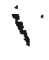
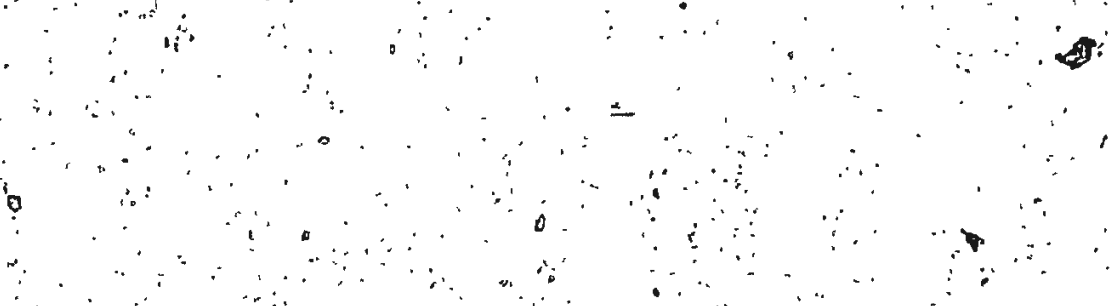

:

o
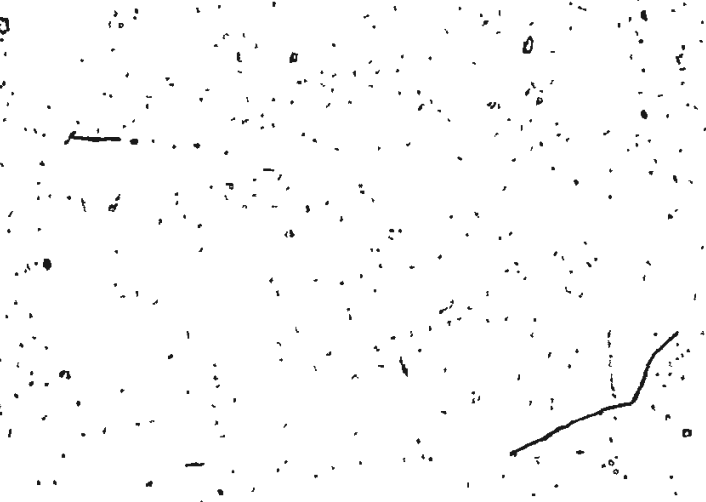

$\therefore$

$\because$

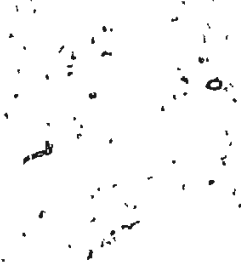

int

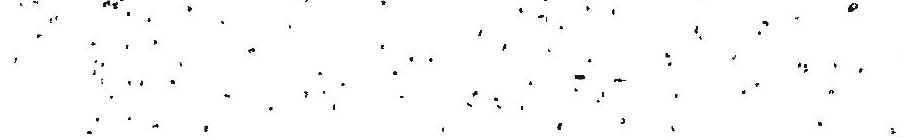


Experiment 4. The Development of Individual Recognition. among Herring Gull Chicks

Individual recognition has been hypothesized to be one important mechanism that maintains family. unity in ground nesting precocial species (Alley \& Boyd, 1950; Davies \& Carrick, 1962; Hailman, 1962; Bateson, 1966). Reciprocal reognition of young (Tinbergen, 1953; Cullen, 1957; Smith, 1966) and părents. (Tinbergen, 1953; Hailman, 1962; Beer, 1969; Evans, 1970b) has been demonstrated in several species at approximately one week post-hatch. The relatively high cohesion of sibling groups, particulariy" during the first week of life (Evans, 1970a), could indicate that individual recognition of brood siblings also occurs at an earlier áge. This.has been demonstrated for Ring-billed Gull chicks that recognize siblings on Day 4 post-hatch. (Evans, 1970a): If sibling. recoğnition -is evident among Herring Gull chicks during. the first week post-hatch, then social stimulation provided by siblings may be an important stimulus in nest site attachment and recognition during this period. The present experiment was designed as a preliminary study to determine if individual recognition occurred among Herring Gull siblings, and if so; to determine its chronological develofiment. 
Method

Subjects

A sample of 15 Herring Gull chicks was randomly

selected from the study site on Little Bell Island.' Chicks were selected from three-egg clutches, individually marked on the day of hatching and the nest site location recorded. Testing began on Day 2 post-hatch.

\section{Apparatus}

The test apparatus consisted of a rectangular wooden runway, measuring $50 \mathrm{~cm} . \times 100 \mathrm{~cm} \cdot \mathrm{x} 30 \mathrm{~cm}$., separated into three compartmenţs by wire screens placed $15 \mathrm{~cm} 8$ from each end of the apparatus (see Fig. 8). The runway was covered by a plexiglass sheet to prevent chicks from escaping. Procedure

stimuluta chicks, one a'sibling and the other a nonsibling, were placed in each end.compartment of the apparatus.

The test chick was placed in the centre of the middle compartment $(35 \mathrm{~cm}$. from the wire screens) to begin testing. Latency to first movement, total time moving ard the stimulus chick the subject approached'were recorded. Vocalization of both test and stimulus chicks was noted. The end containing the sibling wàs alternated to control for any. pIace response.f Testing was terminated when the chick made a choice (within $5 \mathrm{~cm}$. of a wire screen, for 45 sec.), or was immobile for 10 minutes. 


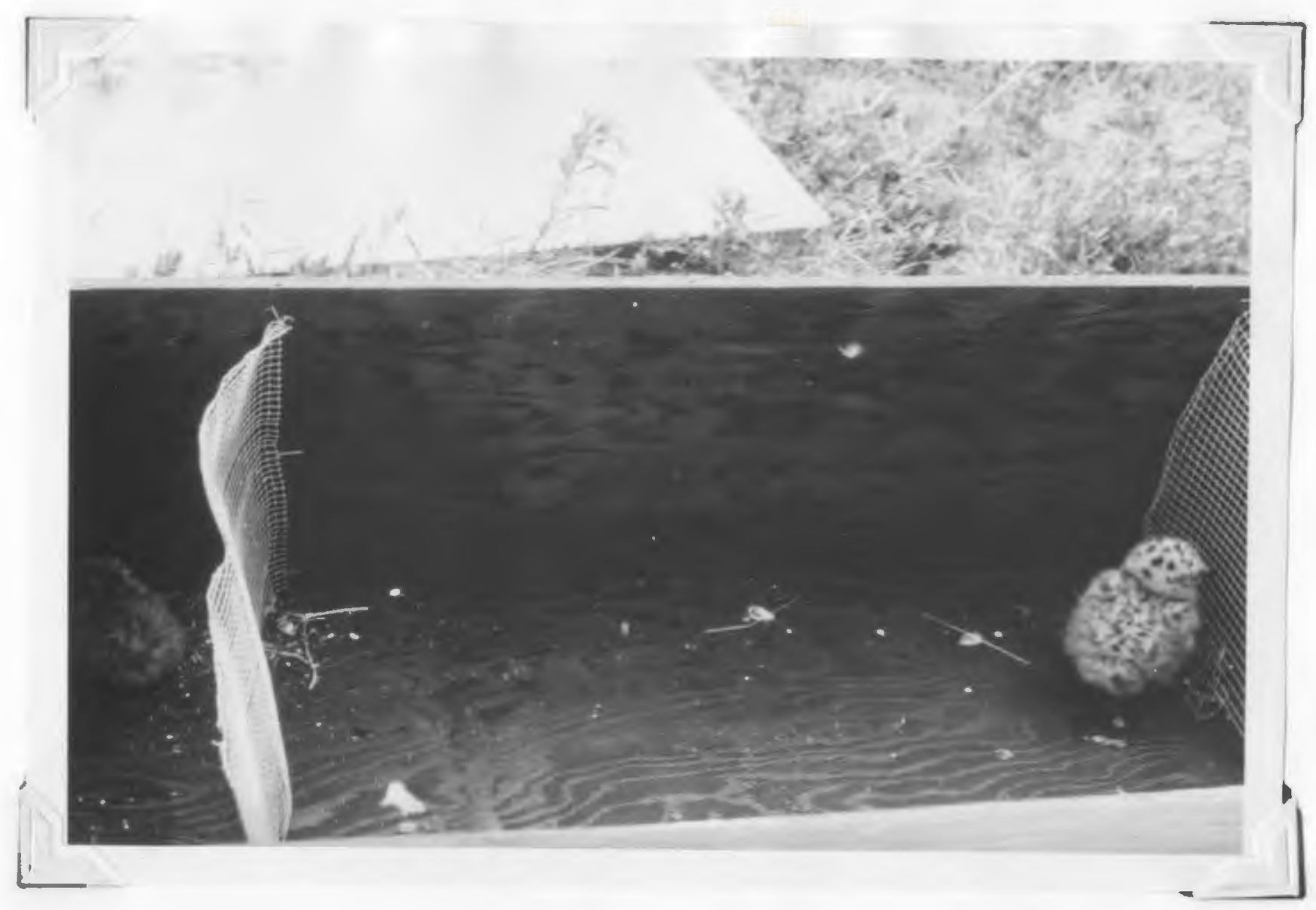

FIG. 8. Apparatus Used to Test Individual Recognition among Siblings in Experiment 4 


\section{Results}

On Day, 2 poist-hatch, 12 of the 15 chicks chose. the sibling (chi=5.4, P.<.02). Since exicks exhibited recognition * at this age, testing was terminated: On 7 of the $1 \dot{2}$ correct. responses, vocalization by one or more'of the chicks was evident: A comparison of trials on which any vocalization occurred and those on which no vocalization occurred was done for latency and time moving. No significant differences were found on eițer latency $(t<1, P .>.05)$ or time moving $\left(t=1.94, P_{.}>05\right)$. between vocalization and non-vocalization trials (see Table 17).

\section{Table 17}

Latency (in seconds) and Time Moving (in seconds) on Vocalization and No Vocalization Trials in Experiment 4 .

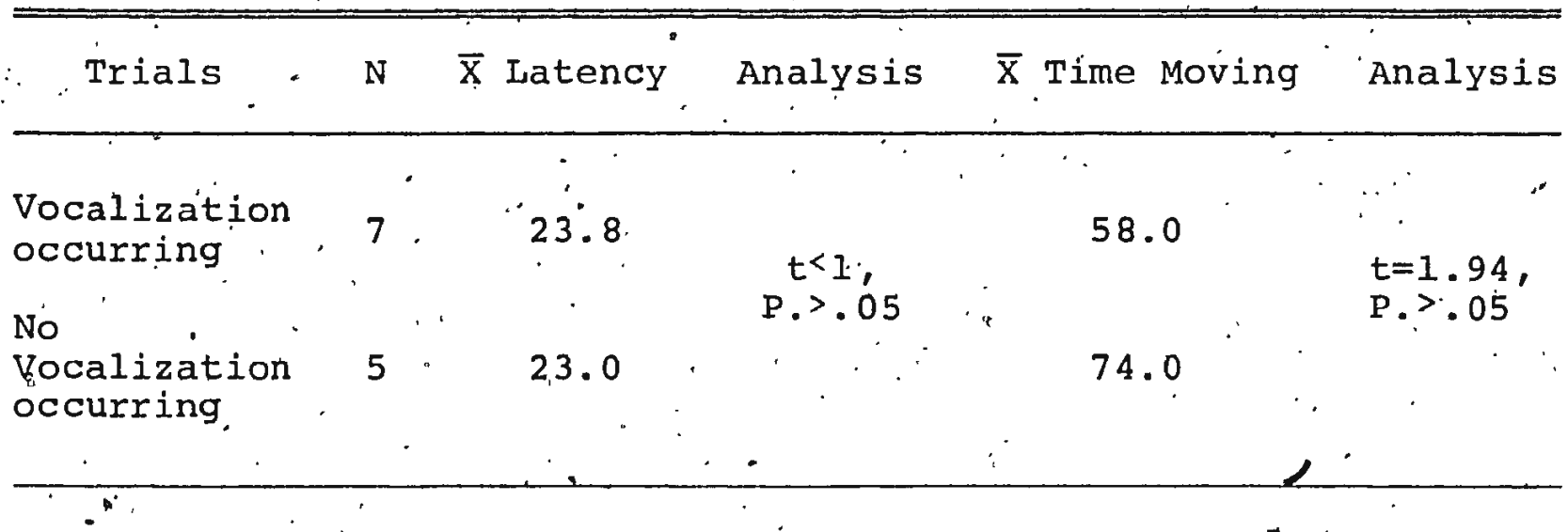

Six additional chicks were tested on. Day I post-hatch to determine whether recognition occurned eariier than Day 2 , None of the Day 1 chicks made the correct choice, 4 of the 6 . making no chọice after $10 \mathrm{~min}$. 


\section{Discussión}

\section{Result's indicate that individual recognition among} Herring Gull siblings occurs by Day 2 post-hatch. This is earlier than reported for Ring-billed gull shicks that exhibit sibling recognition on Day 4 post-hatch) (Evans, 19̈70a). It is also as early as or earlier than parental recognition which is clearly evident on Day 6 post-hatch in Laughing gulls (Beer, 1969), and on Day. 2-3 post-hatch in Black-billed gulls (Evans, 1970b). The early onset of sibling recognition does suggest that siblings as a source of social stimulation would be.important in family cohesion 'and nest site attachment evident during the first week after hatching. This possibility is examined in following experiments.

Vocalization does not appear to be necessary for individual recognition, since no differences were. found. between trialf on which vocalization occurred and those on which none ofcurred. Moreover, 5 of the 12. correct choices were made in the absence of any vocalization evident to the . experimenter. It seems, therefore, that Herring Gull chicks can recognize each other using visual stimuli. It should be noted, however, that the failure to find vocalization differences may be related to the gross measure used. That is, there was not suffiaient data to analyse vocalization differentially by source, i.e., test chick,' sibling, "etc. :in which differences would be most likely to be evident. 
Furthermore, poolfing 'such sources as was done here would. terta to cancel any differences. Therefore, although chicks can recognize each other visually, it is quite possible "that vocalization would have à facilitatory effect upon recognition. The enhanced effect of combined visual and auditory stimuli on recognition has been reported by Evans (1970b), as has the ability of gull chicks to reçognize each othep .visually.

$\theta$

$y$

is

I 
Experiment 5. The Role of Social Stimulation in Nest Șite Attachment and Recognition in Herring Gull Chicks Social stimulation has been postulated to be, an important factor in establishing habitat preferences, particularly in such gregarious species as gulis (Klopfer \& Hailman, 1965). Although social stimulation in the form of the presence of other gulis is known to enhance the formation of early spring 'club' aggregations (Tinbergen, 1953) ana the selection of feeding areas (Frings et al, 1955) in Herring Gulls, little is known about the effect of social stimulation on nest site attachment. Since Herring Gull chicks exhibit. individual recognition as earlÿ as Day 2 post-hatch; it seems likely that other chicks could serve as important stimuli in nest site attachment during the first week after hatching. The presence of other chicks may servera's social stimuli in, nest attachment in at least two ways, (1) the presence of other chicks in social testing may facilitate attachment, and (2) chicks at the nest site may serve as discriminative stimuli in nest relocation: since Herring Gull chicks exhibit individual recognition early in the first. week of hatching, both of the above may vary according to whether or not chicks are sibligy or non-siblings. The present experiment, was, therefore $y^{\prime}$ designed to detemine whether social stimulation by other chicks enhances nest site attachment, whether such stimuli serye as discriminative stimuli for nest site recognition, and whether these effects vary with sibling and non-sibling stimulation. 


\section{6 \\ Method}

Subjects

A sample of 36 -Herring Gull chicks was randomly

selected from the study site on Little Bell Island. Chicks. were chosen from three-egg clutches and were individually marked on the day of hatching so that age could be accurately determined. The location of the nest site was recorded on the grid map of the island. Chicks were tested on Day 6 post-hatch, and were assigned-to one of six testing conditions presented in Table 18.

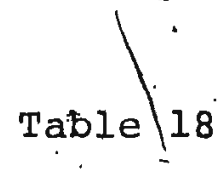

Experimental Design of Experiment 5

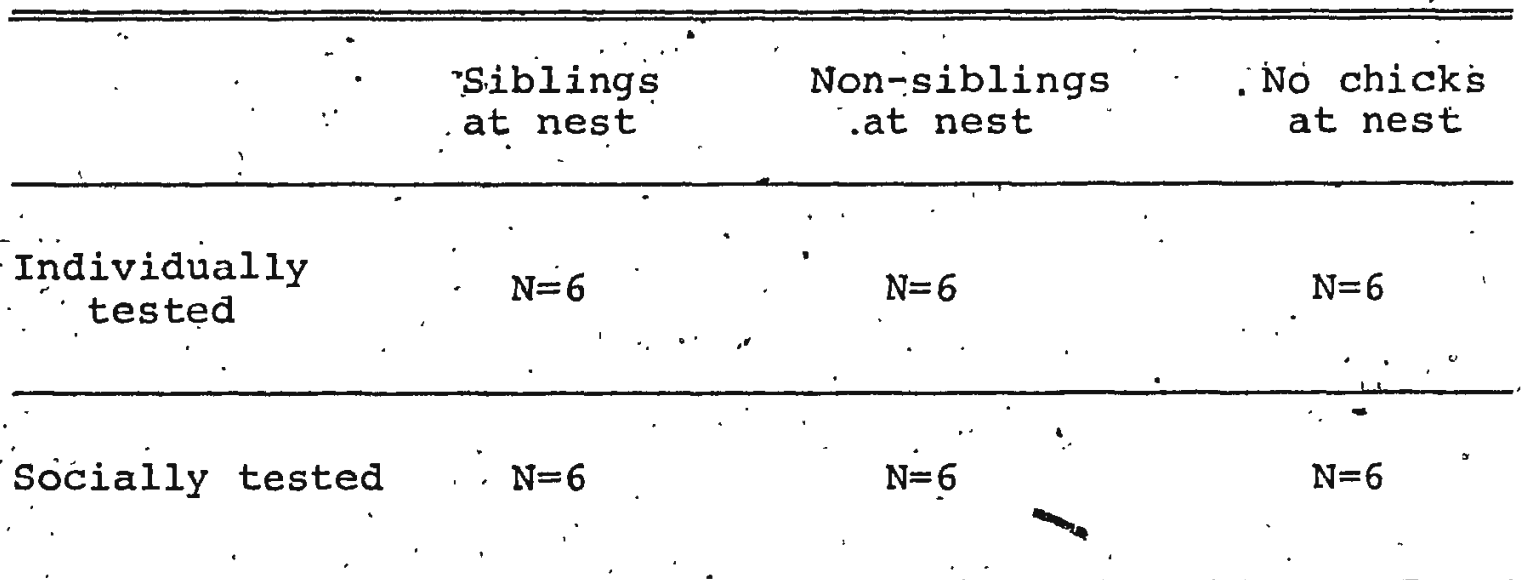

Procedure

Ton Day 6 post-hatch, chicks were removed from the nest site, placed in the wooden carrying box previously described, transported $10 \mathrm{~m}$. from the nest in a random direction and freleased. The $10 \mathrm{~m}$. distance was used in order to maximize. 
the chances that test chicks coudd perceive conditions at the nest. Mòvement latericy (in seconds), time moving (in.. seconds), initial orientation (in degrees deviance from a straight line to the nest) and final distance from the nest (in meters) were recorded. Testing was terminated when the chick was.within one meter of the nest site or was immobile for 10 minutes. All chicks were returned to the collection" point after testing.: Group tested chicks were. tested in the same way except in groups of two. Additionally, to determine the effect of social stimulation on area preferences and excursion patterns of older chicks, 12 chicks were, selected from the above sample for retesting on Day 12 post-hatch. Chicks were relocated as described in Experiment 1. Once a chick was located, its identification and locallon were recorded. The çhick was then transported $20 \mathrm{~m}$. to a different. vegetation type and released with a stimulus chick. This was a sibling for p. half of the chicks and a non-sibling for the other half.. Retesting procedure. was the same as above.

\section{Results}

The means and standard déviations of ail dependent measures are shown in Table 19 ' (see Table 33, Appendix, for corresponding 'raw and transformed data summaries).

- Latency. A test for homogeneity of variance was significant for latency (F $\max =51.02 ; \mathrm{P} .<.01)$. Latency was then transformed into response speed using a reciprocal 
Table 19

Means and standard Deviations of Transformed Latency (Response Speed), Initial orientation, Time Moving and Final Distance from the Nest, Experiment 5

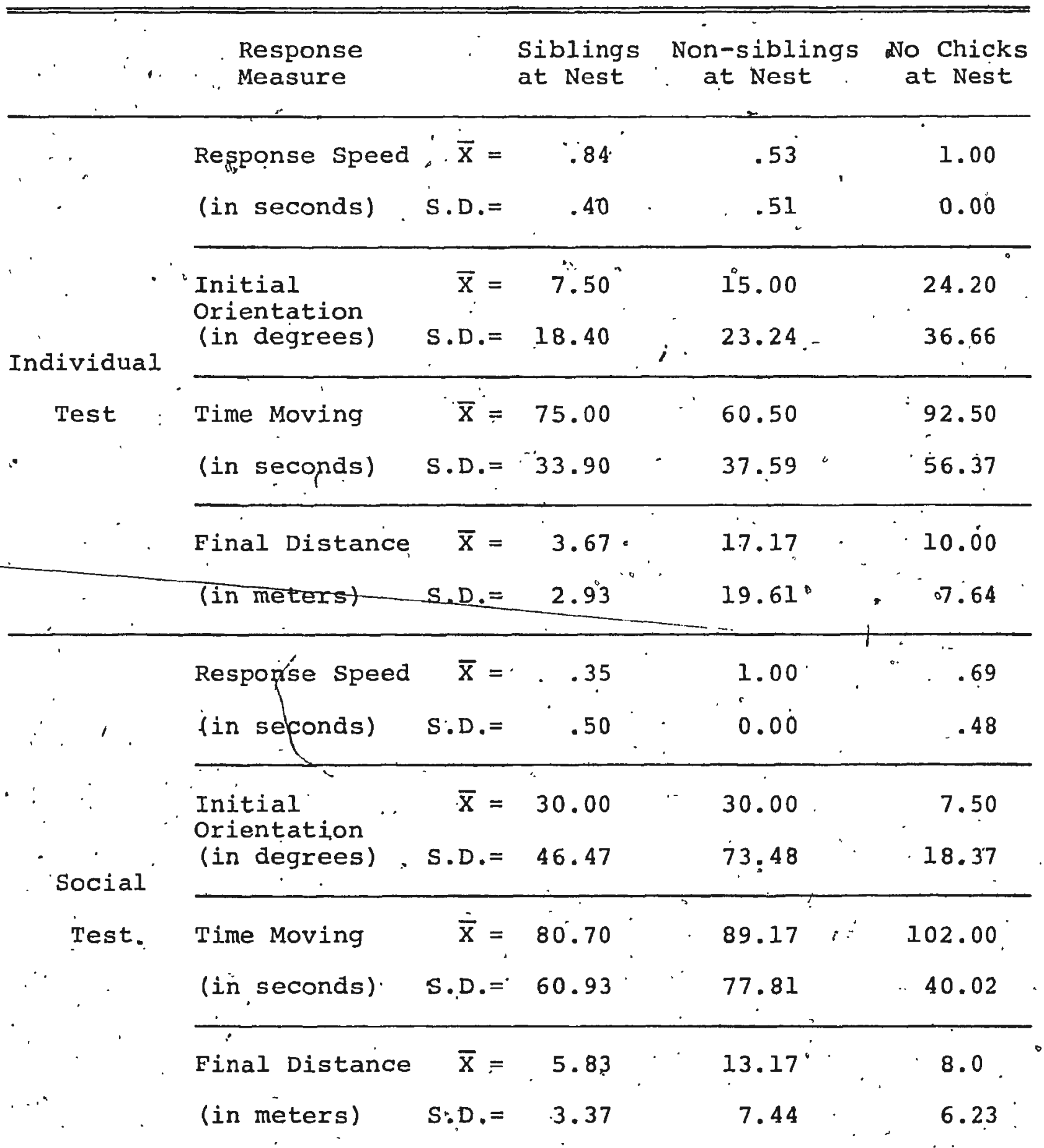


transformation. Analysis of variance of transformed data yielded a significant interaction of nest "and test conditions $(F=5.06, P .<.01)$ on response speed. A summary of this analysis is shown in Table.20.' (See Table 34, Appendix, for raw data summary). Figure 9 presents a graphic representation of this interaction. Individual comparisons (t tests, winer, 1971) showed that individually tested chicks had- a lower mean response speed $(\bar{x}=.53)$ when non-siblings were at the nést than when no chicks were at the nest $(\bar{x}=1.00$; F=4.41, P.<.04). Socially tested chicks had a lower mean response ${ }^{0}$ speed when siblings were at the nest $\left(\bar{X}_{\bar{y}} \cdot 35\right)$. than when non-siblings, were at the nest $(\bar{X}=1.00 ; F=4.80 ; P .<.03)$. Additionally, socially tested chicks had a lowe'r response speed $(\bar{X}=.35)$ thạn individually tested chicks $(\bar{X}=.84)$ "when siblings were at the nest $\left(F=4.80 ; P_{.}<.03\right)$, and a higher. response speed $(\bar{x}=1.00)$ than individually, tested chicks $(\bar{X}=.53)$ when non-siblings were at the nest $(F=4.41, P,<.04)$. Time Moving. An F max test. fór homogeneity of variance was significant ffor time moving ( $\mathrm{F} \max =9.33, \mathrm{P} .<.05$ ) . Areciprocal transformation was then performed and transformed data analýsed. $3^{\text {No }}$ significant différences were found in analysis of variance.

Initial Orientation. An F max test of homogeneity of variance was not significant ( $F \max =5.41$, P.>.05).

Analysis of variance thowed no significant differences' among groups on initial orientation. 


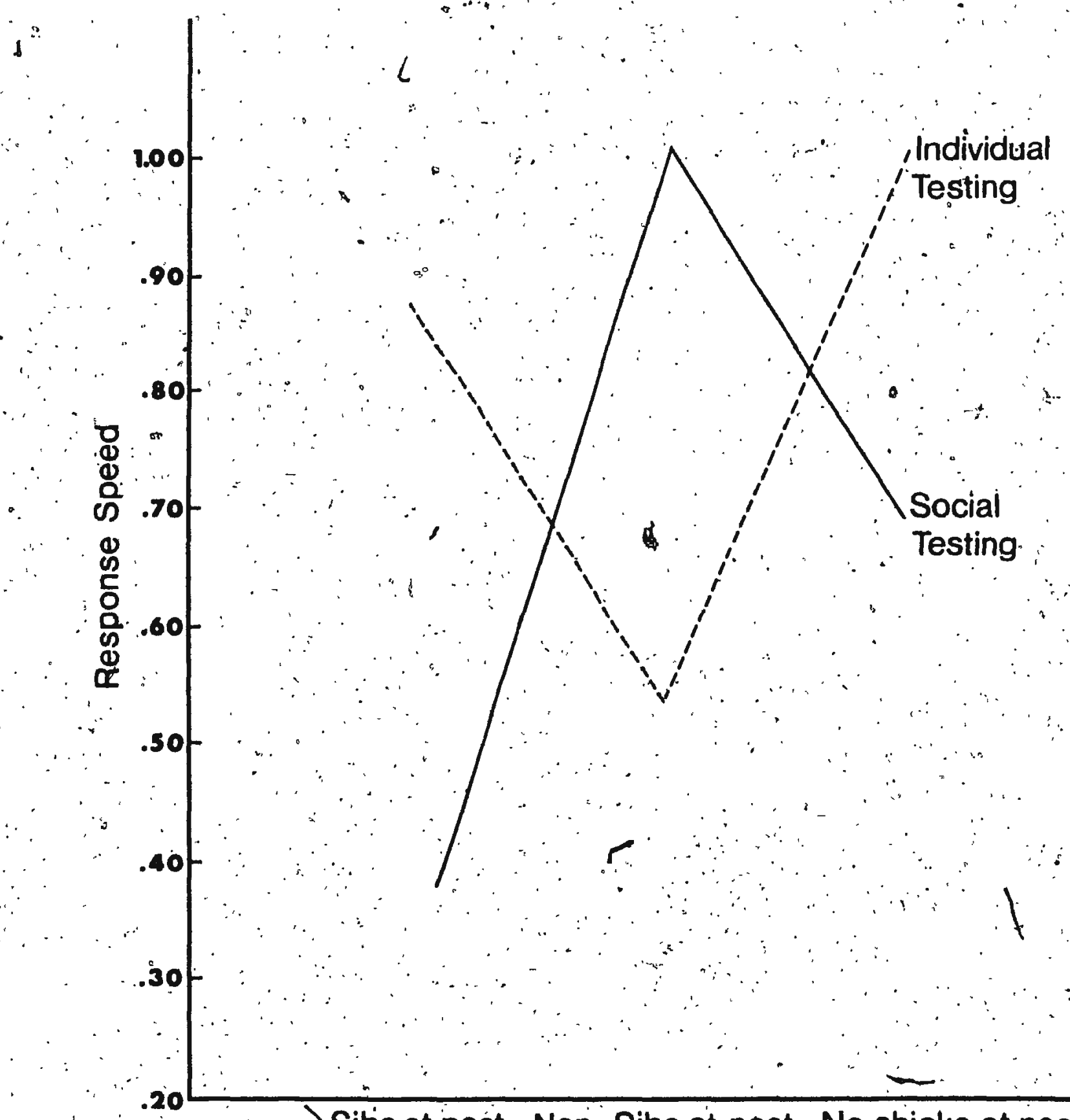

Sibs at nest Non-Sibs at nest No chicks at nest

FIG. 9.: Interaction of Nest and Test Condition on Rèsponse Speed (Transformed Latency); Experiment 5 
Final Distance: An A $\max$ test for homogeneity of variance was significant for final distance '(F max $=47.07$, P.<.01) : A log transformation was then performed on final distance and both raw and transformed data analysed. Analysis of varlance revealed a significant main effect of nest condition on fina- 1 distance $(F=3.55$, P.<. 04 , see Table 35 ," Appendix; for 'corresponding transformed data analysis). A summary of this analysis is presented in Table 27 . Individual comparisons showed that final distancé from the nest was lower when siblings were at. the nest $\left(\bar{x}=4^{\circ} .75\right)$ than when nonsiblings were at the nest $(\bar{X}=15.17 ; \mathrm{F}=7.01, \mathrm{P} .<.01)$. The Einal distance from the nest when no chicks were at the nest. $\left(\bar{X}=9^{\prime} .0\right)$ did not differ from the other two conditions. Chicks Rèleased with Siblings and Non-siblings

Table 22 prèsents the means and standard deviations for all dependent measures.

Latency. An $F$ test for the difference between variances of two groups. (Winer, 1971) was significant for latency $(\mathrm{F}=7.92, \mathrm{P} .<.01)$. A Welch $t^{\prime}$ (Ferguson, 1966) was then used to analyse the data. No significant difference. was found on latency $(t !=1.00, P .>.05)$. Time Moving. An $F$ test for the difference between variances was significant for time moving $(F=4.40, \mathrm{P} .<.03)$. A Welch $t$ ' was used to analyse the data and no significant difference was found between groups ( $\left.t^{\prime}=1.00, P .>05\right)$.

orientation. An $F$, test for the difference between. variances of two groups was significant $(F=8.02, P .<.01)$ : 
Table 20

Summary of Ánalysis of Väriance of Response Speed, Experiment 5

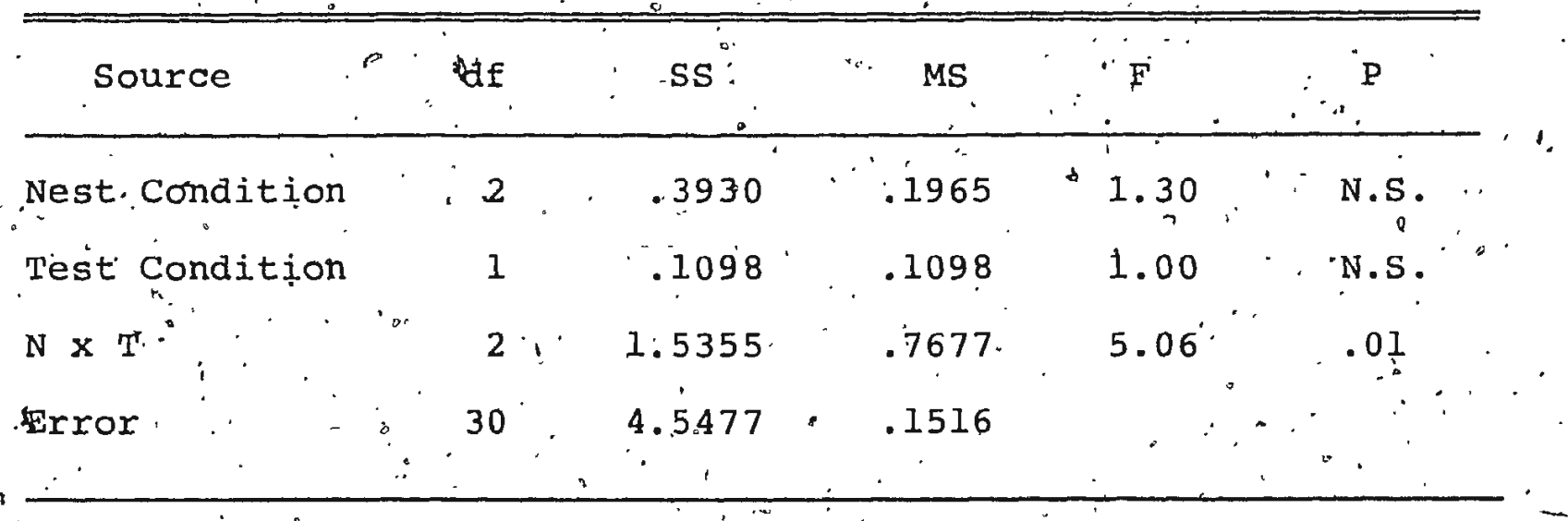

Table 21

Summary of Analysis of Variarice of Final Distance from the Nest, Experiment 5

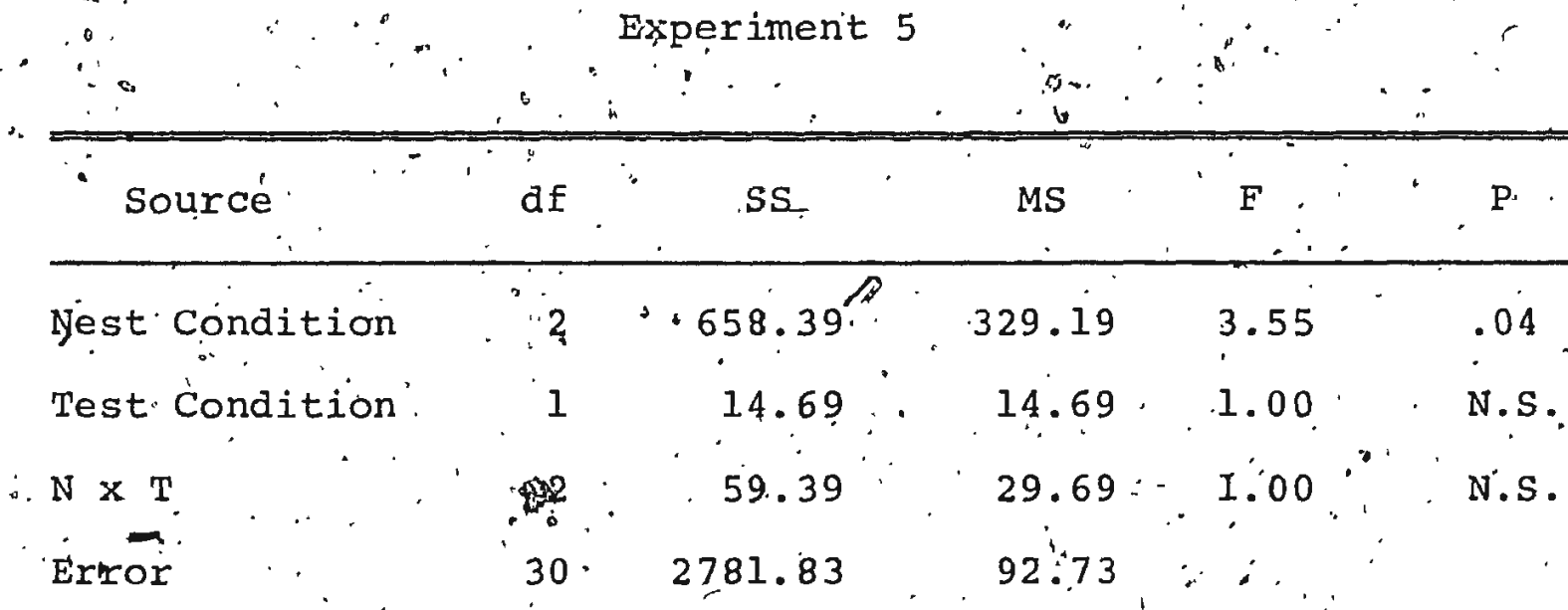


Table 2.2 .

Time"Moving, Initial Oxientation; Lațency, and Final Distance from Nest of Chicks, Released with Siblings and Non-siblings,

Experiment 5

$\therefore 1$

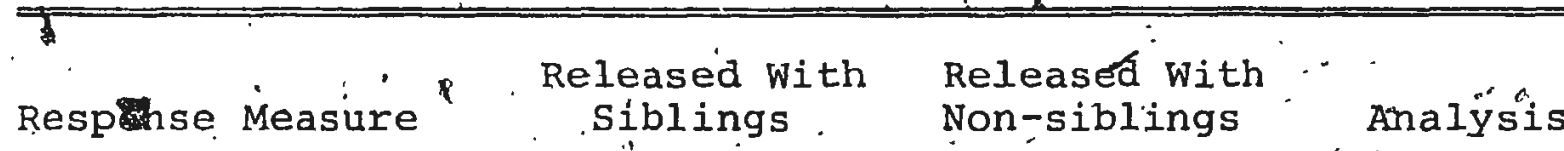

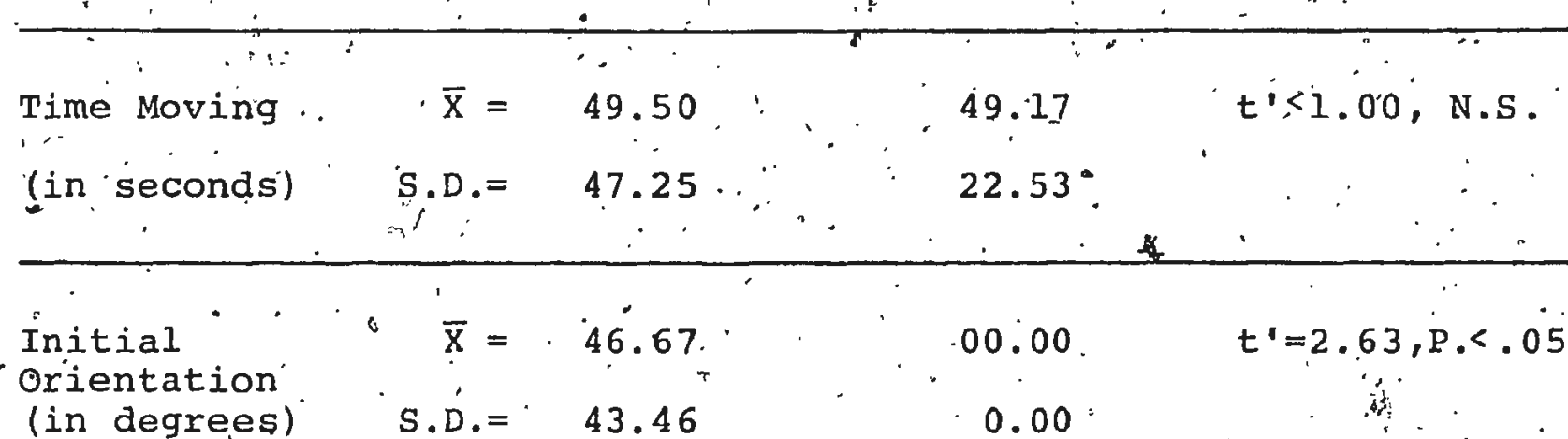

is

Final Distance $\overline{\mathrm{x}}=20.00$
(in meters) $\quad$ S.D. $=14.35$

$\therefore \quad \because 2$

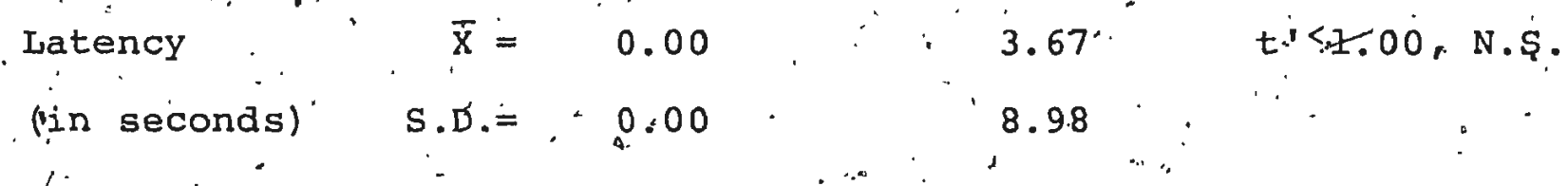

$\frac{1}{2 ! \cdots,}, \cdots, \cdots$, 
A Welch $t$ ' wạs used to analyse the data and a significant difference was found on orientation between chicks released with a sibling and those released with a non-sibling ( $t^{\prime}=$ 2.63, P.<.05). The mean degree deviance of chicks released with a sibling $(\bar{X}=46.67)$ was greater than tht of chicks released with a non-sibling $(\bar{X}=0.0)$.

Final Distance. An F test for the difference between variances of two groups was significant for final distance from the nest $\left(F=7.86, \mathrm{P}_{i}<.01\right)$. A Welch $t$ ' was used to analyse the data and no significant differences were found. $\left(t^{\prime}=1.66, ; P .>.05\right)$.

It was also found that testing with a sibling or nonsibling had ho effect on vegetation preferences. All chicks in both groups relocated in the same vegetation type as the one in which they were captured.

\section{Discussion}

The data support the hypothesis that social stimulation provided by other chicks serves as a cue "uor nest site recognition: A differential effect of sibling and nonsibling stimulation wàs found:' Chicks were found closest to the nest when siblings were present at the nest. site. Non-siblings, on the ther hand, appear to adversely affect. this behaviour since chicks were farthest from the nest when non-siblings were present at the nest.site.

How chicks perceive the conditions at the nest site from the release point is an interesting problem. on a ) 
majority of test trials; no vocalization by stimulús chicks was evident to the experimenter, which impliẹs that auditory stimuli from other chicks were not being used. It is also unlikely that test chicks could see stimulus chicks.10 m. away since the latter usuplly hid in the nest vegetation. In the case of non-siblings at the nest, it may be that parent gulls perceived aerially the change in the nest situation and comminicated a disturbance to their chicks. This would account for the difference between non-sibling 'and no chick conditions,' since in the latter parents presumably would not be as disturbed. That such a reaction by parent gulls to strange nest conditions may occur appears. 'plausibie as results in-Experiment 2-indicate.

Although social stimulation during testing did not seem to enhance nest" returns, it did appear to facilitate nest returns according to the conditions at the nest. This is eyident in the interaction of nest and test condition's on response speed.' In a disturbed situation such as nonsiblings at the nest, social stimulation facilitates the response perhaps by reducing fear or anxiety produced by the disturbance. Under normal conditions of siblings at the nest, however, social.stimulation appears to inhibit nest return evident in individual testing. Recent studies by Hogan \& Abel (1971) support this argument. They demonstrated. that the presence of "social companions reduces fear in an unfamiliar environment and that the visual stimuli provided by chicks,are of primary importance for fear reduction: 
These authoŕs found similar differences between individualiy versus socially tested chicks. However, they found no :differences between sibling, and non-sibling stimúlation. This disparity with the present results may be due to a species difference or to the differences in the experimental situations. . For example, these authors used tabotory-. reared animals and tested in the labóratory while the present pne used animals requed and tested in a. field situation.

Data on older chicks also indicates a differential

effect according to sibling and non-sibling stimulation. The presence of' a companion sibling during testing séméd to inhibit feturn to. the nest' while the presence of a'knonsibling stimulated return, to the nest. This behaviour would. have an adaptive function, keeping chicks away from potential predators and close to the nest in any urisual circumstances. Vegetation preferences do not appear to be influenced by social companions, at least once they are developed. Ail chicks released with a non-sibling relocated in the preferred vegetation regardless of where the non-sibiling went. This it Consistent. with Bongiorno's (1970) argument that nest site seléction in adult gulis is strongly dependent on their. response ta the habitat with social factors playing a secondary role, It appears that social stimulation is an. important factor in young chicks' attachient to and recog nition of the rest site and its efféct varies with sibling and non-sibling stimulation. 


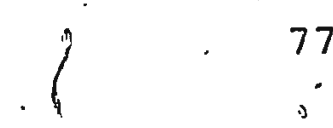

Experiment 6: Effect of Rearing and Testing Conditions on Nest Site Recognition and Attachment in Herring Gull Chicks

The effect of social stimulation on nest site attachment and recognition. may vary according to the rearing experience of young. This would seem particularly likely in view of the facilitatory effect of sibling over non- . sibling stimulation on nest site rêturn noted in the previous experiment. Evans'(1970a) has investigated the effect of social verșus isolate rearing and testing on' home pen preferences in the laboratory $y$. He found no differences between rearing conditions and the effect of testing conditions was not clear from his data. However, since a' significant preference for the rearing area-was not demonstrated, it seems probable that the experimental rearing situation did not include the relevant stimulus difensions necessary for preference development|in Ring-billed Gull chicks.. This would account for the failure to find clear differences, on rearing and tèsting conditions. . Since it has been demonstrated that social versus individual stimulation conditions do have an effect on nest site returns, it seems reasonable to propose that there will be an effect of socin rearing on returns to the nest. Therefore, the present.experiment was designed to determine whether the effect of social versus individual testing conditions on nest, site réturns varied according to rearing experience in neonatal Herring Gull chicks. 
Method

Subjects

A total of 24 Herring Güll chicks was randomly selected from the study site on Little Bell Island, so that half were from 3-egg clutches and half were from l-egg clutches. Chicks were individually marked on the day of hatching and the nest site location ecorded on the grid map of the island. Chicks were tested on Day $6 \cdot$ post-hatch and assigned to one of four. experimental conditions as presented in Tabie 23 .

Table 23'.

Experimental Desigh of Experiment 6

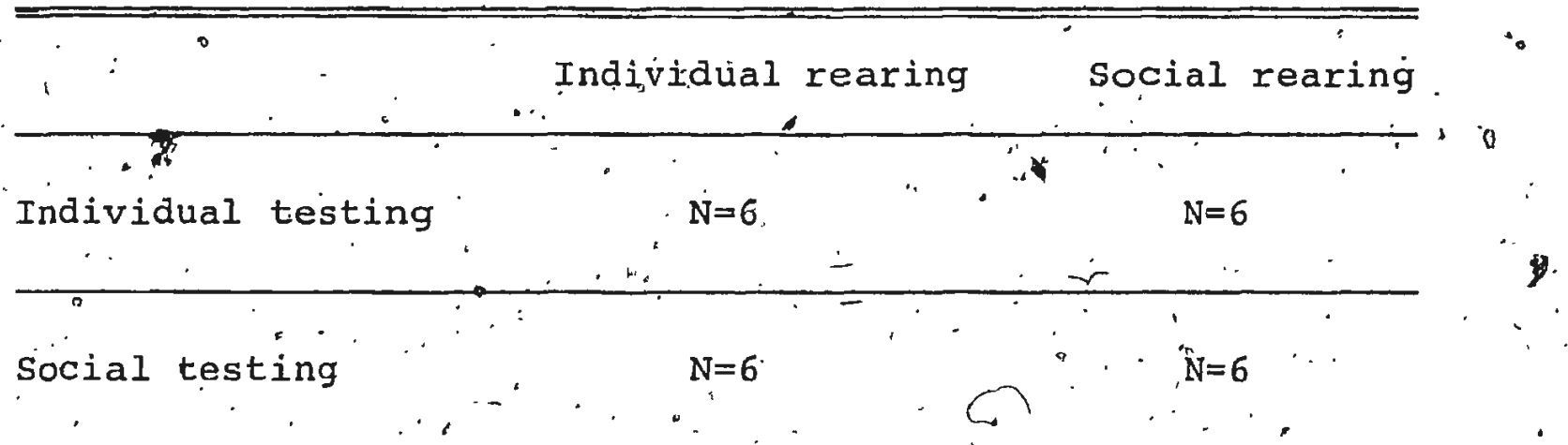

rocedure

When the chick's achieved testing-age, they were removed. from the nest site, placed in the wooden carrying box previously described, ánd transported $20 \mathrm{~m}$. from the nest. in a random direction and released." Movement latency (in'seconds), time moving (in seconds), orientation (in degrees deviance from a striaight line to 'the nestl and final distancé from the nest (in meters) were recorded. Testing was terminated when thé 
chick was within one meter of the nest site or was immobile for 10 minutes." Social testing followed the same procedure except that chicks were tested in groups of two, so that three pairs were tested in each social condition. Alì chicks were returned to the collection point after testing.

\section{$\because, \quad \vdots \quad$ Results}

The means and standard deviations for all dependent measures are presented in Table 24.

Latency. An $F \max$ test for homageneity of variance -of laténcy was significant (F máx=1406:26, 户.<.001). Latency was then transformed into response speed using á reciprocal transformation. Analysis of variance showed no significant. differences on atency (see Appendix, Pables 36 \& 37). However, a significant main effect of testing was found on "response speed $(\mathrm{F}=8.21, \mathrm{P} .<101)$. Assummary of this analysis is presented in Table 25. Chicks tested individually had a higher response"speed $(\bar{X}=.85)$, than did chicks tested" socially $(\overline{\mathrm{X}}=.36)$, regardless of rearing conditions.

Time Moving. An F' max test for homogeneity of variance of time moving was not significant ( $F \max 5.32$, . P... 05). Analýsis of varịance, showed nó significant differences among groups on time moving:

orientation. An $\mathrm{F} \max$ test for homogeneity of variance was not signifiçant, $(F$ mak=12.51, P.>..05). Analysis of variance, revealed no significant différences among groups on initial orientation $\left(F=.53^{\circ}, \mathrm{P}:>05\right)$. 'c 


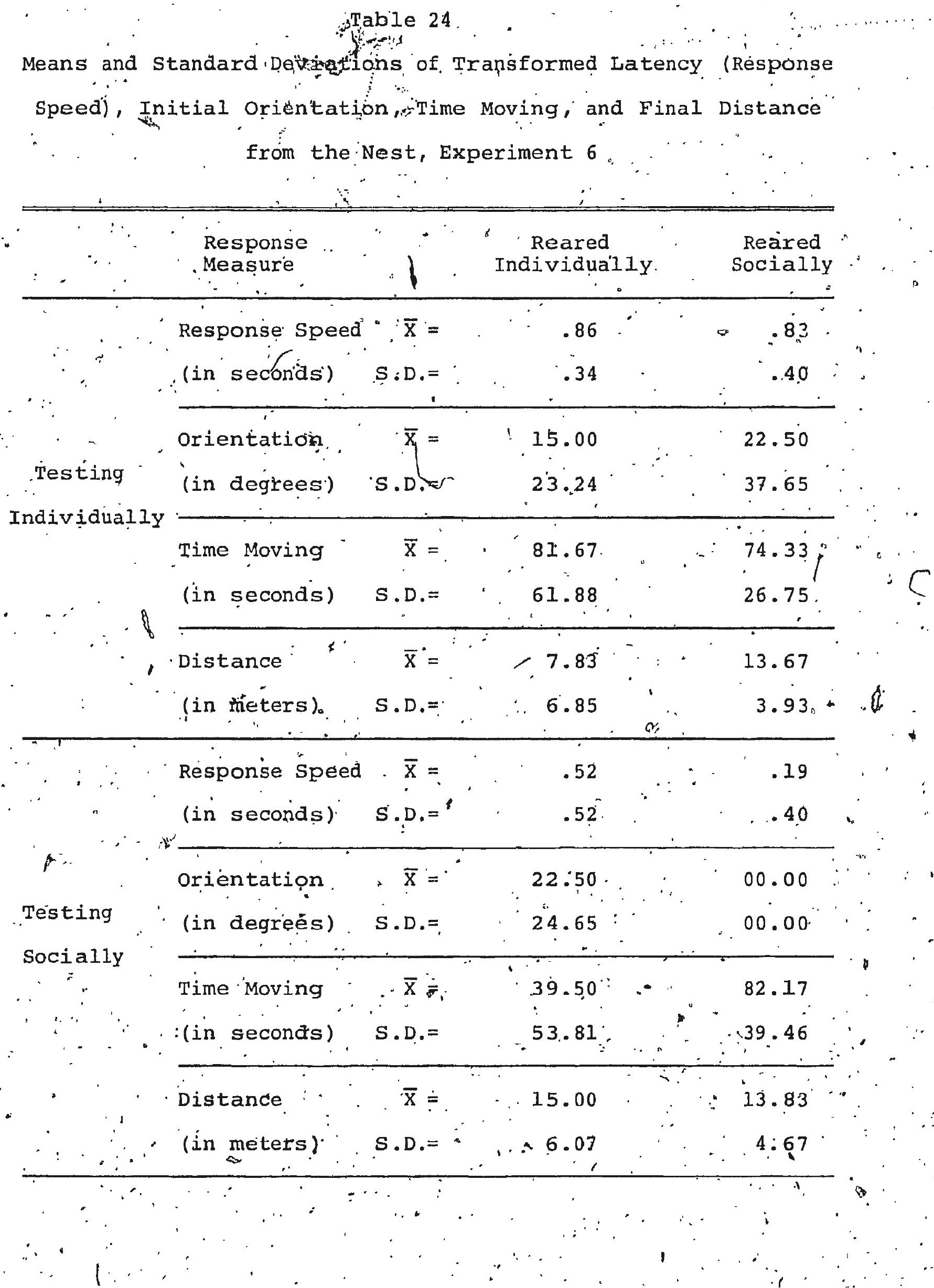


81

Tåble 25

Summary of Analysis of. Variance of Response Speed, Experiment 6 :

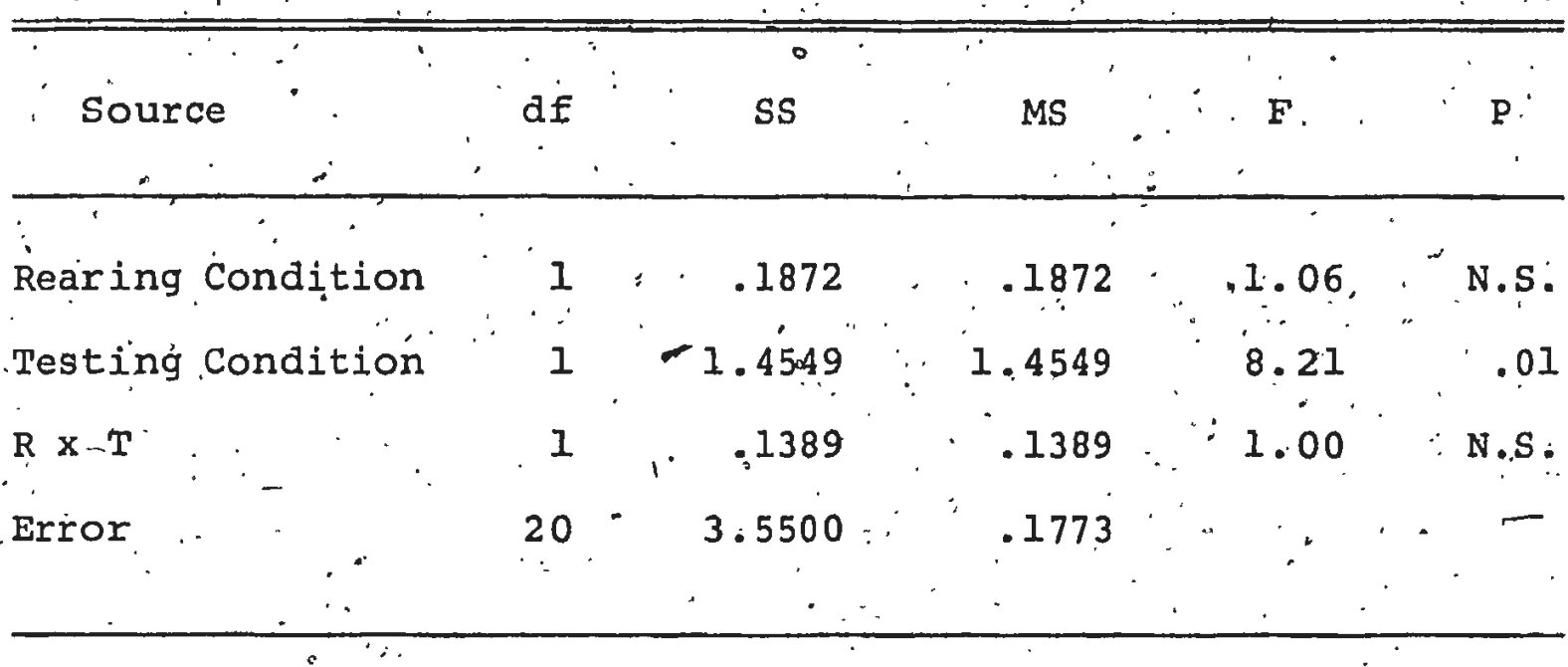

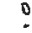

$\infty$
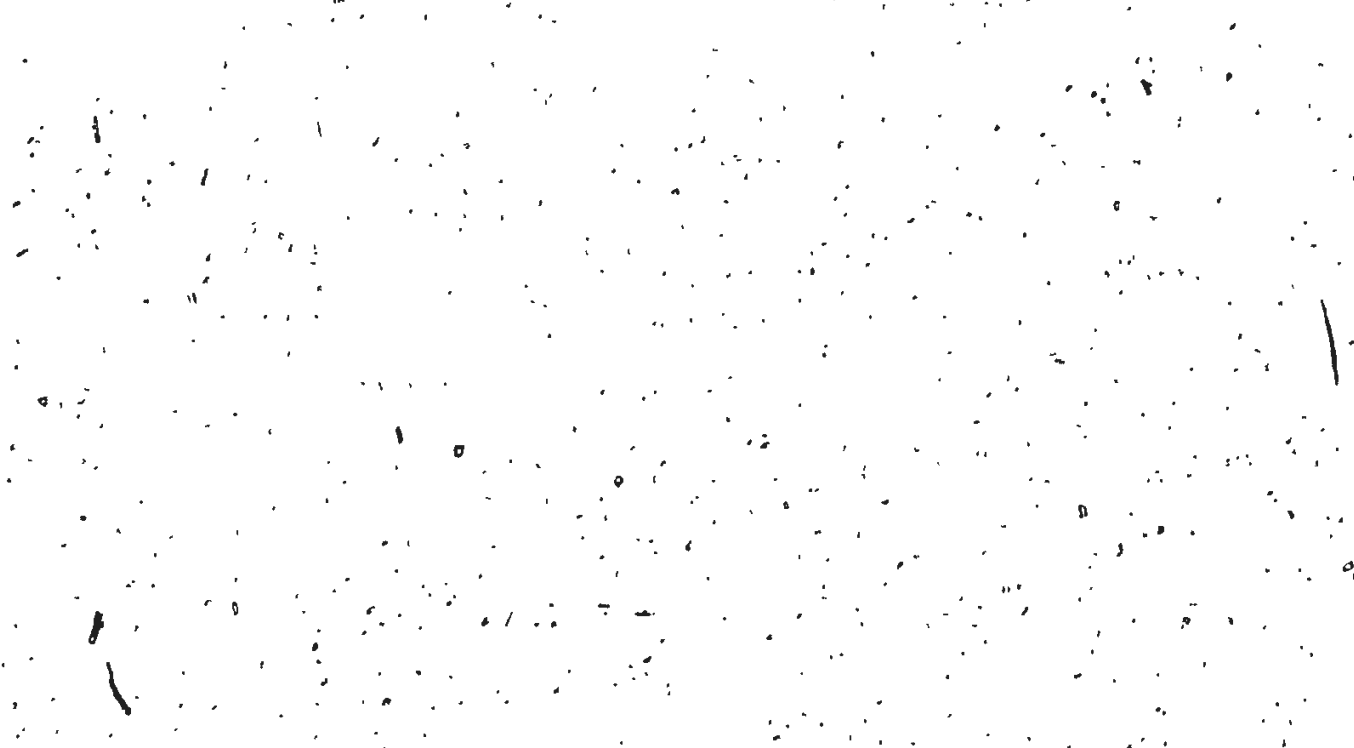

1

4
$\cdots+i^{2}$

Testing Conditión

i -1.4549

1.4549

01

$i$
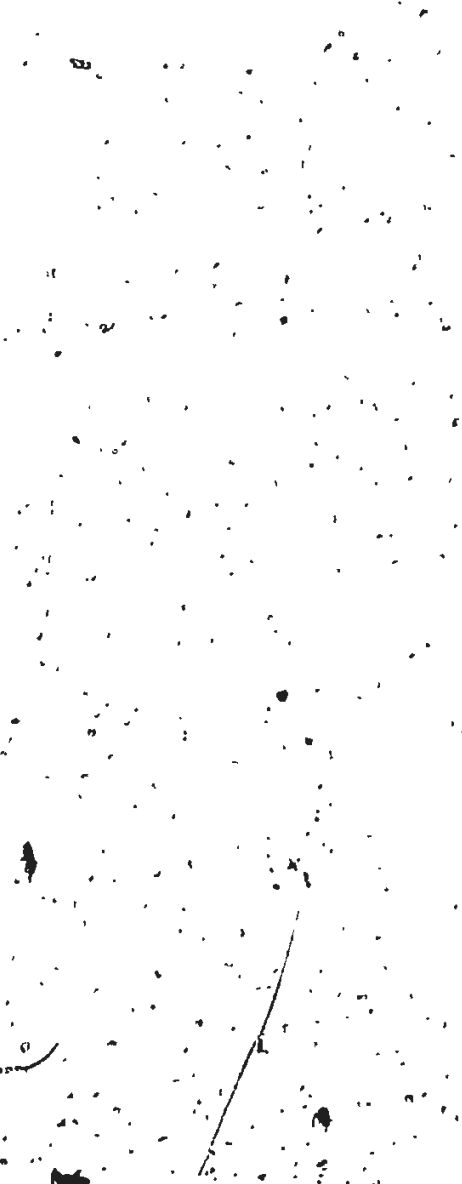

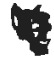
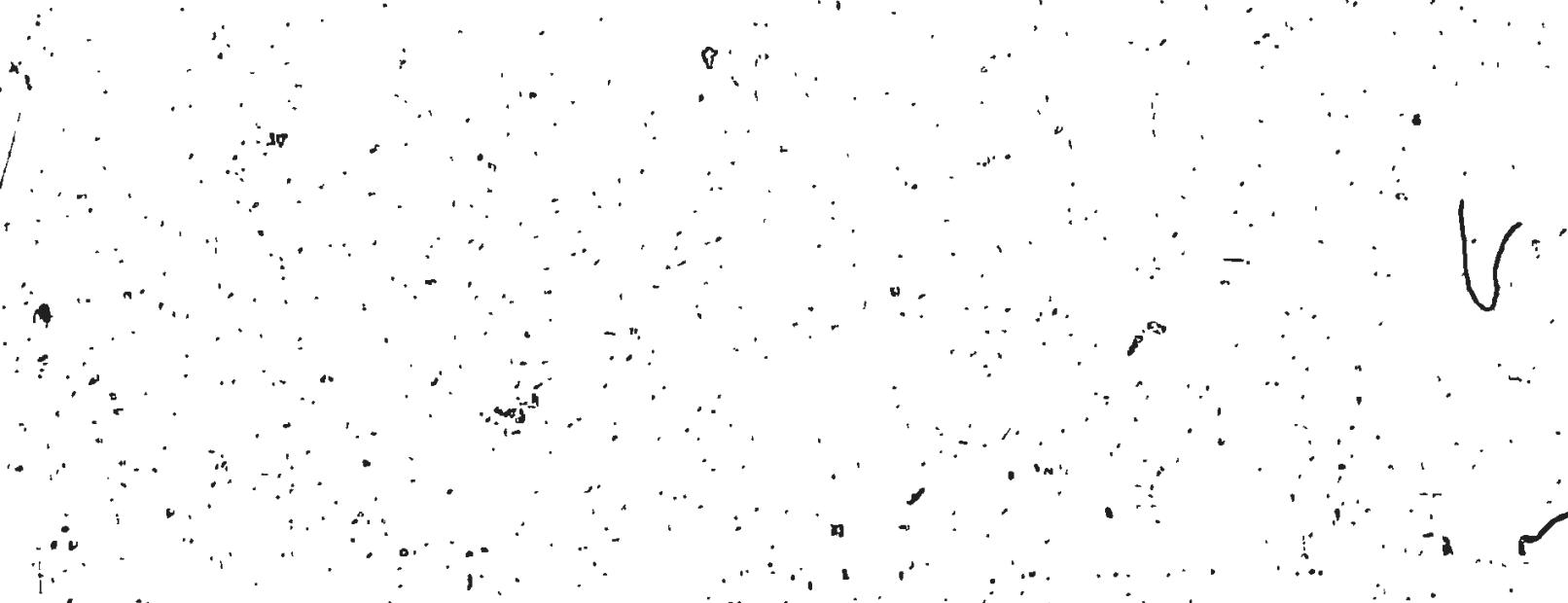
a.

Final Distance. Án F max test for homogeneity of variance was not significant ( $F \max =2.70, P_{Y}>05$ ). No significant differences were found among groups on final distance in analysis, of variance $\left(F^{\prime}=2.67\right.$, P.>.05).

\section{Discussion}

Results, in terms of response speed, indicated that individual testing leads to a stronger nest site attachment response than does social testing regardless of rearing. experience. piresence of social companions during testing leads to."a deçease in nest returns. Recent data reported_by

- Hogan \& Abel (1971) on the effect of social and isolate rearing and testing on response to familiar and unfamiliar environments also indicate decreased response in sociallý tested birds regardless of how they are reared. The authors interpreted these results to be a result of the inhibition of fear by the presence of social companions. Results of the present. experiment are compatible with that view:

No significant rearing effect was found in this experiment. Evans (1970a) also failed tó find a rearing difference between socialıy and individually geared Ring-billed' Gull chic̈ks : Hogan \& Abel (1971) also did not find a main effect of rearing although they did report that socially reared domestic chicks that were tested individualiy differed from other groups by changes in preening, calling, pecking, and sleeping: These studies indicate that social versus isolate rearing coñitions do not have a significant effect 
on preferences for a rearing area.

It may be, however, that the failure to find rearing differences is related to methodological problems, at least in the present study. It may be argued that selecting chicks. from natural one-egg clutches introduces a pösisible genetic or parental behaviour bias since one-egg clutches' are rare among Herring Gulls. However, this does not seem likely since:no. differences were found between individually and socially reared chicks whith should be evident if there were genetic or behavioural differences:

A. further problem arises because individually reared chjcks were t experimentally isolated. Such chicks were reared normally at the nest, where interactions with parents occurred and where social companions could be seen and heard from neighboring nests. Hence, individually reared chicks were deprived 'only of interaction with sibilings. The effect of the absence 'of sibilings during indiviaual rearing' may weli' have been counteracted by the presence of parents and other birds in: the'nest colony. For this reasón, individually reared chicks may not have differed greatly from socially. reared chicks that had contact with sibilings. Similar circumstances would, apply to socially reared chicks tested alone. These chicks were not isolated but tested with siblings remaining at the nest. site. Isolate-conditions in this experiment, then, may be somewhat confounded by the attempt to test under the natural conditions of the nest site. This may adcount for the failure to find rearing differences and 
the fajilure to find differences on the other dependent. measures. However, the 'results are, for the same reasons, more "representative of what does occur under natural conditions of the nest colony. Furthermore, if parental and conspecific stimulation compensates for sibling stimulation., this would support the original contention that soicial stimulation is an important factor in nest site attachment.

\section{Generál Discussion.}

Stereotyped habitat preferences evident in the. behaviour of gulis have been hypothesized to have antecedent's in chick behaviour. Thus the prefledging period may be important in establishing habitat 'bonds' (Klopfer \& Hailman," 1965). This investigation was designed, to, test the above hypothesis and to examine the development of nesting habitat recognition and preferences as a function of habitat:and". social stimujl in neonatal Herring Gull chicks: The initial experiment studied the dajly development of nest site preference during the IfIst 'week post-hatch and weekly development uritil fledging. The test procedure; which was essentially the same for "all' experiments, consisted of relocating chicks 20 meters from the nest and recording the chick's movement: latency, time moving, initial orientation relative to the nest. and 'final distance from the nest. "Several experiments examined the importance of vision and the use of landmarks". in nest site recognition. "Later experiments studied the role of vegetation characterístics and social stimuli provided 
by other chicks in nest site âttachment and recognitipn. "The hypothesis thàt Herring Gill. chicks develop an attachment to the nest site area during the first week post-hatch was supported by Experiment $\dot{1}$. Chicks exhibited an attachment to the nest site which was optimal on "Day 6-7. The hypothesis that nest site attachment, would wane after the first week post-hatch with the onset of reciprocal recognition of parents and young was also supported by the first experiment. Weekly relocations of chicks until. fledging revealed" that chicks were increasingly further from the nest with increasing age. The evidencé of chick preferences for the nest site support the notion that adult habitat preferences may be establithed during the prefledging period: "Such preferences may account for the return of many birds to their natal colonies for nesting (Béer, 1966; Bonglorno, 1970; LeReche \& sladen, 1970) $\therefore$ long tem."studies of chicks from hatching to the first nesting season in which chick nest site preferences are correlated with.adult:preferencés for a 'nésting area would test' this possibiaty. - Early nest site attáchment appears to be established through rearing in a particular area, chicks reared in foster'nests from eggs 'showed the same preferences for the foster area as did normal-reared chicks for their naturali nest sites. This data is consistent with other studies (Emlén, 1963; Smith, 1966) in' which transfèr of gudll eggs, "wais affected and the post-hatch behaviour observed. Howeve

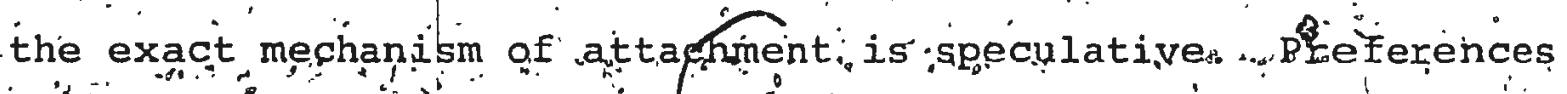


for vegetation characteristics similar to those of the. rearing area-súpport the suggestion that habitiat preférences may be esstablished through environmental imprinting (Thorpe, 1944; 1945; Collias, 1951; Hilden, 1965). in that spme form of exposure learning seems to be involved; studies similar to those done to investigate imprinting to stationary objects (Hess, 1.959; Gray"' 1960; Bateson, "1966; Bateson \& Reese, 1969) using vegetation characteristics as stimuli could be. done to assess this possibility. Once established, such nest site preferences could be strengthened by the reinforcing events at the nest site, such as feeding, ishelter, protection. from predators, social stimulation, etc.

Stimulus properties of the nest site situation which appear to be important in the development of nest site preferences are vegetation topography, and social stimuli provided by other chicks. Chicks were found to discriminate between vegetation types and prefér the vegetation type surrounding the nest: Moreover, although preferences for the nest site, per se, wane, with age, preferences for the nest site vegetation apparently remain constant, and chick's restrict their activity to areas of similar vegetation to. that of the nest site. These vegetation preferences may be one factior accounting for the stereotypy of habitat preferences noted in, gulls. Furthermore, such stable vegetation preferences support the enviromental imprinting hypothesis as being the mechanism of attachment. To determine the relation between early vegetation preferende, of chicks and 
later nest site selection, the vegetation preferences of chicks could be correlated with vegetation characteristics chosen by the same chicks during their first nesting season." " Sibling stimulation was, found to be superior to "non'sibling stimulation 'in Experiment 5: Siblings at', the nest. during testing seemed to enhance nest site attachment, while non-siblings at the nest during testing decreased nest . returns. However, testing siblongs together as compared to.isqlate testing decreased nest returns. Hogan \& Abel (i971) found similar differences between social and individual testing, and interpreted this difference as being indicative of the inhibition of a fear response by the presence of social companions during testing. It appears, then, that siblings may serve as a mgtivating stimulus in nest site attachment and may override the nest preference response when present during testing. The latter effect indicates the presence of siblings to be a potent stimulus in preference development. ?

- Cues used in nest site recognition, Which seem, to be the same for young and adults, include vegetation cues, landmarks and social stimuli. It was demonstrated in Experiment', 3 that landmarks are among the cues used by 'Herring Gull chicks to recognize the nest site. Tinbergen (1953) has reported that adult Herring Gulls use landmarks - to. lọcate the nest site. In both cases such landmarks were distinguishable from the background which indicates that "conspicuousness" of stimuli is also impottant." However ; 
no conspicuousness differences were found in this study. This failure was most likely due to the lack of different? iation across conspicuous levels, which could be easily. corrected by including a'stimulus which was not distinguishable from the? background vegetation or by levelling an area to enșure that no conspicuous objects were available. Vegetation type' was al found to be an important. cue used by Herring Gull chick' in nest site fecognition. Correlational data from Experiment 1 showed that chicks were found and relocated in vegetation similar to that. of 'the' nest site area. Similar use of vegetation cues has been reported by Bongiorno:(1970) for adult Laughing Gulls and by-Anderson (1971) for Prairie Chickens. Vegetation height and density may also be used as cues in nest site recognition. Experiment 2 revealed that chicks" deprived of vision colild successfully relociate in vegetation of the same height and density'a's that of the collection point. This suggests that auditory and tactile cues may be used in conjunction with visual ones. However, chicks did not relocate in the same yegetation type nor were thqy' able to relocate the nest. site. It seems that for these functions vision is heavily relied. upon, at least in visually experienced animals. The pre6. potency of visual stimuli in preference develment is also indicated by the fact that visually imprinted stimuli can facilitate the acquisition of an auditory discrimination (Evans, 1972): and can act as reinforcers in imprinting (Bateson \& Reese, 1969). Whether visual experience is; 
necessary to nest site recognition requịes furthẹr study. It mày well be that visually naive animals can use other sensory modalitiès to successfully. locate the nest area. This is quite feasible in. view of the response of blindfolded chicks to height and density aspect's of vegetation and the fact that gull chicks càn recognize siblings (Evans, 19.70a) and parents (Béer, 1969) using, some auditory stimuli."

Social conditions at the niest serve as cues in nest site recognition. Experiment 5 showed' that other chicks at the nest site serve as discriminative stimuli in nest site reçognition. sinfe test chicks could often not see or $\}$ apparently hear stipmulus chicks at the nest, it is likely that parental stimulation is also involved. "The reaction of parents to hooded chicks in Experiment 2 shows that parents are aware of changes that occur in the nest situation. Parental vocalization cauld then influence chick recognition of the nest site, at. leajst when nest conditions are altered, such as when strange chicks are placed at the nest. To. assess the role of parental stimulation, marked adults could be observed for vocalization, etc. during testing of their chicks. Also, a control procedure in which parents are not in the vicinity of the nest or are captured during, testing, could be compared to testing with parents it the vicinity... of testing.

In conclusion, the data support the hypothesis, that Herring Gull 'chicks develop an attachment to the nest site area, during the first week after, hatching and that the 
preference wanes during the following weeks until fledging. chicks of ali ages show a preference for vegetation areas similar to tha nest site area. Nest site preferences seem to be ecotypically controlled and it is likely that preferences are established through some form of envirormental imprinting and strengthened by the reinforcing events that occur at. the nest. site' stimuli controlling nest site preferences include vègetation characterïstics and social stimuli. Landmarks, social stimuli provided by 'siblings, and vegetation characteristics are also among the cues used in"-nest site recognition. Further study of these factors is required to determine more preçisely their role in the development of habitat preferences.

\section{s.}

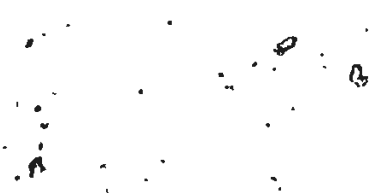

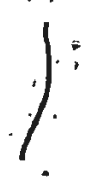




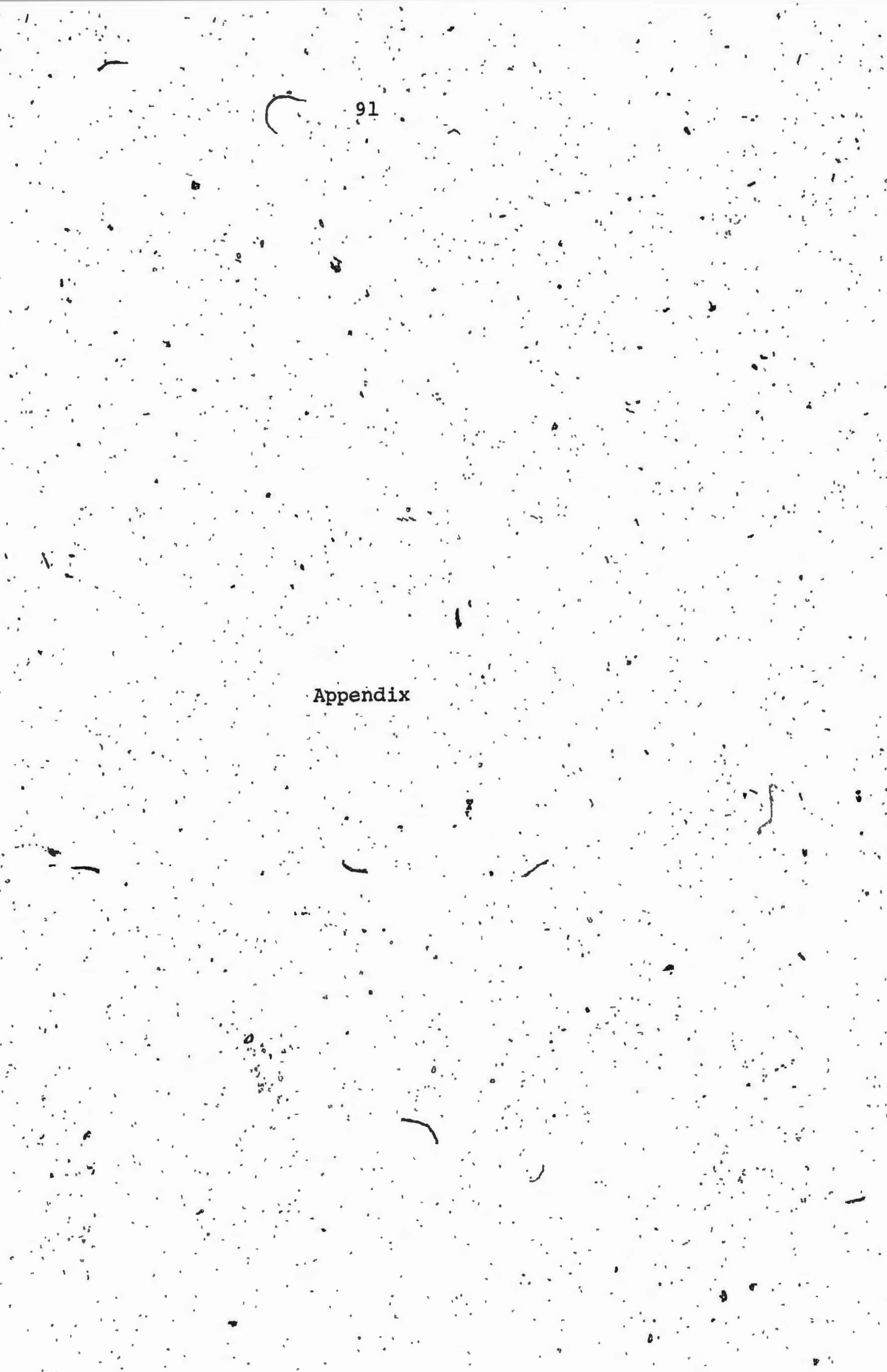


List of Plant Genepra Found on Iittle.Beli Is land

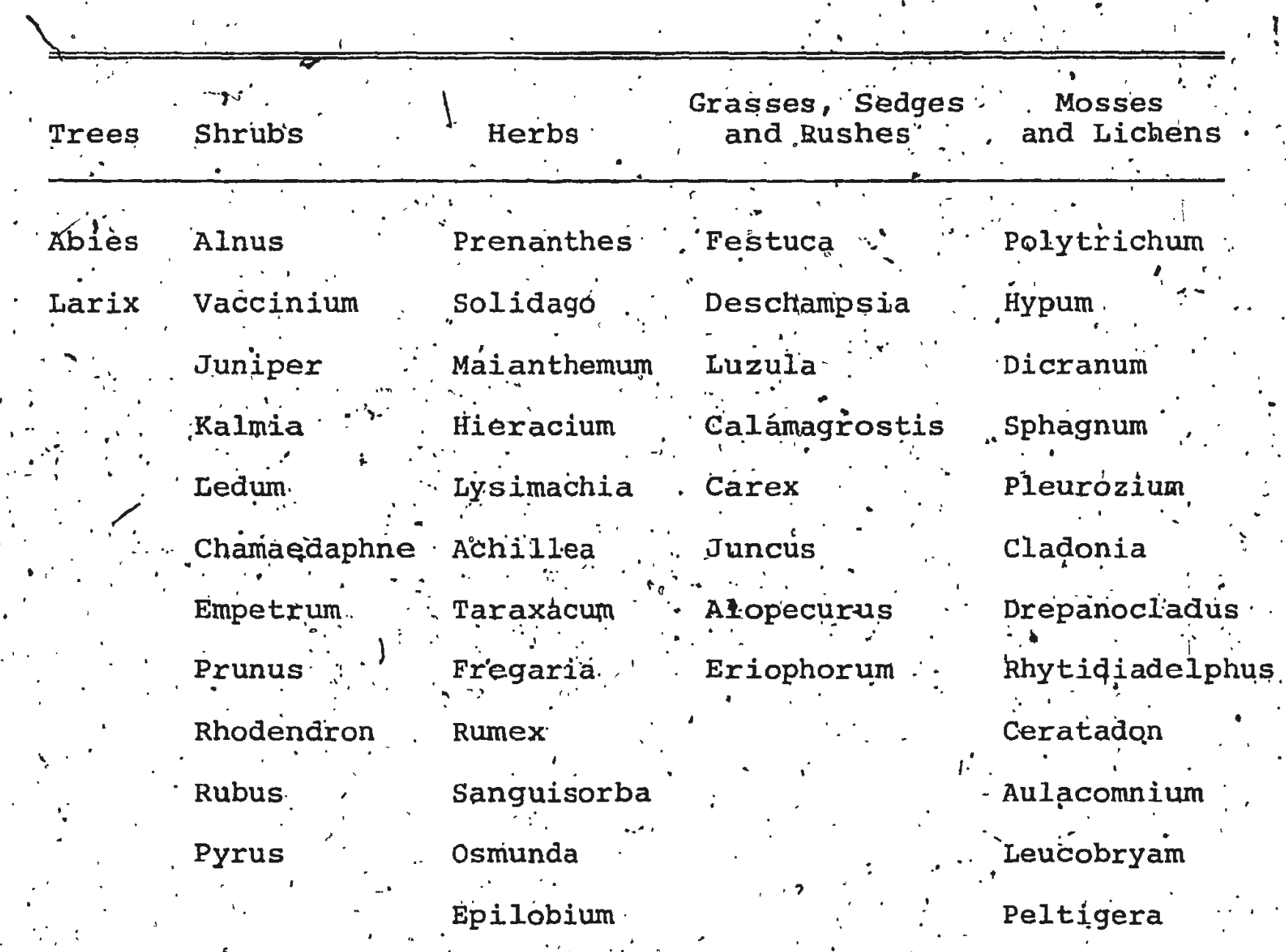


Tablè '2.

Means and standard Deviations of Látency and Transformed Time Moving for Chicks Tested during the First, Week Post-hatch, Experiment 1

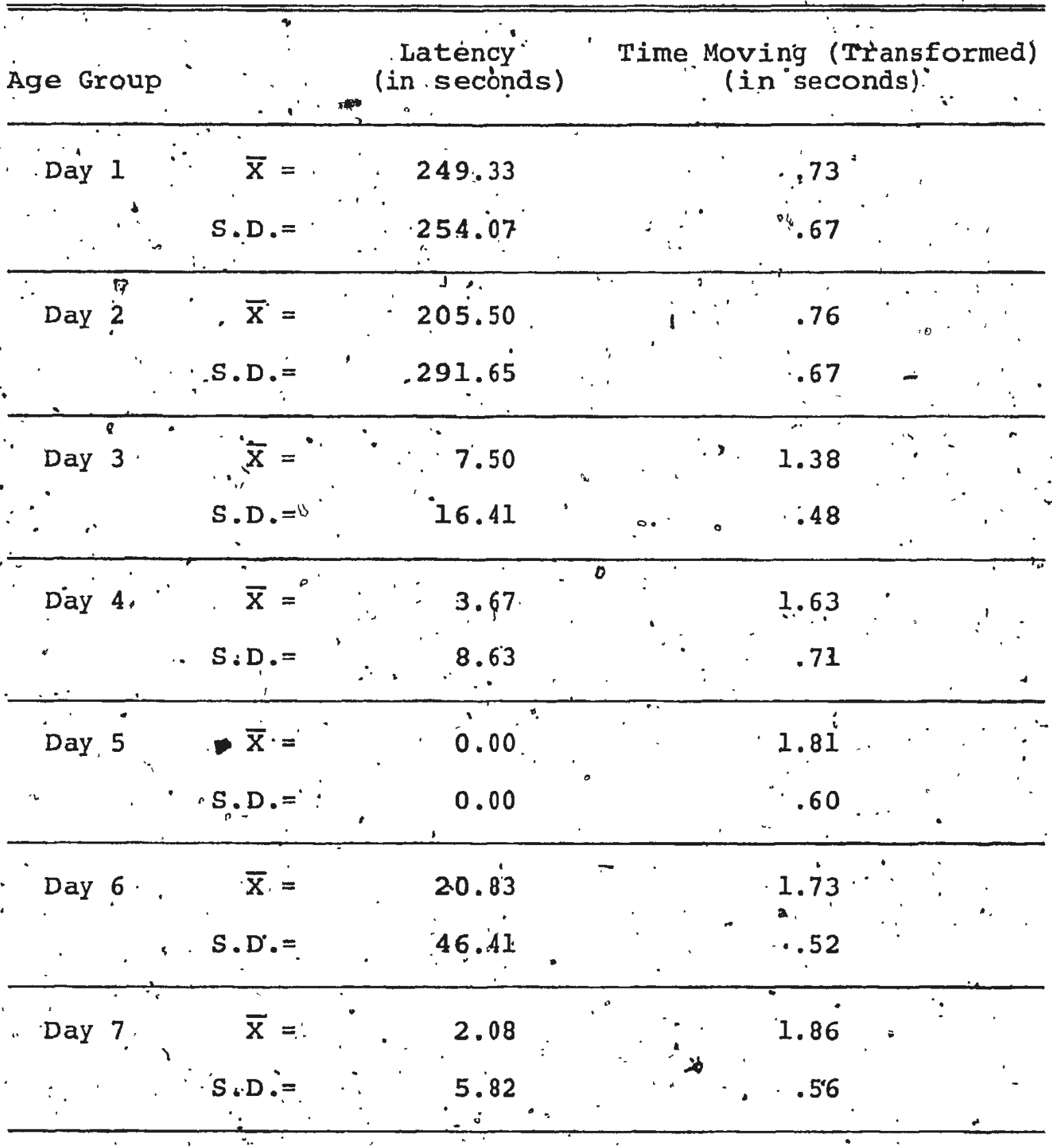


Table 28

Sumary of Analysis of Variance of Latency for Chicks tested during the First Week Post-hatch; Experiment 1

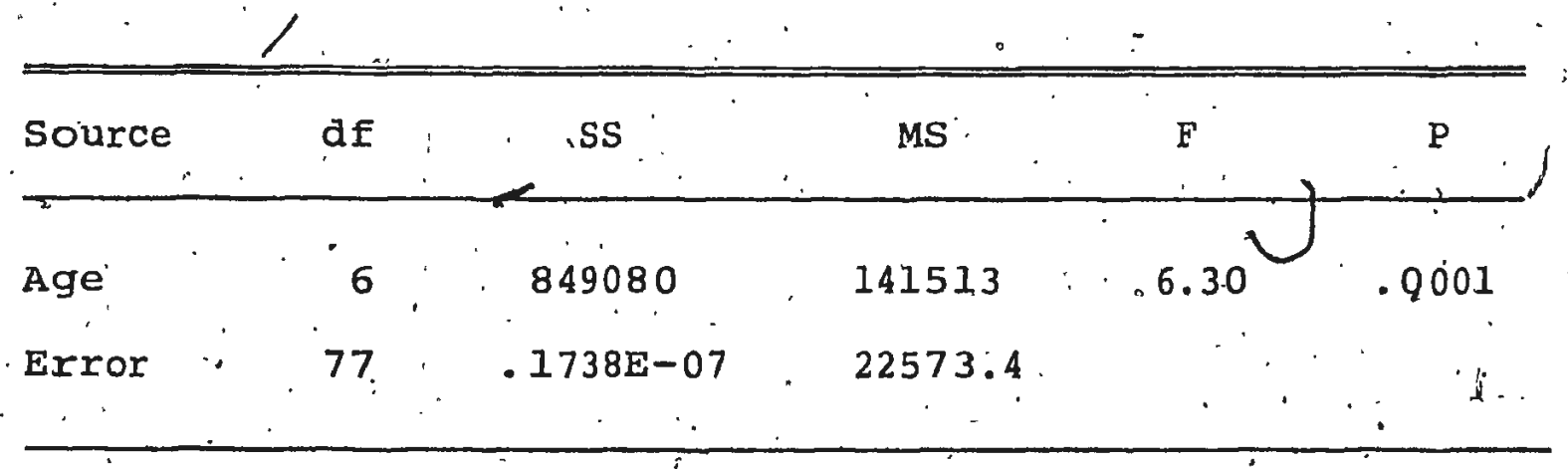

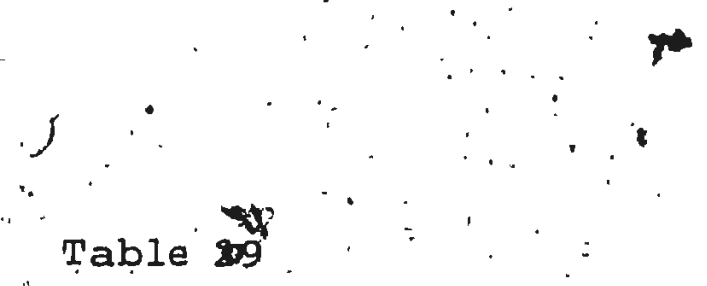

Summary of Analysis of Variance of Timemoving (Transformed) for Chicks tested during the Fir theek Post-hatch, Experiment 1

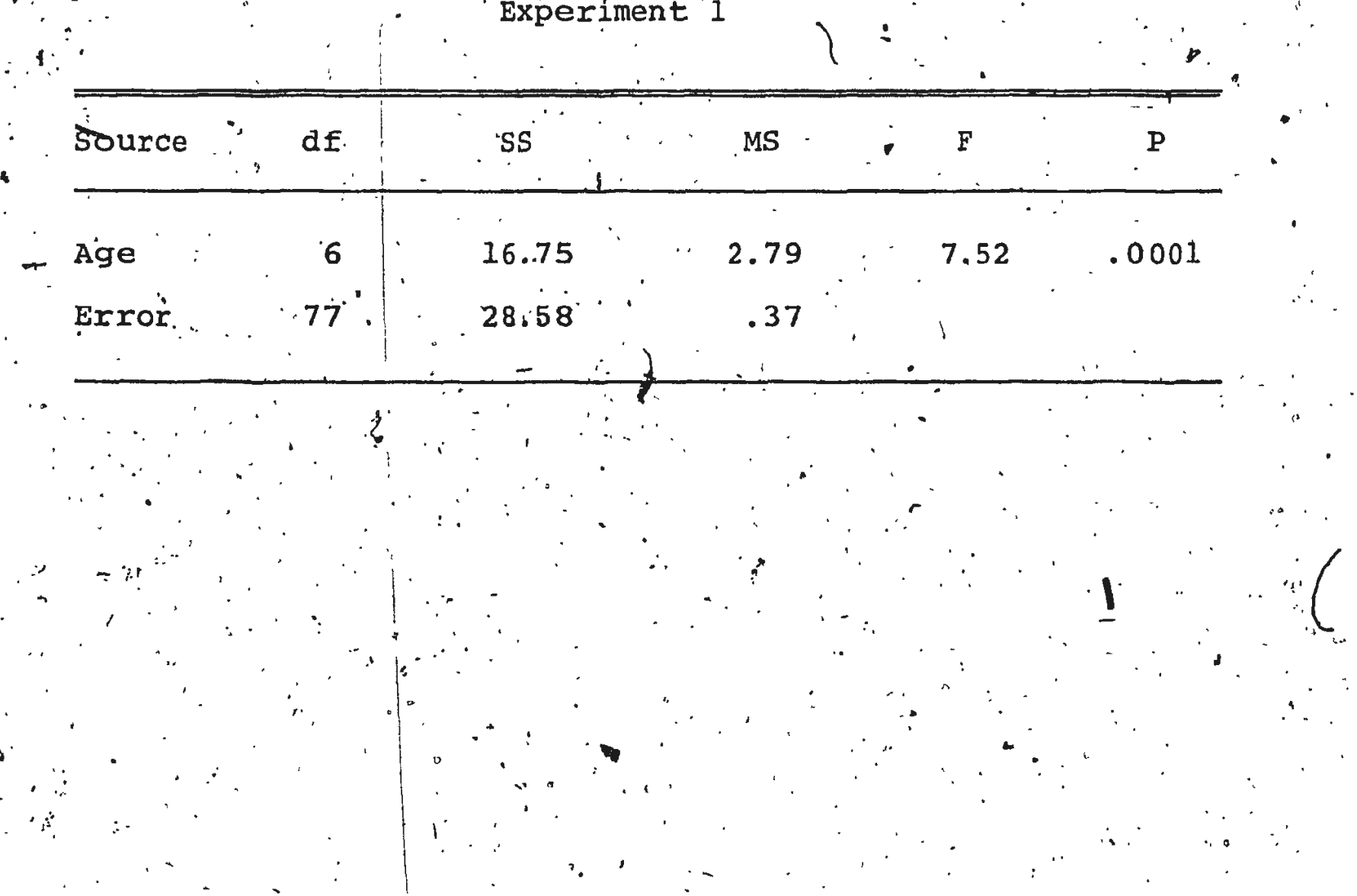


Table 30

Number of Chicks Relocated During Weeks 1-5

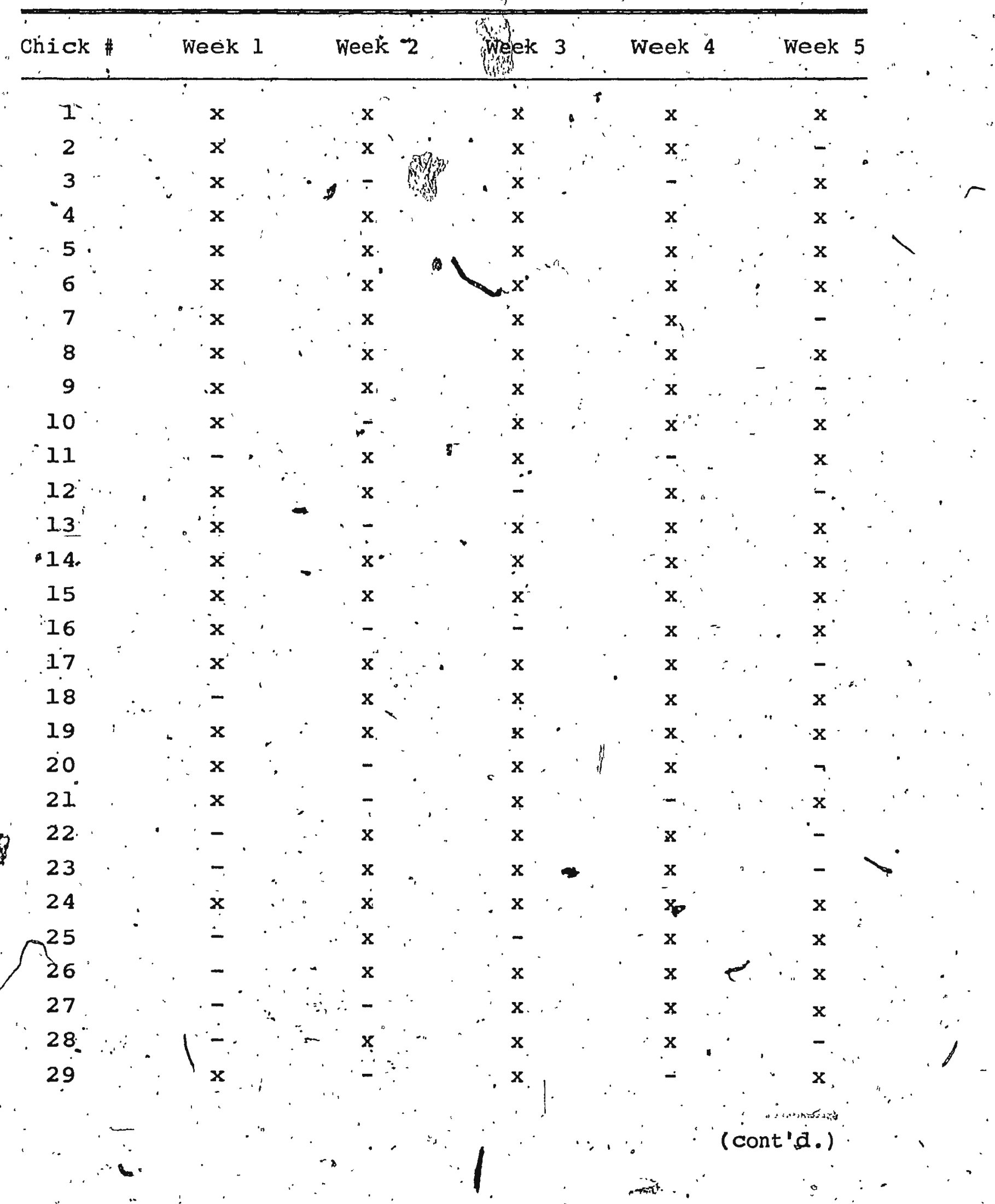


Table 30 (cont'd.)

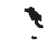

Chick \#. Week 1 1 Week 2 Week 3 Week 4 Week 5

$\bigcap$

$30 \quad \therefore$

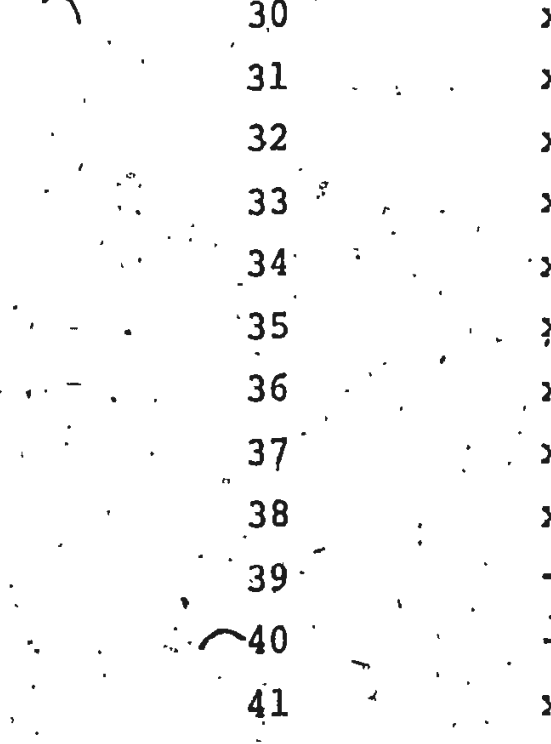

42.

43

44

45

46
47

$\because \quad \because 49 \quad \begin{array}{r}48 \\ 4\end{array}$

50

51

5
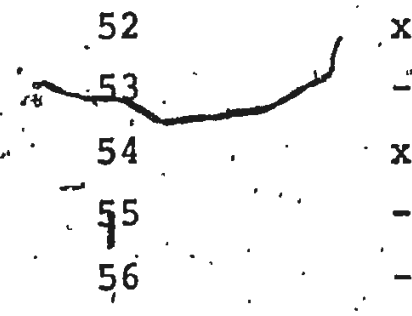

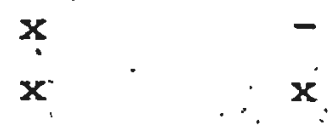

$\mathbf{x} \cdot \because \mathbf{x}$

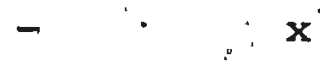

x

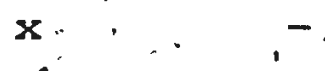

$\therefore$ '
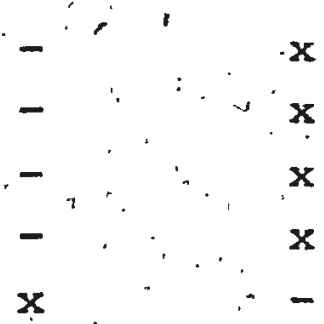

$\mathbf{x} \quad \mathbf{x}$

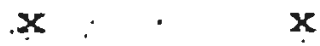

$\mathbf{x}$

$\mathrm{x}$
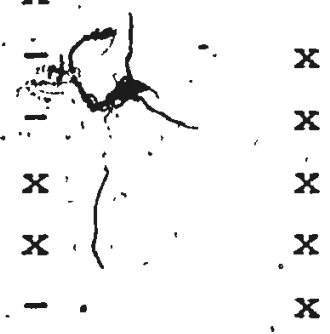

$\mathbf{x}$

$\dot{x}$

$\mathbf{x}$

$\mathbf{x} \cdots \quad \mathbf{x}$

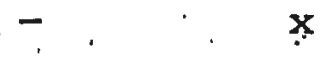

$\mathbf{x} \mathbf{x}$
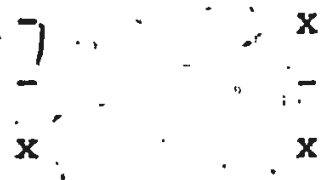

$\mathrm{x}$

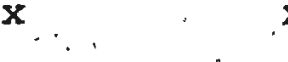

$-\quad \therefore \quad: x$

x

$-$

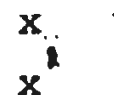

$\mathbf{x}$.

$\mathbf{x}$

$\mathrm{x}$

$\mathbf{x}$

$\mathrm{x}$

$x$

$\cdot x$

$\dot{x}$
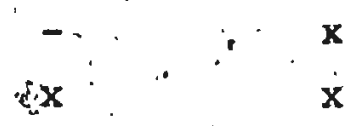

$\dot{x}$

$-$

x

$x$

$x$
$x$

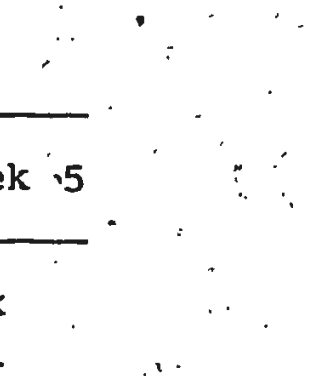

5 
Table 31

List of Variables in the Correlation Matrix for Daily-tested Chicks

1. '. Initial distance from the neșt

2. Lócation vegetation

3. Location vegetation height

4. ' Ĺocation vegetation density

5. Release vegetation

6. Release vegetation height

7. Release vegetation density

8. 'Latenicy

9. Time mơving

$\therefore$-10 Initial arientation

11. - Final distarice, from the nest

12. Final vegetation type

13. Final vegetatign height

. 14. Final vegetation density

15. . Temperature

16. Wind speed

17. Precipitation

18:: Nest site vegetation type

19. Sky condition.

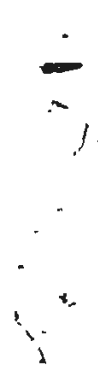


(6)

Table 32

Significant Correlation Coefficients and. Probability Levels. for Chicks Tested during the First Week Post-hatch
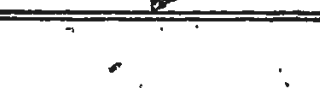

\section{Variable}

Correlation

Coefficient

$1:$ Location vegetation height and density

rho $=.53$

.001

2. Location vegetation height and final vegetation heirght

3. Releàse vegetation height and final. vegetation hèight

4. Latency and temperature

5. Final distance and final vegetation type

6. Temperature and wind speed

iv $\therefore$

7. Sky condition and temperature

8. Sky condition and. location vegetation type

$$
x_{x y}=.49 \quad .001
$$

$\mathrm{xyy}_{\mathrm{x}}=.34 .010$

$r_{x y}=.32$. 010

ino $=-28$ : 010

$r_{x y}=.57 \div .001$.

rho $=.53 \cdot .001$

rho $=.33: .010$
9. 'Release vegetation height and final vegetation density

rho $=.32$

10. Rélease vegetation density and final vegetation density

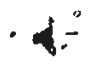

rho $=.32$

.010
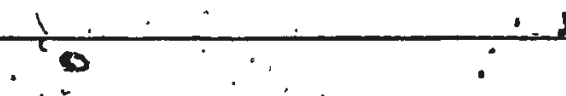
Table 33
$\therefore$ Meang and Standara Deviations of Latency, Time Moving (Transformed) and Final Distance from the Nest (Transformed), Experiment 5

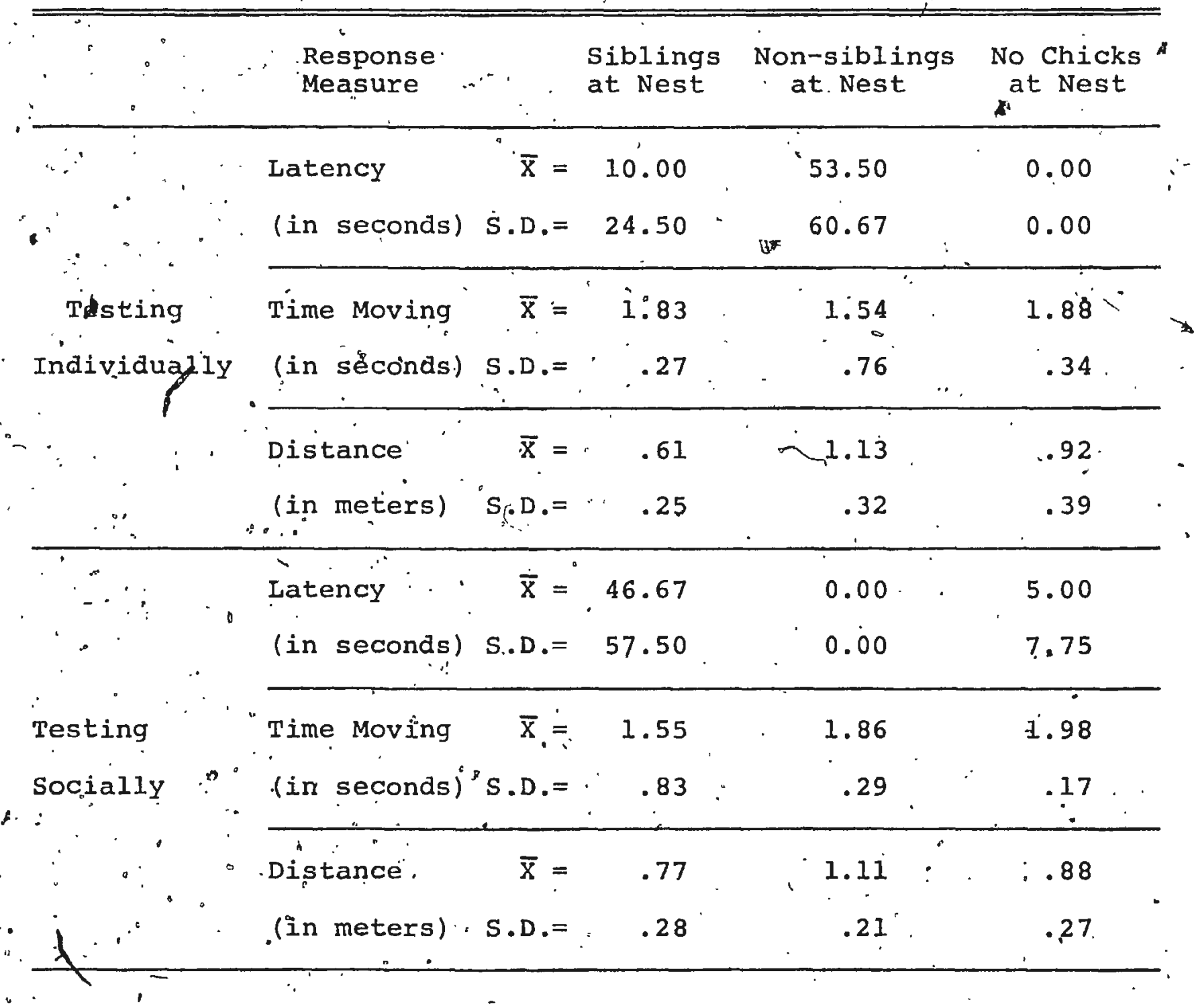




\section{Table 34}

Summary of Analysis of Variance of Latency, Experiment 5

\begin{tabular}{lllllll}
\hline Source & df & SS & MS & $F$ & P
\end{tabular}

\begin{tabular}{|c|c|c|c|c|c|c|}
\hline- & ." & & - & & & \\
\hline Nest $C$ & Condition. & 2 & 5031.71 & 2515.86 & 1.00 & N.S. \\
\hline Test C & Condition & " 1 & 140.031 & 140.03 & $1.00^{\circ}$ & N.S. \\
\hline $\mathrm{N} \times \mathrm{T}$ & 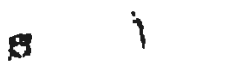 & -2 & $12555: 00^{\circ}$ & 6277.52 & 2.03 & N.S. \\
\hline Error & '. & 30 & $\begin{array}{c}92919.70 \\
-\end{array}$ & $3097 \cdot 32$ & - & $\cdot$ \\
\hline.$\quad *$ & & $=$ & - & 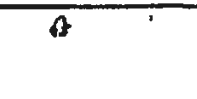 & & \\
\hline
\end{tabular}

.

Table 35

Summary of Analysis of Variance of Final.Distance (Transformed), Experiment 5

\begin{tabular}{llllll} 
Source & & & & \\
\hline \\
\hline
\end{tabular}


Table 36

Meañs and Standard Deviations of Latency, Experiment 6

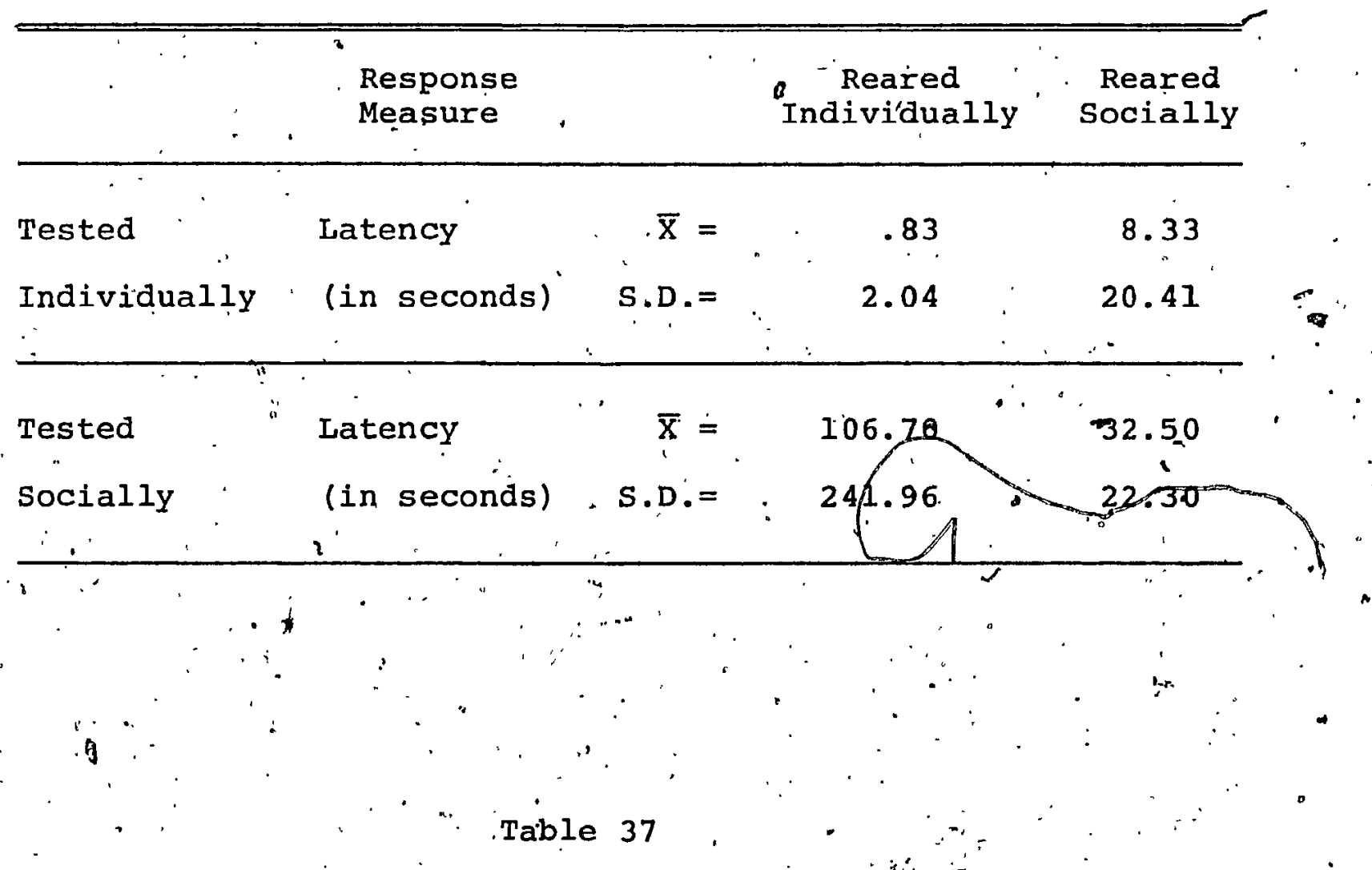

Summary of Analysis of Variance of Latency, Experiment 6

\begin{tabular}{|c|c|c|c|c|c|}
\hline Source & . df & ss & MS & $\dot{\mathrm{F}}$ & $\mathbf{P}$ \\
\hline Rẹaring Condition & 1 & .6666 .62 & 6666.62 & 1.00 & N.S. \\
\hline Testing Condition & 1 & $25349.90^{\circ}+$ & $+25349^{\circ} .90$ & $1.71 \ldots$ & N.S. \\
\hline$R \times T$ & 1 & 10004.10 & 10004.10 & 1.80 & N.S. \\
\hline Error. & 20 & 297324.00 & 14866.20 & & \\
\hline
\end{tabular}


Alley, R: \& Boyd, H. Parent-young recognition in the Coot, Fulica atra. Ibis, 1950, 92, 46-51.

Anderson, R.K. Orientation in Prairie Chickens. Auk, 1971, $88,286-290:$

Austin, 0 . Site tenacity; a behariour trait of the Common Tern. (Sterna hirundo L.). Bird Banding, 1949, 20, 1-39;

Baerends, G., Drent R., Glas, P., Groenewold, H. An ethological analysis of incubation in the Herring Gull: Behaviour Supplemen't, $1970,18,135-234$.

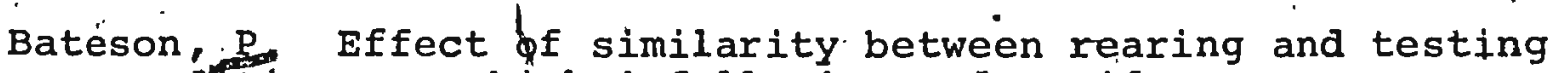
condfions on chicks' following and avoidance responses. Journal of Comparative and Physiological Psychology, $7964 a, 57,100-103$.

Bateson, P. Relation between conspicuousness of stimuli and their effectiveness in the imprinting situation. Journal of Comparative and Physiological Psychology, $1964 \mathrm{~b}, 58, \cdots$ 407-41.1.

'Bateson, P." The characteristics and context of imprinting. Biological Review, 1966, 41, 177-220.

Bateson, P. \& Reese, E.P. The reinforcing properties of conspicuous stimuli in the "imprinting situation. Animal 'Behaviour, 1969, 17, 692-699.

Beer, C. Incubation and nest building behaviour of Blackheaded Gulls. V. The post-hatching period. Behaviour, $1966,26,189-214$.

Beer, C. Laughing Gull chicks : recognition of their parents' voices. Science, 1969, 166, 1030-1032.

Bongiorno, S.F. Nest-site selection by adult Laughing Gulls (Larus atricilia). Animal Behaviour, 1970, 18, 43.4-444.

Boyd, Af \& Landsborough, T. Recoveries of marked swallows within the British, Isles. British Birds, 1937, 30, 278287.

Collias, N. Social life and the individual among vertebrate animals. Annals of the New York Academy of Science, 1951, $51,1074-1092$.

Cuilen, E. Adaptations in the Kittiwake to cliff-nesting. Ibis, $1957,99,275-302$. 
Davies, S. \& Carrick, R.' On the ability of Crested frerns, Sterna be'rgii, to recognize their. own chicks. Australian Journa 1 of Zoology, 1962, 10, 171-177.

Dice, I. Some factors affecting the distribution of the prairie vole, forest deermouse, and the prairie deermouse. Ecology, 1922, 3, 29-47.

Drost, R. Uber die Ansiedlung von jung ins Binnenland verfrachteten Silbermowen (Larus argentatus) . Vogelwarte, $1958,1.9,169-173$.

Elton, $C_{0}$ Animal ecology and evolution. Oxford; 1930,

Emlen, J. Midwinter aistribution of the American crow in New York State. Ecology, 1938, 19, 264-275.

Eimlen, J. The midwinter distribution of the crow in California.: Condor, 1940, 42, 287-294:

Emlen; $J$. Determinants of cliff edge and escape respoinses in Hepring Gull chicks in nature. Behaviour, 1963, 22, $1-15^{\circ}$

Evans, R. Imprinting and mobility in young Ring-billed Gulłs, Larus delawarensis. Animal Behaviour Monographs, 1970a, 3, 194-247.

Evans, R. Parental recognition and the 'mew call' in Black- billed Gulls (Larus bulleri). Auk: 1970b, 87, 503-513.

- Evans, R. Development of an auditory discrimination in domestic chicks (Gallus gallus). Ainimal Behaviour, 1972', $20,77-87$.

Fabricius, E. Zur ethologie junger Anatiden. . Acta Zoologica Fennica, 1951, 68., 1-178.

Farner, D. The return of robins to their birthplaces. Bird Banding, 1945, 16, 81-99:

Ferguson, G.A. Statistical Analysis in Psychology and Education. New York: McGraw-Hill Co., 1966.

Fisher, J. \& Hinde, R. The opening of mi-lk bottles by birds. British Birds, $1950,42,347-357$.

Frings, H., Frings, M., Cox, B.' \& Peissner, I. Auditory and visual mechanisms in food-finding behaviour of the Herring Gull. Wilson Bulletin, 1955, 67, 155-170.

Goethe, F.'Beobachtungen und. untersuchungen zur Biologie - der Silbermówe auf der Vogelinsel Memmerstand. Journal. 
Ornithologie, $19 \not 7,85,1-119$.

Gottlieb, G. Imprinting in relation to parental and species identification by avián neoriates. Journal of Comparative and Physiological Psychology, $1965,59,345-356$.

Gray, P. "Evidence that retinal flicker is not a necessary condition of imprinting. Science, 1960, 132, 1834-1835.

- Gross, A. The migration of Kent Island Herring Gulls. Birä Banding, 1940, 11, 129-155:

Guillon, Gr. Ecology of Gambel's Quail in Nevada and in the arid southwest. Ecology, 1960, 41, 518-536.

Hailman, J. Development of species recognition in gulls. In Behavioural Aspects of Ecology, '(P. Klopfer, ed.) Englewood Cliffs: Prentice Hall, 1962.

Hasler, $\dot{A}$. Perception of pathways by fishes in migration: Quarterly Review of Biology, 1956, 31, 200-209.

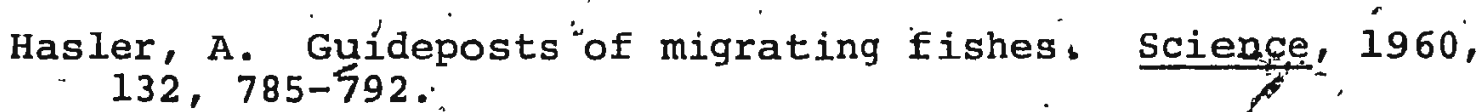

Harris, V. 'An experimental study of häbitat selectionf by prairif arid forest. races of the deer mouse, Peromyscus maniculatus. Contributions of the Laboratory of. . Vertebrate Biology. University of Michigan, 1952, 56 , 1-53:

Hess, E. The relationship between imprinting and motivation. Nebraska symposium on motivation (M. Jones, ed.), Lincoln: University of 'Nebraska" Press. 1959:

Hilden, O. Habitat selection in birds. Annales Zoologici Fennici, 1965, 2, 53-75.

Hińde, R. Behaviour and speciation in birds and lower vertebrates. Biological Review, 1959, 34, 85-128.

Hogan, J.A. \& Abel, E.L. Effects of social factors on response to unfamiliar environments in Gallus gallus spadiceus. Animal, Behaviour, $1971,419, \overline{687-694 .}$

Howells, T. V Vine, D. The innate differential in social learning. Journal of Abnormal and Social Psychology, $1940,35,537-548$.

Kendeigh, S. Territorial and mating behaviour of the House Wren. Illinois Biological Monographs, 1941, 18, 1-120. 
Kendeigh, S. Community selection by birds on the Helderberg plateau \&f New York. Auk, 1945, 62, 418-436.

Kilham, P, Klopfer, P., \& Oelke, H. Species identification and color preferences in chicks. Animal Behaviolir, 1968, $16,238-244$.

King, J. Social behaviour, social organization and population dynamics in a black-tailed prairie dog.town in the Black Hills of South Dakota. Contributions of the Laboratory. of Vertebrate Biology, No. 67, 1955 .

Kirkman, F. Bird behaviour. London \& Edinburgh: Nelson, 1937.

Klopfer, -P: Behavioural aspect's of habitat selection: the role of early experience: Wilson Bulletin, 1963, 75; $15-22$.

Klopfer, P. Behavioural aspects of habitat selection. I. - Wilson Bulletin, 1965, 77,.376-381.

Klopfer, P. Behavioural stereotypy in birds: Wilson Bulletin, 1967, 79, 290-300.

Klopfer, P. Habitats and territories. NeW York: Basic Books, . $19 \overline{69 .}$

Klopfer, P.. \& Hailman, J. Habitat selection in birds, In Advances in the study of. Behavieur. Vol. I. "(Lehrman, ed.). 'New York: Academic Press, 1965.

Klujver, $\mathrm{H}$. The population ecology of the Great Tit. Ardea, $1951,39,1$.

Lack, D. Habitat selection in birds with special reference to effects of afforestation on Breckland avifauna. Journal of Animal Ecology, 1933;-2, 239-262.'.

irack, D. The psychological factor in bird distribution. British Birds, 1937, 31, 130-136.

Lack; D. The life of the robin. London: Witherby, 1943.

Lack, D. The natural regulation of animal numbers. New. York : oxfordUniversisy Press, 1954.

Lack, D. \& Venables, I. Habitat distribution of British woodland birds. Journal of Animal Ecology, 1939, 8, $39-71$.

LeResche, P.E. \& Sladen, W.J. Establishment of pair and breeding site bonds by young known-age Adelie Penguins 
(Pygoscelis adeliae). Anímal Behaviour, 1970, 18, 517$5 \overline{26}$.

Miller, $\dot{A}$. Habitat selection among higher viertebrates and its relation to intraspecific variation.' American. Naturalist, $1942,76,25-35$ :

Miller, A. Panmixia and population' size" with reference "to birds. Evolution, 1947; 1, 186-190.

Miyadi, D. On some new habits and their propagation in Japanese monkey troups. XV International Congress of Zoology, 1959, 857-860.

Moreau, R. A critical analysis of the distribution of birds in a tropical African area. Journal of Animal Ecology, $1935,4,167-191$.

Moynihan; M.' 'Notes on the behaviour of some North American -Gulls. IV. The ontogeny of hostile behaviour and display patterns. Behaviour, 1959, 14, 214-239.

'* Nice, M. Studies in the life history of the song sparrow. Vol. II. The behaviour of the song sparrow and other passerines, New York: Dover Publications, 1943.

soseworthy, C., Iuien, J.\& Stoker, S. Habitat preferences in neonatal Herring. Gulls: Auk, 1973, 90, 193-194.

Noseworthy, C., Lien, J., Martin, G. Fisher, J. Nesting microhabita't and behavioural adaptations in the chicks of the Herring Gull, Larus argentatus Pontoppidan. Auk, 1973 (in press):

Pitelka, F. Distribution of birds in relation to major biotic communities. American Midland Naturalist,' 1941 , 25 , $113-137$.

Rau, P. A note on the attachment of the wasp Bembix a nubilipennis" to their nesting sites. 'Psyche, 1934, 61, $243-244$.

'Richdale', L. Sexual behaviour' im Penguins. University of Kansás Press, 1951.

Ruiter, C. Waarnemingen omtrent de levënswijze van de. Gekraagde Phoenicurus ph. phoenicurus L. Ardea, 1941, $30, \cdot 175-214$.

Schuz, E. Uber kunstliche verṕflanzung bei vogelus "Compt. Reud. 9me Congr. Ornithol. Internat., 1938, 311-325. 
Schüz, E. Bericht der Vogelwarte rossitten der, Kaiser Wilhelm-Gesellschatt zur Forderung der Wissenschatten. Vogelzug, 1940, 11, 109-120.

Smith, N. Adaptations to cliff-nesting in" some arctic gulis (Larus). Ibis, 1966, 108, 68-83.

Snyder, L. Tradition in bird life. The Canadian FieldNaturalist, 1948,$62 ; 75-77 .$.

Sțoddard; H. The Bobwhite Quail. New York: Scribners, 1931:

Stoner; D. \& Stoner, $\dot{L}$ : Feeding of nestling Bânk Swallows. Auk, $1941,58,51-54$.

Strong, R. On the habits and behaviour of the Herring Guli, Larus argentatus Pont. Auk, 1914, 31, 22-50, 178-200.

Svardson, G: Competition and habitat selection in birds. Oikos, 1949, 1, 15.7-174.

Thorpe, W. Types of learning in insects and other arthropods. Part III. British Journal of Psychology, 1944, 34, 66-76.

Thorpe, W. The evolutionary significance of habitat selection. Journal of Animal Ecology, 1945, 14, 67-70.

Tinbergen, N. "The Herring Gull's' world. London: Collins Press, 1953 .

Tinbergen, N., Broekhựssen, G., Feekes, F., Houghtọn, J., Kruuk, H., \& Szule, E. Egg shell removal by the Blackheaded Gull, La,rus ridibundús, I. A behaviour component of camouflage: Behaviour, 1962, 19, 74-117.

Von Haàrtman, L. Der ṫrăuerflliegenschnappèr. I. Ortstreue und rassenbildung. Acta Zoologica Fennica, 1949, 56, 1-104:

Von Uexkul1, J. Umwelt und innenwelt der tiere. Berlin: Springer, $192 \overline{1}$.

Wasilewski., A. Ceirtain aspects of the habitat selection of birds. Edologia Polska. Seria A. Warszawa; 1961, 9; 111-137.

Wecker, S. The role of early experience in habitat selection by the práirie deer mouse, Peromyscus maniculatus bairdi. Ecological Monographs, $1963,33,4,307-325$.

Winer, B.J. Statistical Principles in Experimental Design. New York: KcGraw-Hill Co., 1971. 


